\title{
The Effects of Coal Capacity Retirement on Wholesale Electricity Prices: A Demand Side Analysis
}

\author{
Michael C. O'Conor \\ mco0001@mix.wvu.edu
}

Follow this and additional works at: https://researchrepository.wvu.edu/etd

\section{Recommended Citation}

O'Conor, Michael C., "The Effects of Coal Capacity Retirement on Wholesale Electricity Prices: A Demand Side Analysis" (2019). Graduate Theses, Dissertations, and Problem Reports. 7480.

https://researchrepository.wvu.edu/etd/7480

This Thesis is protected by copyright and/or related rights. It has been brought to you by the The Research Repository @ WVU with permission from the rights-holder(s). You are free to use this Thesis in any way that is permitted by the copyright and related rights legislation that applies to your use. For other uses you must obtain permission from the rights-holder(s) directly, unless additional rights are indicated by a Creative Commons license in the record and/ or on the work itself. This Thesis has been accepted for inclusion in WVU Graduate Theses, Dissertations, and Problem Reports collection by an authorized administrator of The Research Repository @ WVU. For more information, please contact researchrepository@mail.wvu.edu. 


\title{
The Effects of Coal Capacity Retirement on Wholesale Electricity Prices: A Demand Side Analysis
}

\author{
Michael O’Conor \\ Thesis submitted \\ to the Davis College of Agriculture, Natural Resources and Design \\ at West Virginia University \\ in partial fulfillment of the requirements for the degree of \\ Master of Science in \\ Resource Economics and Management
}

\author{
Alan R. Collins, Ph.D., Chair \\ Xiaoli Etienne, Ph.D. \\ Peter Schaeffer, Ph.D.
}

Division of Resource Economics and Management

$$
\text { Morgantown, West Virginia }
$$

2019

Keywords: Locational marginal price (LMP), Pennsylvania-New Jersey-Maryland Interconnection (PJM), electricity, demand-side, coal, retirement, generation, Regional Transmission Organization (RTO), deregulation, market 


\begin{abstract}
The Effects of Coal Capacity Retirement on Wholesale Electricity Prices:
\end{abstract}

A Demand Side Analysis

\title{
Michael O’Conor
}

U.S. electric utilities retired $47 \%$ of their coal-fired generation capacity between 2008 2017 and have plans to continue decreasing this capacity through 2020. This means that areas of the U.S., like the Pennsylvania-New Jersey-Maryland Interconnection (PJM) Regional Transmission Organization, not only have experienced, but will continue to experience major shifts in its energy fuel mix and available electricity generation capacity. On June 1, 2015, the American Electric Power (AEP) zone experienced the retirement of 5,408 MW of coal-fired generation capacity from the wholesale electricity market. This research analyzes the impacts of this retirement on wholesale prices, i.e., locational marginal price (LMP) of electricity. Demandside analyses of wholesale electricity prices are performed by regressing LMP against electricity demand variables. These variables include: the generation forecast error occurring from differences between forecasted day-ahead electricity consumption and real-time consumption, degree cooling and heating days, and accounting for hourly, daily, and seasonal differences in electricity consumption. Regression analyses were performed for six zones within the PJM for a 24-month period from June $1^{\text {st }}, 2014$ - June $1^{\text {st }}, 2016$, thus including 12 months of available data before and after the capacity retirement. Four analyses were created to measure the effects of consumption forecast error and coal-fired capacity retirement timing on LMP. The results from the four analyses demonstrate that: (1) average LMP in all zones decreased by between $16.6 \%$ and $29.2 \%$ if coal-fired generation capacity was projected to retire a year earlier than its observed retirement, and (2) average LMP in all zones increased by between $15.0 \%$ and $26.9 \%$ if this capacity was projected not to retire. The outcomes also showed early retirement of the coal-fired capacity resulted in more stable LMPs. The magnitude of percent decreases in LMP in the top $5 \%$ of observations was much larger during the early retirement analyses compared to the no retirement analyses. These price trends align with the national wholesale electricity price averages decreasing from June 1st, 2014 - June 1st, 2016. Thus, each of the six PJM zones did not experience any observed adverse effects on LMP from retirement of coal-fired generation capacity. 


\section{Table of Contents}

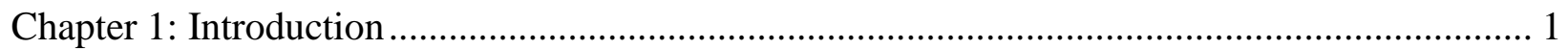

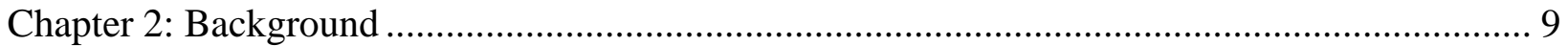

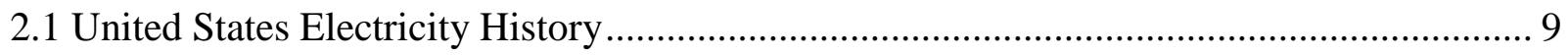

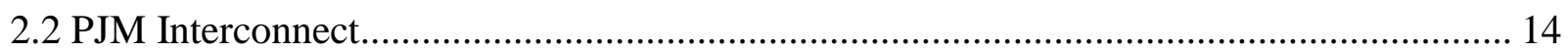

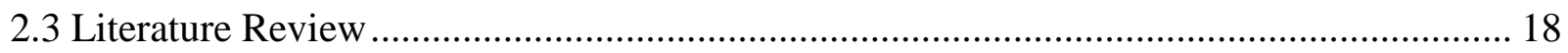

2.3.1 Industry, History, and Factors Effecting Wholesale Price ……….............................. 19

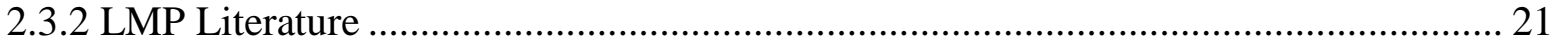

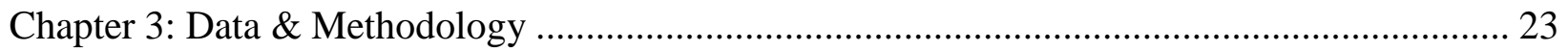

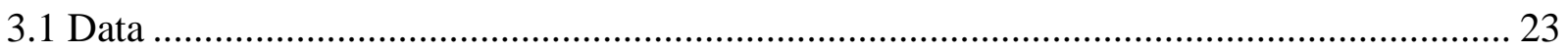

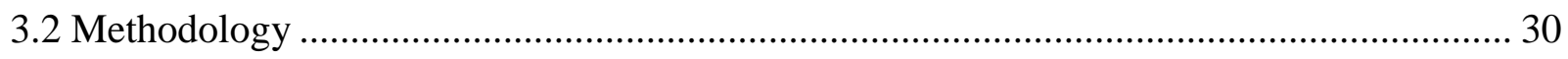

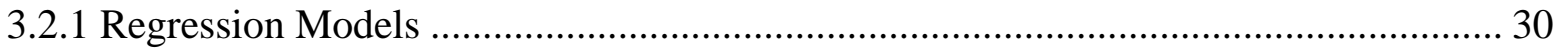

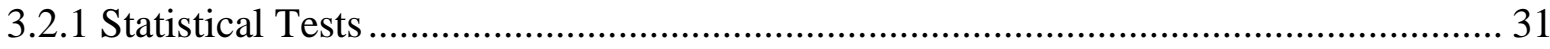

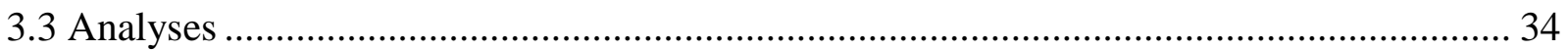

3.3.1 Early Retirement with Over-Predicted Consumption................................................... 34

3.3.2 No Retirement with Over-Predicted Consumption ..................................................... 36

3.3.3 Early Retirement with Under-Predicted Consumption................................................... 37

3.3.4 No Retirement with Under-Predicted Consumption ...................................................... 38

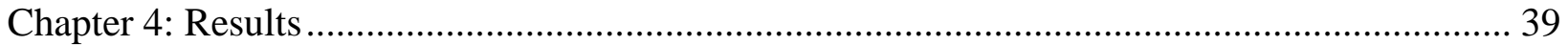

4.1 Regression Models .................................................................................................... 39

4.1.1 Pre-Retirement with Over-Predicted Consumption.................................................... 39

4.1.2 Post-Retirement with Over-Predicted Consumption .................................................... 40

4.1.3 Pre-Retirement with Under-Predicted Consumption..................................................... 42

4.1.4 Post-Retirement with Under-Predicted Consumption .................................................... 42

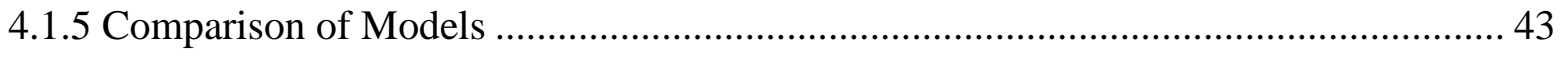

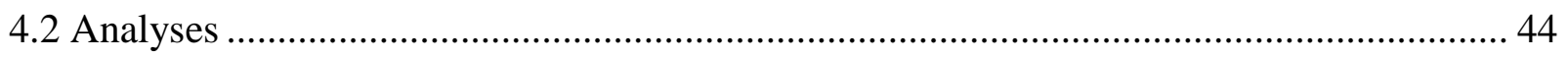

4.2.1 Early Retirement with Over-Predicted Consumption................................................... 45

4.2.2 No Retirement with Over-Predicted Consumption ...................................................... 46

4.2.3 Early Retirement with Under-Predicted Consumption................................................ 48

4.2.4 No Retirement with Under-Predicted Consumption .................................................... 49 


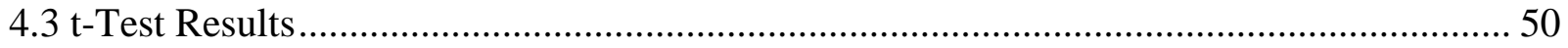

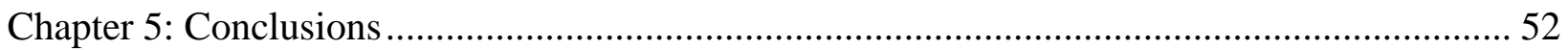

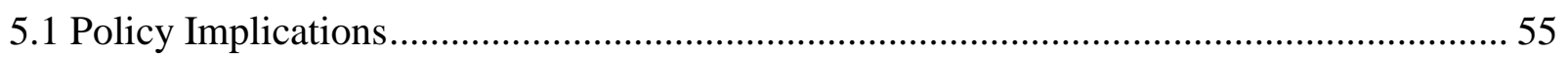


Figure 1: United States Electric Power Energy Consumption (U.S. Energy Information

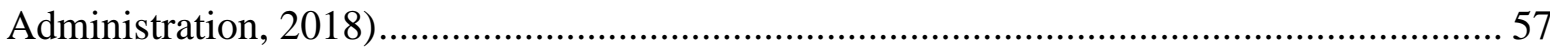

Figure 2: U.S. Electricity Generation by Fuel, All Sectors (U.S. Energy Information Administration, 2019)

Figure 3: Electricity Generation from Coal and the Delivered Prices of Coal and Natural Gas (monthly for the United States) (Alexopoulos, 2017) 59

Figure 4: U.S. Utility-Scale Generating Capacity by Initial Opening Year (as of Dec 2016) (Jell, 2017)

Figure 5. Wholesale Electric Power Markets Map (United States Environmental Protection Agency, 2018)

Figure 6: Competitive Market Daily Wholesale Electricity Price (Per MW) (U.S. Energy Information Administration, 2018).

Figure 7: 10-Year United States Competitive Market Average Electricity Price (Per MW) (U.S. Energy Information Administration, 2018). 63

Figure 8: Marcellus Shale Formation (U.S. Energy Information Administration, 2018) ..... 64

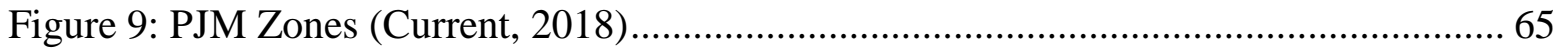

Figure 10: PJM Backbone Transmission System (TEAC, 2018) ........................................... 66

Figure 11: PJM Wholesale Average Daily Price 2007-2017 (PJM, 2018) ........................... 67

Figure 12: Hourly Price Average Pre-Retirement (PJM, 2018) …………………................ 68

Figure 13: Hourly Price Average Post- Retirement (PJM, 2018)........................................... 69

Figure 14: Daily Price Average Pre-Retirement (PJM, 2018)............................................ 70

Figure 15: Daily Price Average Post-Retirement (PJM, 2018) ............................................ 71

Figure 16: Monthly Price Average Pre-Retirement (PJM, 2018)......................................... 72 
Tables 75

Table 1: Fuel Mix over the Entire PJM Region (Capacity, 2017) ................................... 75

Table 2: Coal Consumption and Capacity Retired 2014-2016 (PJM, 2019)...................... 76

Table 3: Metropolitan Locations (U.S. Census Bureau, 2017) ....................................... 77

Table 4: Pre-Retirement Variables Summary ........................................................... 78

Table 5: Post-Retirement Variables Summary ................................................................. 79

Table 6: Pre-Retirement with Over-Predicted Consumption Regression Model ................. 80

Table 7: Post-Retirement with Over-Predicted Consumption Regression Model................ 83

Table 8: Pre-Retirement with Under-Predicted Consumption Regression Model ............... 86

Table 9: Post-Retirement with Under-Predicted Consumption Regression Model.............. 89

Table 10: Pre-Retirement with Over-Predicted Consumption Correlation .......................... 92

Table 11: Pre-Retirement with Under-Predicted Consumption Correlation ........................ 92

Table 12: Post-Retirement with Over-Predicted Consumption Correlation ........................ 92

Table 13: Post-Retirement with Under-Predicted Consumption Correlation....................... 92

Table 14: Structural Break Chow Test Caused by Capacity Retirement ............................ 93

Table 15: Structural Break Chow Test Caused by Predicted Consumption ........................ 94

Table 16: LR-Test to Split Predicted Consumption .......................................................... 95

Table 17: Hourly T-Test of Diff Against Zero .............................................................. 96

Table 18: Daily T-Test of Zones’ Observed LMP Against Market Prices......................... 97

Table 19: Early Retirement with Over-Predicted Consumption Model .............................. 99

Table 20: No Retirement with Over-Predicted Consumption Model ................................. 99

Table 21: Early Retirement with Under-Predicted Consumption Model ............................ 99

Table 22: No Retirement with Under-Predicted Consumption Model............................... 99

Table 23: Early Retirement with Over-Predicted Consumption Model ............................ 100

Table 24: No Retirement with Over-Predicted Consumption Model ................................ 100

Table 25: Early Retirement with Under-Predicted Consumption Model .......................... 100

Table 26: No Retirement with Under-Predicted Consumption Model............................. 100

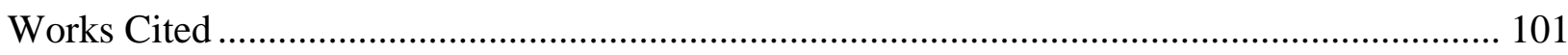




\section{Chapter 1: Introduction}

Electricity is an integral aspect of everyday life in developed economies. In the United States (U.S.), people use electricity for work and leisure every hour of the day, year-round. Consumers of electricity often take it for granted when a switch is flicked or a button is pressed that electricity will be provided. When over 328 million people expect the electricity in their homes and offices to be available on demand, the U.S. electricity sector must utilize an immense amount of energy to meet the electricity needs of its people.

The U.S. economy consumed 97.7 quadrillion British thermal units (BTU) of energy in 2017 (U.S. Energy Information Administration, 2018). From this total, the electricity sector consumed the largest share at 38\% (37.2 quadrillion BTU). The remaining energy consuming sectors were the transportation sector (29\%), industrial sector (22\%), and residential and commercial sectors (11\%) (U.S. Energy Information Administration, 2018). The electricity sector uses a multitude of different energy resources to generate enough electricity in order to meet the nation's consumption needs.

Electricity in the U.S. is primarily generated from coal, natural gas, and nuclear power. Renewable energy forms such as solar, wind, and hydroelectric power have been a growing portion of the electricity generation mix in the U.S. over the past 20 years (U.S. Energy Information Administration, 2018). Figure 1 shows the energy resource consumption to generate electricity over the past two decades. While dropping steadily since 2008, coal-fired generation has remained the leading source of electricity over the past 20 years. There are, however, signs of declining coal-fired generation and expansion of natural gas consumption. The past ten years have seen growth in the natural gas and renewables sectors, which are replacing much of the coal-fired capacity. Figure 2 displays the U.S. electricity generation fuel mix from 2012-2018 
with the projected generation mix for 2019 and 2020. Natural gas-fueled generation passed coal in 2016 in terms of the amount of electricity generated and is expected to continue increasing its share of the market in the future.

Coal is facing new competition in the U.S. Demand for coal and coal-fired electricity generation is falling due to decreasing natural gas prices and production costs (Alexopolous, 2017). Figure 3 shows the 10 -year trend of quarterly electrical generation produced by coal combined with coal and natural gas prices in the U.S. This figure shows the generation of electricity from coal has declined while the price of coal has relatively remained constant. Also shown in Figure 3 is a mostly downward trend in natural gas prices since 2008. As Coglianese et al. (2017) report: "Over the full period, of the 433-million-ton decline in production, 397 million tons $-92 \%$ of the reduction - is attributable to cheaper gas relative to coal". Thus, drops in natural gas prices are responsible for the coal production decline. Low prices of natural gas caused by the shale boom in 2008 have allowed electricity generators to produce gas-powered electricity at lower costs. The decrease in coal generation also shows that many coal power plants are no longer economically capable of competing within their respective Independent System Operator or Regional Transmission Organization (ISO/RTO).

While Figure 3 shows that coal is cheaper than natural gas on a per MMBtu basis, this advantage does not ensure that electricity generation costs from coal are lower than natural gas. Other factors related to generation costs are the transportation of the resources to the generator, ramping costs, and environmental costs. While coal is easy to transport and store at a power station, coal-fired generators require more time to ramp-up and ramp-down their electricity output compared to natural gas power stations. Another cost which coal-fired generators must consider is the environmental cost of burning coal. 
The status of electricity generation infrastructure in the U.S. shows few signs of new coal-fired power plants being built. The average age of a coal plant across the nation is 39 years (Jell, 2017). With an expected lifespan of a coal power plant being about 40 years, utilities across the U.S. are facing difficult decisions of whether to renovate their existing coal plants or build new generation plants. Utilities that decide to build brand new energy generators are transitioning away from coal and towards natural gas and renewable generation. Economic reality explains why natural gas power plants are being built at a swift rate, outpacing coal plants by 14.2 times in new capacity additions since 2000 (see Figure 4) (Jell, 2017). Natural gas power plants are brought on-line for various reasons, including faster ramping speeds and decreased amounts of harmful emissions. Coal-fired power plants are rarely being considered when utility companies and investors are planning to build new generating capacity due to their high cost and pollution.

Along with facing competitive price difficulties, coal-fired electricity generation faces current and future environmental challenges. Common emissions from burning coal are sulfur dioxide, nitrogen oxide, particulate matter, carbon dioxide, and mercury. The Clean Air Act and Clean Water Act restrict harmful emissions from electricity generators. An important amendment to the Clean Air Act was passed in 1990 which increased the number of controlled pollutants. The Maximum Achievable Control Technology (MACT) standard was part of the amendment. MACT created "MACT floors" that forced existing industry emitters to decrease their levels of emissions of harmful pollutants into the environment. The amendment created, "MACT floor" for existing sources is the average level of HAP emission control achieved by the top $12 \%$ of that industry group's currently operating sources. At a minimum, a MACT standard must achieve, throughout the industry, a level of emissions control that is at least equivalent to the MACT 
floor" (Ohio Environmental Protection Agency, 2019). Older generators were forced to adapt to the new restrictions on sulfur dioxide and mercury. Coal power plants were hit hard by the new regulation since most of these generators were built before 1990 and did not fall in the top $12 \%$ of the industry group's lowest pollution emitter. Older, less efficient power plants were required to install new technology to make their production clean enough to warrant the necessary permits by the Environmental Protection Agency to continue generating electricity.

Emission standards are constantly evolving and often change depending on the administration in control of the EPA. While the U.S. government is working to produce less environmentally harmful energy, it is also focused on maintaining reliability through diversified generation. The electricity sector has seen $37 \mathrm{GW}$ of coal-fired generation retired from 2010 to 2015. These retirements accounted for 52 percent of the total retirement capacity over the fiveyear period. Nuclear generation accounted for another 15 percent of the retirement capacity during this time-period (Department of Energy, 2018). The DOE, in this proposal, believes the benefits of a power plant's resiliency is not being properly accounted for. The resilient energy generators are, therefore, not being properly compensated for the benefits they provide.

To keep the American energy fuel mix resilient and diverse, the U.S. DOE proposed on September 29, 2017 a regulation to subsidize resilient energy sources. This proposal stated: "The nation's electric grid is threatened by the premature retirements of power plants that can withstand major fuel supply disruptions caused by natural or man-made disasters." (Department of Energy, 2018) The DOE argues that it is in America's best interest to protect resilient energy sources for economic, national security and quality of life purposes. Coal and nuclear power generation, because of the ability to store stockpiles of natural resources on site, are considered very resilient forms of electricity generation. 
This proposal would have been extremely beneficial to the owners of coal and nuclear generation plants. The DOE proposal, however, was rejected by the Federal Energy Regulatory Commission on January 8, 2018. It was declined because the rule did not follow the Federal Power Act (FPA). The FPA requires that current tariffs in the existing RTO/ISO must be unjust and unreasonable for a change to occur. The FPA also found that the planned generation retirements do not threaten grid resiliency in the U.S.

The economic makeup of the U.S. electricity markets is diverse. The regulatory structure of the electricity market changes depending on the geographic location. Figure 5 shows seven competitive wholesale electricity markets in assorted colors. The gray areas on the map remain regulated markets. The colored regions are competitive wholesale markets which are run by an Independent Systems Operator (ISO) or Regional Transmission Organization (RTO). The ruling ISO/RTO in the area, "uses competitive market mechanisms that allow independent power producers and non-utility generators to trade power" (United States Environmental Protection Agency, 2018). The governing ISO/RTO forecasts the consumption of electricity and, using market signals, solicits bids from generators to generate the correct amount of electricity needed at any given time. In competitive markets, there is not a single owner and operator of both generation and transmission resources. The opposite is true for regulated markets. Regulated markets have, "vertically-integrated utilities which are responsible for the entire flow of electricity to consumers. Utilities own the generation, transmission and distribution systems used to serve electricity consumers" (United States Environmental Protection Agency, 2018). Consumers in these areas do not have the option of choosing their power provider. The rates for electricity in these vertically-integrated areas are regulated by utility commissions, and one utility is given a regulated monopoly over a certain area in the provision of electricity. 
While competitive markets are monitored by their ISO/RTO and regulated by the national government, market prices are not controlled. Electricity generators in these markets can be considered profit maximizing firms. Figure 6 presents information on the eight competitive wholesale electricity regions from June $1^{\text {st }}, 2014$ - June $1^{\text {st }}, 2016$. Figure 6 analyzes all volumetric weighted average index market prices for electricity in the U.S. An overview of the markets shows they all follow a similar price path over the two-year period. All markets display a downward linear trend of prices over time. The price of electricity in the PJM and NEPOOL (New England Power Pool) experienced a massive average price spike in the winter of 2015, but that was the result of the extreme cold temperatures.

Figure 7 displays the weighted average Intercontinental Exchange (ICE) wholesale electricity prices based on averages over all the competitive regions shown in Figure 6 . The linear trend line shows a downward slope in weighted average price. The ICE has managed to provide wholesale electricity in the U.S. at decreasing prices. The price drops are the result of different factors. Factors that often help wholesale price decreases are markets and generators becoming more efficient, favorable weather, and natural resource price decreases.

While there is a total of seven wholesale electricity markets in the U.S., this research specifically examines price trends only in the PJM Interconnect. The PJM is an RTO that provides electricity in 13 states in the northeast United States (purple shaded region in Figure 5). The PJM is suited for this research because of its large capacity of aging coal power generation and the market's competitive makeup. The PJM allows generators to compete when offering wholesale electricity to the market. The PJM, while being competitive, includes states with vertically-integrated regulation along with states whose electricity markets are deregulated. This variation creates the potential for different incentives of utility-owned power stations depending 
on if they are located within a regulated or deregulated market. When a utility within a regulated state owns power plants, the cost (including a reasonable rate of return) of the electricity generation is covered for the generation plant owner regardless of whether the generation of electricity is profitable at the wholesale electricity market prices. Any extra costs of a generation not covered by the electricity revenue is passed onto its consumers who are mandated to use that provider's electricity. Power plants within regulated states are therefore always able to compete with unregulated power plants. Coal power plants in regulated markets that have aged past being competitive are still able to generate electricity for the market. This situation has the potential to increase the amount of electricity generated into the PJM market, thus driving wholesale prices down.

Natural gas is relatively cheap and accessible in the PJM region. The electric power price of purchasing and delivering natural gas to consumers in West Virginia was \$3.66 (\$3.66 in Pennsylvania and \$3.40 in Ohio) in dollars per thousand cubic feet during January 2019. The electric power price for the entire U.S. was \$4.16 in January 2019 (U.S. Energy Information Administration, 2019). The PJM's geographic region has lower natural gas prices than the U.S. average. Its production is becoming heavily linked to electricity prices in the PJM. The connection between prices exist, "the cross-correlation between the quantile-hit processes in PJM is found to be around $20-30 \%$ from gas to electricity and around $15 \%$ from electricity to gas" (Uribe et al., 2018). The price of natural gas has a 20-30\% correlation related to influencing electricity prices in the PJM. The price of electricity in the PJM has a $15 \%$ correlation related to influencing natural gas prices. The Marcellus Shale Formation is located directly under the western portion of the PJM, making access to natural gas deposits for energy production in the region increasingly cheaper over the past decade. The Marcellus Shale play, as seen in Figure 8, 
extends from West Virginia into Ohio, Pennsylvania, a small part of Maryland and lower New York. Most natural gas production occurs in West Virginia and Pennsylvania. There are ample natural gas supplies in the PJM region for new natural gas-powered electricity generation capacity.

Related research on the electricity markets, policy, and regulated versus deregulated markets is plentiful. Three essential articles that relate to this research are Woo et al. (2014), Kaufmann and Vaid (2016), and Rahmani et al. (2016). Woo et al. (2014) use a regression model to evaluate nuclear power plant deactivations in California. This paper examines the effects of closed nuclear power plants on each of California's zonal locational marginal prices of electricity. Kaufman and Viad (2016) perform a study similar to Woo et al.'s, but their paper relates to solar energy in Massachusetts. This paper offers insight into the effects of weather on electricity generation. The authors also calculate the potential external benefits received from federal renewable energy credits and emission reductions. Finally, Rahmani et al. (2016) use a security constrained unit commitment model to address the PJM region's recent closure of coalfired power plants. These authors find that deactivating the coal power plants will likely lead to more transmission congestion and increased energy prices. Each of these three articles examines electricity markets from the generation side. Megawatt production from each plant is a known variable. This research utilizes demand-side information to explain wholesale electricity prices.

The objective of this thesis is to analyze the impacts of coal-fired capacity retirement in the PJM region on wholesale electricity prices. This research differs from other studies because it examines the demand-side effects of plant closures on electricity prices. The study utilizes hourly data from June 1, 2014 to June 1, 2016. On June 1, 2015, a total of 5,408 MW of coal-fired electricity generation capacity was retired from the American Electric Power zone in the PJM. 
This research will examine hourly wholesale electricity price data from six PJM zones one year before and one year after the plant closures. While it is common for aging and inefficient power plants to be retired in the PJM RTO, a mass retirement of one type of generation, however, can raise questions about the stability of the entire system. Do wholesale electricity prices in the PJM region react to this sudden loss in coal-fired generation capacity? How are PJM wholesale price extremes (low and high) impacted by the retirements? Does the change in price differ with overpredicted and underpredicted electricity consumptions? These questions will be answered in this research.

The rest of the thesis will be reported as follows. Chapter 2 will begin with an overview of the electricity industry: its history, its state and federal regulations, and the PJM. This chapter also provides a literature review on the effects of regulation on the electricity industry in various countries including the United States and factors that affect wholesale price changes in competitive electricity markets. Chapter 3 presents the data used for the analyses and the methods utilized to analyze these data. Chapter 4 provides the results which were obtained by identifying important time series regression outputs and drawing conclusions from their coefficients. Chapter 5 concludes the research by showing the significance and policy implications of the findings, describe the limitations of the report, and present areas that demand further research.

\section{Chapter 2: Background}

\subsection{United States Electricity History}

The North American electricity grid is a complicated infrastructure that provides power throughout the United States and Canada. The energy industry transforms natural resources into electricity. It is then transported directly to the consumers' homes and businesses. In order to 
provide power consistently, the electrical grid must have exceptionally reliable generation capabilities, transmission lines, and people to monitor the grid and properly react as consumption of electricity rises and falls. Over the course of more than 100 years, the U.S. has experienced private unregulated, public regulated, and private regulated markets for electricity. While the electricity industry has grown and shifted drastically over this time period, the reliability of providing electricity to consumers on demand at reasonable prices remains a top priority for the United States.

The electricity industry requires a complex interconnected system to provide electricity to our homes and businesses. The process is effectively divided into three categories: generation, transmission and distribution. Generation is the first step; primary energy sources such as coal or wind are converted into electrical power here. Transmission is next; it moves bulk electricity at high voltage levels from the generation site over long distances to areas of demand for electricity. The transmission stage includes transmission lines, transformers, substations and other equipment that manages the "stepping down" of current before it reaches its destination. Distribution is the final stage of electricity. When power is "stepped down" from the transmission level to a voltage capable of being delivered to the consumer, it has reached the distribution phase. Generation and transmission of electricity are priced on the wholesale level while the distribution part of delivering electricity uses retail prices. This paper focuses primarily on the generation side of the electricity industry and thus uses wholesale price data.

Electricity production across multiple locations first began in Manhattan in 1882. The initial power plant provided electricity to 400 lamps and served 85 customers when electricity was still in its infancy. Edison and Tesla/Westinghouse were competing over whether direct current (DC) or alternating current (AC) was the more effective form of current for 
transportation of electricity. In the end, AC was chosen as the distribution current for its ability to provide electricity over long distances and for its ease of 'step up' and 'step down' voltage capabilities. The industry was initially private and unregulated. Every producer of electricity installed its own electrical wire system to transport their product to their consumers. This led to a very cluttered transmission system. When the great depression hit in 1929, the U.S. electricity market was forced to change drastically. The federal government invested in infrastructure projects to provide jobs to its citizens. The new influx of publicly funded electricity generation and transmission led to federal regulation of the electricity industry in the United States. The Public Utility Holding Company Act (PUHCA) was signed in 1935 to facilitate regulation of electric utilities throughout the U.S. PUHCA was created to limit the geographic spread of utility holding companies; control amount of loan debt; regulate cross-subsidies of unregulated business to regulated business; limit common ownership of both electric and natural gas (Hargis, 2018). Overall, PUHCA regulated electricity in the U.S. to prevent companies from monopolizing the entire national energy industry. Electric companies were limited to owning utilities in one state; they were also unable to leverage their utilities to obtain a loan for business ventures unrelated to the utilities they already own.

The regulated utility model remained mostly unchanged until the 1970s. At this time, high worldwide energy prices and a growing population led to utilities building large-scale coal and nuclear power plants in the United States. To encourage small firms to participate in the electricity generation industry, President Jimmy Carter signed the Public Utility Regulatory Act of 1978 (PURPA). The act mandated utilities to purchase electric energy from co-generation plants and renewable generation facilities with a capacity of $80 \mathrm{MW}$ or less at a rate that does not exceed the utility's avoided cost. The avoided cost rates, terms, and conditions are determined by 
each state's Public Utility Commission (PUC). Natural gas generators, however, were prevented from growing with the other fuel types during the 1970's due to the Power Plant and Industrial Fuel Use Act (PIFUA) (Tuttle et al., 2016). At the time the United States believed it only had small reserves of natural gas and did not want to rely on foreign countries for this resource. Congress reorganized FERC to, "Streamline regulations, encourage greater energy security, and contain the increases in energy costs" (Tuttle et al., 2016). U.S. power generation was shifted from foreign resources to domestic sources of energy.

Regulated electricity laws began to change again in 1992 with the passing of the National Energy Policy Act (United States Congress, 1992). The act allowed for private market competition within wholesale electricity generation. FERC made decisions after the National Energy Policy Act of 1992 that affected the entire makeup of the U.S. electricity industry. More reforms were added to the act over time. Orders 888 and 889 allowed the transmission to separate from the generation which led to the beginning of deregulating the electricity market. The schism effectively lowered the barriers to entry in the market and allowed new companies to invest and own stakes in the electricity industry. Independent Power Producers (IPPs) were created as a result of the orders. They encouraged new forms of energy technology to enter the market by raising capital and taking advantage of government tax credits. Order 2000 created Regional Transmission Organizations (RTOs) which allowed organizations to form across state borders to create larger markets for electricity generation and vaster control of the transmission grid. While the FERC loosened their rules on electricity regulations, the U.S. government tightened regulations on environmental standards for pollution.

Environmental regulation is another influential factor in molding the United States utility industry into what it is today. The Environmental Protection Agency (EPA) has issued important 
regulations on air and water that directly affect energy production. The Clean Air Act (1963) and the Clean Water Act (1977) were among the first acts signed into federal law and enforced by the EPA that continue to alter the power generation process today. The Clean Water Act, in section 316, created thermal pollution standards that mandate power plants and other industrial industries to clean the polluted water they use as a coolant in production (Federal Water Pollution Control Act, 2002). The Clean Air Act was initially created to research and regulate air pollution. The act was amended in 1990 to add emission restrictions on electric power plants for nitrogen oxide and sulfur dioxide. The amendment also created MACTS regulation. The EPA researched the topic for ten years, a report called "Utility Air Toxic Study" which was given to Congress stating regulation of coal-fired electric utilities was needed (History, 2017). In 2005, the EPA issued the final Clean Air Mercury Rule which placed restrictions on mercury emissions from new and existing utilities. This rule did not come to fruition and was vacated in 2008 by the D.C. Circuit court. In 2011, the EPA proposed a new rule called "Mercury and Air Toxic Standards" (MATS). This rule passed in January 2018.

MATS effectively set emission standards on existing coal and oil-fired electric generators that have a capacity equal to and greater than $25 \mathrm{MW}$. The sources of generation are allowed four years to reduce emissions to levels equal to or better than those achieved by the baseline top $12 \%$ of current generators (United States Environmental Protection Agency, 2017). The hazardous air pollutants include: benzene, perchloroethylene, methylene chloride, dioxin, asbestos, toluene, cadmium, mercury, chromium, and lead. (United States Environmental Protection Agency, 2017) The new standards are going to require most of the coal and oil-fired generators to either spend money to update their plants or retire them. 


\subsection{PJM Interconnect}

One of the first regions to shift towards deregulation ensued in the northeast U.S. with the PJM Interconnect. The PJM interconnect was first created in 1927, but it did not become an independent organization until 1997. Before 1997 it acted as a fully regulated industry. After deregulation, the PJM became the United States' first independent system operator (ISO). The duty of an ISO is to "operate, but do not own, transmission systems in order to provide open access to the grid for non-utility users" (PJM, 2019). In 1998, the PJM became the first bid-based energy market based on locational marginal pricing created in the US. As the PJM expanded over time, incorporating more states into the deregulated ISO, FERC encouraged the ISO to form into an RTO in 2002.

The PJM Interconnection is a regional transmission organization located in the Eastern Interconnection grid. The PJM contains 20 zones and serves 13 Eastern and Midwest states including the District of Columbia (Figure 9). Each zone has its own specific locational marginal price (LMP). The zones are connected through high capacity transmission lines known as the "backbone" of the PJM transmission system (Figure 10). Transmission lines are responsible for delivering the generator's electricity at the proper voltage to the distributors. While transmission is not the focus of this study, transmission lines affect the LMP of zones. Transmission lines experience constraints when delivering electricity called congestion and marginal loss. Congestion occurs when transmission lines carry too much load and are unable to provide enough electricity to an area. The electricity lines are only capable of delivering a certain amount of electricity at a safe level. When there is too much demand in a certain area, congestion happens. Marginal loss occurs when electricity must be carried from the generator to the customer. Energy is lost through electrical resistance and heating of conductors. The further a customer is from the generator, the higher the marginal loss of electricity is likely to be (Energy 
Markets, 2011). Both costs are added to the total cost of the generator producing the energy to create the LMP in a zone.

LMP is the price of electricity within the borders of each zone. The prices are very dynamic and are subject to change every five minutes depending on what the needs of the PJM are. This study utilizes LMPs, and it is important to develop a stronger understanding of what they are and how they help explain the state of electricity flow in the PJM RTO. Locational marginal prices are calculated by combining the system energy price, transmission congestion cost and the cost of marginal losses. The system energy price "represents optimal dispatch ignoring congestion and losses" (Energy Markets, 2011). It is the price of electricity without interference from external forces. Transmission congestion and marginal loss often add to the LMP for generators. When there is congestion in the transmission lines it adds costs to the system generators to deliver electricity to the customer in high demand areas and times. The cost of marginal loss is dependent on loss of power caused by changes in the system load and generation patterns. Congestion and marginal loss are both capable of having positive and negative prices. Negative congestion prices occur when generators create more electricity than is being consumed, and the generators are willing to pay to have the electricity handled by another entity. Negative marginal loss prices occur when the load losses are smaller than the generation loss. (Monitoring Analytics, 2012) Locational marginal price is the most effective way to measure cost variance within the PJM. LMP accounts for both system energy price and transmission inefficiency within the specific zone being measured. This leaves forecasting error, unplanned maintenance and severe weather as externalities that would explain drastic short-term shifts in price. 
The PJM provides an average daily wholesale price of electricity report on its website. Figure 11 reports daily prices over ten years from June $1^{\text {st }}, 2007$ to June $1^{\text {st }}, 2017$. A linear trend line was added to the graph to show the downward trend in average price per MWH. The longterm price decrease in wholesale electricity from the PJM RTO follows in line with the national trend of decreasing wholesale electricity prices. Upon further examination, the rapid spikes in price seen in Figure 11 are likely the result of extreme weather conditions. The most significant increase occurred in January 2014. A polar vortex blew through the Midwest into the east coast, and on January $7^{\text {th }}, 2014$ states experienced record low temperatures. Morgantown had a record low temperature of $-7^{\circ}$ Fahrenheit on this day (Weather Underground, 2018). Two other price spikes that occurred during the time period being assessed were February $18^{\text {th }}-21^{\text {st }}, 2015$ and July $20^{\text {th }}, 2015$, both of which also experienced extreme temperatures. Catalão et al. (2007) state that large temperature fluctuations lead to increases in the short-term price of electricity. Even when cold temperatures are forecasted and properly accounted for by electricity generators, the price of electricity can still soar as electricity customers demand more electricity during this time.

A market's ability to handle large shifts in electricity consumption over short time periods depends on its fuel generation mix. Having a good mix of baseload and peaking generation sources allows the wholesale market to properly adjust generation based on costumers' needs. Baseload electricity generation is the minimum amount of electricity supplied to the grid at a given time. These generators are commonly the lowest cost generators which maintain production over extended periods of time. Coal and Nuclear generators are examples of baseload generators. Peaking electricity generators commonly only generate electricity when there is a high electricity consumption. Gas and hydroelectric plants offer peaking capable electricity generation for when consumption is high. 
The event that unfolded in the PJM on June $1^{\text {st }}, 2015$ was a massive overhaul of the current energy balance in the RTO. On this day 5,408 MW of available coal powered generation capacity was retired from the PJM. Table 1 reveals the generation mix of natural resources at approximately six-month intervals from June $1^{\text {st }}, 2014$ to June $1^{\text {st }}, 2016$. Coal generated $41.3 \%$ of the energy mix in the PJM in June 2014. By June 2016, coal generation only accounted for $36.6 \%$ of the PJM fuel mix. Coal-fired generation lost $4.7 \%$ of its share of the PJM in two years. Natural gas was the second largest producer in the PJM and grew at a rapid pace from $29.2 \%$ in June 2014 to $35.5 \%$ in June 2016. The capacity lost by coal over this time period was mostly replaced by natural gas power plants. Nuclear, hydro and oil generate almost all the rest of the PJM's fuel mix with renewables like solar, solid waste, and wind only contributing about one percent of the total mix.

As Table 1 suggests, the PJM is highly dependent on fossil fuel resources for its energy generation. This perhaps due to the geologic makeup of the region it covers. The RTO lies directly on top of abundant recoverable coal and natural gas reserves. The Northern and Central Appalachian coal basins are located in parts of Ohio, Pennsylvania, and West Virginia and provide coal at low cost to power plants within the PJM. The Marcellus Shale Play is currently the largest source of gas in the United States. It produced over 30,000 million cubic feet of natural gas in March 2019, and the play has shown constant growth in production since 2010 where production in the area was under 6,000 million cubic feet per day (U.S. Energy Information Administration, 2019). The play is also believed to be the largest reserve of recoverable natural gas in the U.S. Proved reserves in 2015 reached 148.7 trillion cubic feet of gas in the Marcellus formation (United States Environmental Protection Agency, 2017). The 
large reserves of available natural gas in the region ensures there will be no potential problem of the natural resource running out in the foreseeable future.

The PJM RTO is a single integrated market for electricity, but each state within the RTO creates its own laws and regulations for electricity production. The six zones examined in this study cover portions of Illinois, Indiana, Kentucky, Maryland, Michigan, Ohio, Pennsylvania, Tennessee, Virginia and West Virginia (Figure 9). The states with regulated electricity utilities are Indiana, Kentucky, Tennessee, and West Virginia. The other states are deregulated. Tennessee has a very small part of its state within the PJM and has not a large influence on the LMP. Indiana, Kentucky and West Virginia have regulated electricity where the consumer has no choice in provider and the total cost of production and transportation of electricity are covered entirely by the consumers. Every electricity producer in these states is guaranteed a predetermined profit which is decided upon by the state commission each year. The state government regulatory commissions also determine when plants will be retired and when new power plants will be proposed.

\subsection{Literature Review}

Power plants in deregulated markets operate based on whether they can produce electricity at a competitive price. Scholarly journal articles focusing on electricity prices remain valuable as the U.S. electricity industry continues to morph due to changes in weather patterns, government regulations, natural resource availability, and technology advancements. The literature review has been separated into two parts. The first part offers background information on the U.S. electricity industry and the external forces affecting market prices. The second part gives a closer examination of three articles, namely Woo et al. (2014), Kaufmann and Vaid (2016), and Rahmani et al. (2016). These articles utilize LMP data to study different forms of 
generation retirement in wholesale markets. They were referenced in the introduction and are very important to why this research was initially performed.

\subsubsection{Industry, History, and Factors Effecting Wholesale Price}

The background information from earlier provides a basic overview on the development

of the U.S. electricity industry over time. In their book The Economics of Electricity Markets, Biggar and Hasamzadeh (2014) provide a more in-depth description of the economic nuances within electricity markets. Another book that offers insight into the recent history of the U.S. electricity industry is Electricity Deregulation: Choices and Challenges by Griffin \& Puller (2005). This book discusses some of the large crises that occurred when the states restructured from regulated into deregulated markets. Both books are useful for anyone who wishes to learn about the electricity industry.

Economists continue to debate the benefits and costs of restructuring the U.S. electricity industry. With only a portion of the U.S. electricity industry residing within competitive markets, it is clear some states see benefits in maintaining a fully regulated industry. Borenstein and Bushnell (2015) discuss the effects of market structure on electricity prices in the U.S. over the past 20 years. They argue that there is a divergence between the commodity of electricity price made by producers and the retail market price of electricity. However, they argue that the creation of markets is not solely responsible for decreasing prices-electricity rates have changed more from, "exogenous factors, such as generation technology advances and natural gas price fluctuations, than by restructuring."

Since this report focuses on LMP within wholesale markets, it is important to understand how firms in this setting are expected to act. Kishimoto et al. (2017) question if acquiring and merging electricity companies create value to the market. While previous studies on this topic show no sign of a positive effect, the paper finds that there is an increase in the acquiring firms' 
share value and improvements to their operating performance, primarily through efficiency gains after the deregulation. The paper examines the time period of 1998-2013 in the UK, France, Germany, Canada and the US. The findings follow Coase's argument that firms enhance shareholder value and reduce transaction costs in a deregulated market. Firms in the electricity industry are encouraged to grow larger in a deregulated market to please the company's shareholders and decrease costs.

Firms attempt to maximize their profit when generating electricity. Firms only generate when the LMP in their zone is above the cost of generation. They must be vigilant in observing exogenous factors like weather and resource prices that affect the electricity price. Fluctuations in weather are strong predictors of electricity price spikes. Valor et al. (2001) consider the relationship between daily air temperature and electricity load in Spain. The results of the study found that the relationship between the two is nonlinear. A comfort interval of $+/-3^{\circ} \mathrm{C}$ around $18^{\circ} \mathrm{C}\left(64.4^{\circ} \mathrm{F}\right)$ and two saturation points occur at which electricity load no longer increases. Population-weighted index, socioeconomic factors, and daily and monthly effects were added to isolate the weather influence on electricity load. The results found in this paper were useful for understanding the expected shift in electricity prices depending on the degree day value. The report found as degree day value increased, the price of electricity increased in a nonlinear fashion. Additionally, the authors noted that days where degree day values exist for warm weather are more likely to increase electricity prices than degree day values caused by cold weather of equivalent magnitude.

Urbine et al. (2018) measure the causality between natural gas and electricity prices in the New England and PJM markets. The report finds that New England has a higher crosscorrelation between the two areas, but both areas experience significant effects on each other's 
prices. The PJM area has a cross-correlation of 20-30\% from gas to electric and $15 \%$ from electric to gas. The conclusion to the paper states "the PJM and the NE interconnection markets show that natural gas prices can indeed be used as a predictor of electricity prices, but it also shows that electricity prices can predict natural gas prices, especially when the two resources are trading relatively high in the market." The fall in natural gas prices and the rise in natural gas production capacity in the U.S. promises the future role of natural gas prices as an increasingly influential determining factor of electricity prices.

Cabral et al. (2017) discuss electricity consumption forecasting in Brazil. The study compares a spatial Autoregressive Integrated Moving Average (ARIMA) model to a regular ARIMA model and found the spatial version to be a better predictor of performance. The authors use the Moran Index neighbor test for spatially identifying neighboring electrical regions. The new method found that regional electricity consumption in Brazil is spatially dependent. Adding a spatial dimension ensures consistent unbiased and efficient estimates. The continuing research plans to study the predictive performance of multivariate models like vector autoregressive (VAR), spatial autoregressive model with autoregressive disturbances (SARAR), and spatial panel vector autoregressive (SpVAR) in the future. This type of analysis is a potential direction this research could take moving forward with the spatial analysis of LMP before and after the coal production retirement.

\subsubsection{LMP Literature}

Three journal articles best define why this research was performed. Woo et al. (2014), Kauffmann and Vaid (2016), and Rahmani et al. (2016) examine LMP change when there is a change in generation capacity within a wholesale market. All articles offer unique approaches to aid in understanding the constant transformation and growth of the U.S. electricity industry. 
These articles offer prior information and standpoints that can be used as a comparison for the results found in this paper.

Woo et al. (2014) examine the likely increase in price due to a nuclear plant closure and the potential ways of mitigating a price increase. The paper performs a regression analysis of electricity market price data from California Independent System Operator (CAISO). Three regions' hourly wholesale price and load data along with daily Henry Hub natural gas price data were obtained to perform the analysis. The results of a shutdown of the nuclear power plants within CAISO raised hourly prices by $\$ 6-\$ 9 / \mathrm{MWH}$. Some recommended ways of mitigating the price increase suggested by the authors are demand reduction and solar and wind generation increases. This paper uses a similar approach to that in our paper, but ours will work with coalfired plant deactivation in the PJM.

Kauffmann and Vaid (2016) analyze Massachusetts rooftop solar utilization and its effects on electricity prices. Massachusetts electricity distribution system is split into three separate zones. It finds that a $10 \%$ increase in solar production could lead to $\$ 184$ million in savings for ratepayers in 2010-2012. The paper uses Newey and West (1987) estimator to avoid difficulties with autocorrelation and heteroscedasticity. It also found that photovoltaic (PV) reduces the amount of carbon emissions by $0.3 \%$ relative to the annual average. This article uses regression analysis to measure the effects of changes in generation capacity on LMP. Implementing PV in Massachusetts will effectively decrease LMP, congestion, and emissions.

Rahmani et al. (2016) review the retirement of coal power plants on transmission congestion and LMP prices. The paper also examines the effect of increased levels of wind power and new EPA rules on the PJM electricity system. By creating a forecast model, the paper was able to predict the effects of different future scenarios for the PJM. The results show, 
"Without transmission upgrades, retirement of coal-fired power plants will likely result in considerable transmission congestion and higher energy prices.” (Rahmani, 2016) The authors argue that the best way to mitigate the problem is to integrate wind power, which will diminish the negative effects of coal retirement while also reducing emissions. Implementing the wind over diverse geographic areas will also reduce congestion and provide larger emissions reduction benefits.

\section{Chapter 3: Data \& Methodology}

\subsection{Data}

There are two possible approaches to the research problem of how wholesale electricity prices will respond to the retirement of coal-fired electricity generation power stations: (1) regression analysis that relates the impact of retirements by comparing the predicted electricity prices and observed wholesale electricity prices; or (2) optimization analysis of the PJM electricity market with and without the retired 5,408 MW of coal-fired capacity in the model assuming different generation replacement responses. Since the second method would require funding to secure and implement the appropriate optimization models, this research will apply a regression analysis. This research utilizes electricity data obtained from the pjm.com website. PJM Interconnection LLC is an organization of more than 900 companies in 14 states that formed a competitive electricity market in northeastern United States. PJM offers zonal hourly load consumed and locational marginal pricing data. The study includes a total of 105,408 unique wholesale price observations from six zones during June $1^{\text {st }}, 2014$ - June $1^{\text {st }}, 2016$.

Data were collected for the following 6 zones within the PJM region: American Electric Power Company (AEP), Allegheny Energy (APS), American Transmission Systems (ATSI), Commonwealth Edison (COMED), Dayton Power and Light Company (DAY) and Duquesne 
Light (DUQ). The data obtained from the PJM contain real-time hourly historical prices, dayahead prices, real-time historical load consumed, and eight separate forecasted loads consumed for each zone. The forecasted loads consumed were formulated at 5:45, 11:45, 17:45, and 23:45 the day ahead (DA) of when the load is physically consumed and the day of (DO) the consumed load. All electricity data used in this report were gathered directly from the PJM website.

The raw data were moved from the PJM website into Excel documents where they were cleaned and reformatted. These data were then transferred into STATA where the regressions would be performed. Each variable was transposed so that the observations read in a vertical column manner from top to bottom according to time. Hours in the day are aligned from 1 to 24 . Hour 1 signifies the hour from 0:00 to 1:00 am and 24 is hour 23:00 to 24:00 or midnight. June $1^{\text {st }}, 2014$ hour 1 is the first observation for each of the six zone's LMP and load consumed variables. This format continues vertically until June 1st, 2015 hour 24. At this point the data set is ended, and a new set of data reading the same way from June $2^{\text {nd }}, 2015$ hour 1 to June $1^{\text {st }}, 2016$ hour 24 was created. Separating the two years allows for evaluation of the retirement of coal generation within the zones to be tested for by regression analysis.

Five of the six zones retired coal-fired capacity on June $1^{\text {st }}, 2015$. Table 2 shows each zone's average load consumption and retired coal capacity over this two-year time span. The AEP zone contained a retired 5,408 MW of coal-fired electricity capacity. The ATSI zone, at 986.6MW retired, had the second highest retirement capacity. The ATSI zone encompasses the northern portion of Ohio and some of Pennsylvania. DAY and DUQ are small zones in terms of consumption at $277 \mathrm{MW}$ and $125 \mathrm{MW}$ respectively. COMED did not experience much coal capacity retirement either at $251 \mathrm{MW}$. Every zone except the APS zone lost some capacity during the two years being observed. Thus, LMP within APS, COMED, DAY, and DUQ should 
experience different LMP shifts than the AEP and ATSI, since these zones experienced less change.

Part of the reason the APS did not lose any capacity is that a large portion of this zone is located within the vertically integrated regulatory state of West Virginia. Large scale retirements are less likely to occur in regulated states since costs of production are covered by the ratepayers. The only other zone of the six chosen for research that encompasses states with regulated markets is the AEP. The power stations retired in the AEP all are located within the deregulated states of Ohio and Virginia. The ATSI, COMED, DAY and DUQ all act in accordance with the PJM to retire generation if their power stations are no longer competitive in the market. Parts of the AEP and APS generation capacity are at the mercy of the regulated states' decisions to keep or retire their power stations.

Generators, both in competitive states and vertically-integrated states, are provided day ahead price and load consumption forecasts by the PJM to signal whether the generator should be expected to produce in the future. These estimates provide an indication of what real-time markets could be. Power generators use these estimates to determine how much electricity they should produce per hour. The estimates are not always correct, however, and incorrect estimates lead to over or underproduction of electricity compared to the real-time consumption of electricity. This market force is accounted for by creating two new variables called overpredicted consumption and under-predicted consumption. Equations (1) and (2) represent the over- and under-predicted consumption by the PJM.

$$
\begin{array}{ll}
\text { Over - Predicted Consumption: } & \sum_{t=1}^{n} D A_{h Z}-\sum_{t=1}^{n} R T_{h Z} \geq 0 \\
\text { Under - Predicted Consumption: } & \sum_{t=1}^{n} D A_{h Z}-\sum_{t=1}^{n} R T_{h Z}<0
\end{array}
$$

$\mathrm{DA}_{\mathrm{hz}}=$ Day Ahead Load Consumed on hour $\mathrm{h}$ assigned to each zone $\mathrm{z}$ 


$$
\begin{aligned}
& \mathrm{RT}_{\mathrm{hz}}=\text { Real Time Load Consumed on hour } \mathrm{h} \text { assigned to each zone } \mathrm{z} \\
& \mathrm{n}=\text { Number of observations measured in hours }
\end{aligned}
$$

Predicted consumption was split into two different variables. The first one involved overpredicting the real-time consumption which is expected to lead to a relatively small shift in realtime prices. The surplus of generated electricity is either sent to zones in need of more electricity or stored using hydro dams (pumped storage) or dumped from the grid using synchronous condensers. The second variable, under-predicting the real-time consumption, is expected to have a more consequential effect on electricity prices. When the estimate is below the real-time electricity consumption, the PJM must find and send electricity from an external area to meet the consumption needs of the area or zone in need. This can lead to real-time increases in LMP in the zones that under-predicted consumption.

Another force which affects the real-time price of electricity is regional temperature. The best available weather data offers daily temperature readings. Weather information was gathered from 16 metropolitan locations within the six zones (Table 3). A single weighted temperature was created for each of the six zones based on the populations of metropolitan locations located within each individual zone. Equations (3) and (4) explain how each metropolitan location was weighted within its zone and describe how the final temperature was determined using the population weights.

$$
\begin{gathered}
w_{I Z}=\frac{P_{I Z}}{\sum_{i=1}^{n} P_{I Z}} \\
T I_{h Z}=\sum_{i=1}^{n} \bar{T}_{h I} W_{I Z} \\
\mathrm{TI}_{\mathrm{hZ}}=\text { Mean Population Weighted Temperature } \\
\bar{T}_{h I}=\text { Mean Temperature }
\end{gathered}
$$




$$
\begin{aligned}
& \mathrm{W}_{\mathrm{IZ}}=\text { Population Weight } \\
& \mathrm{P}_{\mathrm{IZ}}=\text { Population } \\
& \mathrm{Z}=\text { Zone } \\
& \mathrm{I}=\text { Metropolitan Area } \\
& \mathrm{h}=\text { Hour } \\
& \mathrm{n}=\text { Number of observations }
\end{aligned}
$$

This approach is similar to the one used by Valor et al. (2001). The population weight in equation (4) weighs the metropolitan areas in each zone based on their total population. The population weight of the area is then multiplied by the temperature for each hour in the metropolitan area to create an average temperature for each zone.

After the weighting, temperature data were split into heating and cooling degree days. The term degree day is defined as, "Measures of how cold or warm a location is. A degree day compares the mean (the average of the high and low) outdoor temperatures recorded for a location to a standard temperature, usually $65^{\circ}$ Fahrenheit $\left({ }^{\circ} \mathrm{F}\right)$ in the United States." A heating degree day (HDD) occurs when the temperature of the day is less than $65^{\circ} \mathrm{F}$. A cooling degree day (CDD) occurs when the temperature is more than $65^{\circ} \mathrm{F}$. Equations (5) and (6) represent the algebraic approach taken to obtain degree days.

$$
\begin{aligned}
& \qquad H D D_{i}=65-T I_{h i} \geq 0 \\
& C D D_{i}=65-T I_{h i}<0 \\
& \mathrm{HDD}=\text { Heating Degree Days } \\
& \mathrm{CDD}=\text { Cooling Degree Days } \\
& \mathrm{TI}_{\mathrm{hz}}=\text { Mean temperature on hour assigned to each zone } \\
& \mathrm{h}=\text { Hour }
\end{aligned}
$$




$$
\mathrm{i}=\mathrm{i}^{\text {th }} \text { zone }
$$

After the degree day values are separated, the variables are then squared. Valor et al. (2001) describes how degree day values increase energy use increases in an exponential fashion. Squaring the variables allows for the magnitude of influence each extra degree has on the wholesale prices to be properly quantified.

Degree days are separated because Valor et al. (2001) show that HDD and CDD have different effects on LMP values. CDD values generally lead to more electricity consumption than HDD days of the same magnitude. For example, a day at $85^{\circ} \mathrm{F}$ is likely to have more electricity consumption than a day at $45^{\circ} \mathrm{F}$ (Valor et al., 2001). Both temperatures maintain a degree day value of 20 , but the degree day with warmer temperature demands more electricity for air conditioning. CDD has a larger impact on prices than HDD. Tables 4 and 5 provide statistical information on the mean, standard deviation, minimum, and maximum of zonal LMPs, degree days, and predicted consumption variables. After degree day and predicted consumption variables were created, dummy variables were created and added to account for time.

Electricity consumption shifts depending on the time of day, day of week, and month of year. To account for the regime switching, dummy variables were created in a similar approach as Kauffman and Vaid (2016). A total of 23 dummy variables were used for hours of the day, six dummy variables for days of the week, and 11 dummy variables for months of the year. Bases for each dummy variable were defined at 0:00 to 1:00, or hour 1, for hours, Wednesday for days, and December for months. Figures 12 and 13 show the average real-time price of electricity in each zone for each hour before and after the coal plants were retired. Figures 12 and 13 show prices are lowest during the night hours, and highest during the day around 18:00-20:00. The average price per Megawatt of electricity for every hour is higher before the capacity was retired. 
The APS has the highest average price and COMED has the lowest average price. The AEP zone falls in the middle relative to the other five zones.

Figures 14 and 15 show the average daily price of electricity in each zone. The values on the $\mathrm{X}$-axis represent the days of the week: Monday is denoted as 1 and Sunday is 7 . Figures 14 and 15 do not follow the same price trend; however, both figures maintain lower average LMPs on the weekend than during weekdays. A quick overview of Figures 16 and 17 shows the average monthly price of electricity in each zone. The values on the $\mathrm{x}$-axis represent the days of the week: January is denoted as 1 and December is 12 . Prices rise during the summer and winter seasons and fall during the spring and autumn seasons. This observation coincides with Kaufmann and Vaid (2016), mentioned in the background, on the effects of weather on electricity prices. The average price of electricity in the APS during the winter months before the plants were retired is abnormally high. While the winter of 2015 was very cold, it does not explain why the APS zone is so much higher than the other zones in the PJM. The APS did not experience the same type of price jump in the second year of data after the other zones' capacity retirements occurred.

The summary of statistical data for the variables utilized in the research is available in Tables 4 and 5. Table 4 summarizes the data used in the pre-retirement period, while Table 5 summarizes the data used in the post-retirement period. The only data altered in the regressions were the heating and cooling degree days. Both variables were squared to emphasize the effects of extreme weather on electricity prices. While consumption $(\mathrm{C})$ was not used in the regressions, the summary of its statistical data is available in Tables 4 and 5. Consumption of electricity in the pre-retirement time period is larger than consumption in the post-retirement time period for every zone. 


\subsection{Methodology}

\subsubsection{Regression Models}

The primary goal of this report is to quantify the effects of coal-fired electricity generation retirements on each of the six zone's LMP. To achieve this, we use a single regression employing the data explained above. Equations (7) and (8) represent a series of six hourly-price regressions, one for each of the six zonal locational marginal prices. The regressions for the zones AEP, APS, ATSI, COMED, DAY, DUQ are represented in equations (7) and (8).

$$
\begin{aligned}
& P_{i}=\alpha+\beta X_{i}+ \beta X_{j}+\beta Z_{j}+\beta H_{i}+\beta C_{i}+\beta H D D_{i}^{2}+\beta C D D_{i}^{2}+\beta h+\beta d+\beta m+\varepsilon \text { (7) } \\
& P_{i}=\alpha+\beta Z_{i}+\beta X_{j}+\beta Z_{j}+\beta H_{i}+\beta C_{i}+\beta H D D_{i}^{2}+\beta C D D_{i}^{2}+\beta h+\beta d+\beta m+\varepsilon(8) \\
& \mathrm{P}=\text { Locational Marginal Price of Electricity } \\
& \mathrm{X}=\text { Over-Predicted Consumption } \\
& \mathrm{Z}=\text { Under-Predicted Consumption } \\
& \mathrm{HDD}=\text { Heating Degree Days } \\
& \mathrm{CDD}=\text { Cooling Degree Days } \\
& \mathrm{i}=\text { Dependent Variable Zone } \\
& \mathrm{j}=\text { Other } 5 \text { Independent Variable Zones } \\
& \mathrm{h}=\text { Dummy Variable Hours (Hour 1 Base) } \\
& \mathrm{d}=\text { Dummy Variable Days (Wednesday Base) } \\
& \mathrm{m}=\text { Dummy Variable Months (December Base) } \\
& \alpha=\text { Y-Intercept } \\
& \varepsilon=\text { Residual }
\end{aligned}
$$

These equations are estimated as regressions based on the Woo et al. (2014) study for electricitymarket price behavior in California when nuclear power stations are shut down. The dependent 
variable in each equation is $\mathrm{P}$ - the real-time locational marginal price $(\$ / \mathrm{MWH})$ at zone $\mathrm{i}$. Equation (7) involves a regression using data when consumption is over-predicted in the dependent variable zone. Equation (8) is a regression using data when consumption is underpredicted in the dependent variable zone. The degree day and dummy variables are used in the same manner for both equations (7) and (8). The final term $\varepsilon$ is an autoregressive error term for the hourly LMP.

Similar regressions to equations (7) and (8) using logged dependent and independent variables were performed at the beginning of this research. Log-log models were created with the intent of minimizing the influence of price spikes on the results. The log-log models are not reported in this research due to an inability to account for negative LMP values. Tables $6,7,8$ and 9 display the results of the regressions performed. Tables 10,11, 12 and 13 display the correlation of over-predicted and under-predicted consumption between zones during the preretirement and post-retirement time periods. Further explanation of these tables is available in the Results section of the report.

\subsubsection{Statistical Tests}

Regressions were examined and adjusted using three tests: Chow, likelihood ratio, and ttest. All three of these tests molded the regression into its final form and are discussed in detail below. The Chow test was utilized to determine if there were structural breaks within the twoyear time series data set. The first Chow test was used to examine whether there was a structural break in the model caused by the retirement of coal-fired electricity generation capacity in the AEP zone on June $1^{\text {st }}, 2015$. Table 14 shows the Chow test results. The null hypothesis is that the model should be singular over the two-years rather than split based on pre-retirement and postretirement of the coal capacity. Based on statistically significant F-tests, there were indeed 
structural breaks in each zone caused by these retirements and that a single regression model with the entire data set is less efficient than two regression models: one before the retirement of the coal capacity from June $1^{\text {st }}, 2014$ - June $1^{\text {st }}, 2015$ (pre-retirement), and one after the retirement of coal capacity from June $2^{\text {nd }}, 2015$ - June $1^{\text {st }}, 2016$ (post-retirement).

A second Chow test was performed after the structural break test to examine if there was a structural break caused by the predicted consumption variables within the model. The null hypothesis is that the pre- and post-models should be one model rather than split again based on whether the zone experiences over-predicted or under-predicted consumption. Table 15 presents the second Chow test results. The interpretation is that there are structural breaks caused by splitting the predicted consumption variable into under-predicted consumption and overpredicted consumption. Every zone in both the pre-retirement, post-retirement, and two-year time periods experiences a statistically significant structural break between a single Diff predicted consumption model, predicted consumption model with only positive Diff values, and a predicted consumption model with only negative Diff values.

While Chow tests are useful for determining whether there is a structural break within the data, they do not explain whether a split model is more effective in explaining price than a whole model. A likelihood ratio test was performed to test for goodness of fit between a two-year single model and two one-year models. The results of the test in Table 16 show the two one-year models had a better fit than the single two-year model when evaluating LMPs as the dependent variable. The two-year model was split into two one-year models because of this LR-test.

A likelihood-ratio test was then utilized on the two-year model and both one-year models to compare the goodness of fit between a single predicted consumption variable against split under-predicted and over-predicted consumption variables. The null hypothesis is that the pre- 
and post-models should be one Diff value model rather than split again based on whether the zone experiences over-predicted or under-predicted consumption. Table 16 displays the LR-test results. For each zone, the model featuring no predicted consumption split was less efficient than the model with separate positive Diff and negative Diff values. The predicted consumption because of the test was separated into positive over-predicted real-time consumption and negative under-predicted real-time consumption. These structural breaks and LR-tests show that four separate models are appropriate: pre-retirement with over-predicted consumption, postretirement with over-predicted consumption, pre-retirement with under-predicted consumption and post-retirement under-predicted consumption.

Finally, student's t-tests are used to determine if there is a significant difference between the averages of two sets of data. The t-test serves three separate purposes for this report. The first use of the t-test will be to compare the average observed LMP values to the average counterfactual LMP values. These t-tests verify whether the observed data is statistically different from the counterfactual data. To accomplish this, a t-test using Diff values against was performed. The null hypothesis of this test is that the Diff values are no different than the counterfactual LMP. The results of this test are available in Table 17. The second t-test is used to determine if each zone's LMP is significantly different from other wholesale electricity markets within the U.S. The null hypothesis of this test is the LMP for each hour is not different than the wholesale price of each hour in other electricity markets within the U.S. Table 18 displays the ttests for observed LMP against other market prices. The third t-test is used to determine if each zone's electricity consumption is significantly different between pre-retirement and postretirement time periods. The null hypothesis of this test is the consumption for pre-retirement is not different than the consumption for post-retirement. Table 19 displays the t-tests for electricity 
consumption between pre-retirement and post-retirement time periods. Each t-test will be explained in further depth in the Results section of this report.

\subsection{Analyses}

Four counterfactual analyses were produced using the obtained data and regression coefficients estimated from equations (7) and (8) which were discussed at length in the methodology section. Each hour of the observed LMP was equated against its counterfactual counterpart for all four analyses being performed to find the change in LMP values. The outputs from sections 3.3.1 through 3.3.4 are shown in Tables 20, 21, 22 and 23. The results were also converted into percent change in LMP and are presented in Tables 24, 25, 26 and 27. Locational Marginal Price is the dependent variable being evaluated in these analyses and change in LMP is the resulting solution. The independent variables affecting the LMP are predicted consumption, degree day, fixed effects and the error term. The analyses examine each zone individually and offer a change in LMP result, also referred to as Diff, measured in $\$ / M W H$.

\subsubsection{Early Retirement with Over-Predicted Consumption}

The early retirement analysis with over-predicted consumption was created to examine the effects of the PJM zones over-predicting real-time consumption of electricity from June $1^{\text {st }}$, $2014-$ June $1^{\text {st }}, 2016$. The analysis utilizes an estimated LMP as if the retirement of electricity occurred on June $1^{\text {st }}, 2014$ rather than the actual retirement date of June $1^{\text {st }}, 2015$. Equation (9) results in the difference in LMP according to the analysis's framework.

$$
\begin{aligned}
& P_{\text {Pre }}-\widehat{P_{\text {Pre }}}=\text { Diff }_{\text {Early Retirement, OP }} \\
& \hat{P}_{\text {Pre }}=\text { Projected LMP Post-Retirement with Over-Predicted Consumption } \\
& \text { Coefficients } \\
& P_{\text {Pre }}=\text { Observed Pre-Retirement Data }
\end{aligned}
$$




\section{Diff = Locational Marginal Price Difference in $\$ / \mathrm{MWH}$ \\ $\mathrm{OP}=$ Over-Prediction of Consumption}

The observed data in this analysis is derived from the pre-retirement time-period of June $1^{\text {st }}$, 2014 - June $1^{\text {st }}, 2015$. The $\hat{P}_{\text {Pre }}$ estimates provide a counterfactual LMP in each zone if the coalfired capacity had retired a year earlier than its actual retirement date.

Under a scenario where early retirement with over-predicted consumption occurs, the expected result is to return positive Diff results for each zone. A positive Diff occurs when the observed $P_{P r e}$ is larger than the $\hat{P}_{P r e}$ counterfactual LMP. If the average of all the Diff values is a positive value, the results of that analysis would lead to a decreased LMP average compared to the observed LMP average. If the average of all the Diff values is a negative value, the results of that analysis would lead to an increased LMP average compared to the observed LMP average.

The observed $P_{P r e}$ is expected to be higher than the $\hat{P}_{\text {Pre }}$ counterfactual LMP because coal-fired capacity being retired is no longer competitive within the wholesale electricity market is being removed to allow more cost competitive generators of electricity to compete in the PJM market. The 25 percent decrease in U.S. coal-fired generation from 2007-2013 was influenced by "Falling natural gas prices combined with increased wind generation account for most of the observed decline in average coal capacity factors" (Fell and Kaffine, 2018). Coal-fired capacity's ability to compete has diminished within wholesale markets over the past decade. The counterfactual experiencing early retirement is therefore expected to decrease each zone's LMP. The over-predicted consumption factor is not expected to be very influential in determining the LMP. If the consumption is over-predicted, the counterfactual may decrease the zone's LMP due to excess generation of electricity within the zone. 


\subsubsection{No Retirement with Over-Predicted Consumption}

This analysis was produced to examine the effects on each zone's LMP given overprediction of consumption conditions using the counterfactual that coal-fired capacity is not retired. Equation (10) is the basis for this analysis as the LMP difference between the actual LMP and projected LMP under the counterfactual of no retirement.

$$
\begin{aligned}
& P_{\text {Post }}-\hat{P}_{\text {Post }}=\text { Diff } \\
& \hat{P}_{\text {Post }}=\text { Protirement }, \text { oP } \\
& \text { Coefficients } \bullet \text { Observed Post-Retirement Data } \\
& P_{\text {Post }}=\text { Post-Retirement Observed LMP Data } \\
& \text { Diff }=\text { Locational Marginal Price Difference in } \$ / \mathrm{MWH} \\
& \text { OP }=\text { Over-Prediction of Consumption }
\end{aligned}
$$

$P_{\text {Post }}$ is derived from the post-retirement time-period of June $1^{\text {st }}, 2015$ - June $1^{\text {st }}, 2016$. The preretirement with over-predicted consumption coefficients were multiplied by the observed postretirement data to create $\hat{P}_{\text {Post. }}$ The observed $P_{\text {Post }}$ was then subtracted by the $\hat{P}_{\text {Post }}$ to create the difference in \$/MWH of non-retirement over-predicted consumption analysis.

Under a scenario containing no retirement with over-predicted consumption, the expectation is for negative Diff results. An average negative Diff is the result of projected LMPs being larger, on average, compared to the observed LMP. The observed $P_{\text {Post }}$ is expected to be lower than the $\hat{P}_{\text {Post }}$ counterfactual LMP because coal-fired capacity that is no longer price competitive with other sources of electricity generation. The coal-fired capacity remaining in the PJM adds unnecessary bloat to the generation side of the RTO. The counterfactual experiencing no retirement is expected to increase the zone's LMP due to this bloat. The over-predicted consumption factor is not expected to be very influential in determining the LMP. 


\subsubsection{Early Retirement with Under-Predicted Consumption}

This analysis was produced to examine the effects of the PJM zones under-predicting real-time consumption of electricity from June $1^{\text {st }}, 2014$ - June $1^{\text {st, }} 2016$. The analysis is based upon equation (11) to find the difference between actual pre-retirement real-time LMP and projected LMP under the counterfactual of the retirement of coal-fired electricity occurred early on June $1^{\text {st }}, 2014$ rather than their actual retirement date of June $1^{\text {st }}, 2015$. Equation (11) presents the difference in LMP according to the analysis's specifications.

$$
\begin{aligned}
& P_{\text {Pre }}-\hat{P}_{\text {Pre }}=\text { Diff } f_{\text {Early Retirement, } U P} \\
& \hat{P}_{\text {Pre }}=\text { Projected LMP Post-Retirement with Under-Predicted Consumption } \\
& \text { Coefficients } • \text { Observed Pre-Retirement Data } \\
& P_{\text {Pre }}=\text { Pre-Retirement Observed LMP Data } \\
& \text { Diff }=\text { Locational Marginal Price Difference in } \$ / M W H \\
& \text { UP }=\text { Under-Prediction of Consumption }
\end{aligned}
$$

The observed data in this analysis is derived from the pre-retirement time-period of June $1^{\text {st }}, 2014$ - June $1^{\text {st }}, 2015$. Projected LMP of each zone is created by the multiplication of the coefficients from the post-retirement regression model times the observed pre-retirement data. The average difference in observed $P_{P r e}$ was subtracted by the average difference in counterfactual $\hat{P}_{P r e}$ to find the average difference in LMP.

A scenario of early retirement with over-predicted consumption was expected to produce positive Diff results. A positive Diff average is the result of smaller projected LMPs compared to the observed LMPs. The counterfactual experiencing early retirement is expected to decrease each zone's LMP due to higher cost coal-fired electricity generation. In addition, the underpredicted consumption factor should increase each zone's LMP. If consumption is under- 
predicted, the counterfactual may experience an increase in LMP due to the lack of electricity generation driving the wholesale prices up within the zone. The Diff value for this analysis should be positive.

\subsubsection{No Retirement with Under-Predicted Consumption}

The no retirement analysis with under-predicted consumption uses observed data from the post-retirement time-period where the real-time consumption is under-predicted. Postretirement data were multiplied by the pre-retirement coefficients to produce projected LMPs that represent a no retirement scenario. Equation (12) was used to find the differences between the observed LMP and the no retirement analysis with under-predicted consumption LMP.

$$
\begin{aligned}
& P_{\text {Post }}-\hat{P}_{\text {Post }}=\text { Diff } f_{\text {No Retirement }, U P} \\
& \hat{P}_{\text {Post }}=\text { Projected LMP Pre-Retirement with Under-Predicted Consumption } \\
& \text { Coefficients } \bullet \text { Observed Post-Retirement Data } \\
& P_{\text {Post }}=\text { Post-Retirement Observed LMP Data } \\
& \text { Diff }=\text { Locational Marginal Price Difference in } \$ / M W H \\
& \text { UP }=\text { Under-Prediction of Consumption }
\end{aligned}
$$

The observed data in this analysis is derived from the no retirement time-period of June $2^{\text {nd }}, 2015$ - June $1^{\text {st }}, 2016$. A projected LMP for each zone as if the coal-fired capacity retired a year earlier than its actual retirement date is created by multiplying the coefficients from preretirement by the observed post-retirement data. Observed LMP was subtracted by projected LMP to find the average difference in LMP.

Under this scenario, the expectation is to return negative Diff results. A negative Diff is the result of projected LMPs being larger than observed LMPs. The counterfactual experiencing no retirement is expected to experience LMP increases for each zone. Under the no retirement 
scenario, the inefficient power stations are kept in the PJM. These inefficient generators drive up the wholesale price of electricity; therefore, the under-predicted consumption factor is expected to increase the LMP.

\section{Chapter 4: Results}

\subsection{Regression Models}

A total of 24 time-series regressions were performed to evaluate the impacts of predicted consumption, degree days, and time fixed effects have on locational marginal prices in the six zones of the PJM RTO. LMPs for each zone were regressed under four different models: (1) pre-retirement with over-predicted consumption, (2) post-retirement with over-predicted consumption, (3) pre-retirement with under-predicted consumption, and (4) post-retirement with under-predicted consumption. Tables 6, 7, 8 and 9 present the coefficient and standard error results of all 24 regressions. The results of the four models are described in sections 4.1.1 through 4.1.4. All the regressions, chow tests, and LR-tests were found to be statistically significant according to the F-test.

\subsubsection{Pre-Retirement with Over-Predicted Consumption}

Table 6 shows the coefficients from the pre-retirement with over-predicted consumption model for the six zones. The variables with statistically significant coefficients at least at the $10 \%$ level across a minimum of four of the six zones are $\mathrm{Z}_{\mathrm{AEP}}, \mathrm{X}_{\mathrm{APS}}, \mathrm{X}_{\mathrm{COMED}}, \mathrm{Z}_{\mathrm{COMED}}, \mathrm{CDD}$, $\mathrm{HDD}^{2}, \mathrm{CDD}^{2}$, and intercept term. The dummy variables that experienced, on a consistent basis, statistically significance coefficients across the six zones are: hours 7 through 23, days Saturday and Sunday, and months October through March. 
The results show that coefficients for $\mathrm{Z}_{\mathrm{AEP}}, \mathrm{X}_{\mathrm{APS}}$, and $\mathrm{ZCOMED}$ are statistically significant and negative. These independent variables significantly lower the dependent variable LMP being regressed. Of the over and underprediction variables, only $\mathrm{X}_{\mathrm{COMED}}$ has consistently positive and statistically significant coefficient estimates over the six zones. Only four of the twelve possible over-prediction and under-prediction variables are consistently significant across the regressions. The results are not substantial enough to derive any formal conclusions about the overall effects of over-predicted and under-predicted consumption variables on LMP. The coefficients for HDD and CDD both show non-linear impacts on LMP from throughout the six zones. The intercept term for every zone except COMED is between 22 and 28. For the COMED zone, it is much lower at 15.07 so that all other variables being equal, this zone had the lowest LMP.

Table 10 and 11 display the cross-correlation data for over-predicted and under-predicted consumption during the pre-retirement time period. When over-predicted consumption occurs, the AEP zone has the highest correlation average with the five other zones at 0.419. COMED has the lowest correlation with other zones at 0.262 . When under-predicted consumption occurs, the ATSI zone has the highest correlation average with the five other zones at 0.501. COMED again has the lowest correlation with other zones at 0.380 . This correlation data displays how the six zones interact with each other, and how likely a zone is to have a similar forecast error as the five other PJM zones being measured. The AEP and ATSI are highly correlated with every zone measured. The COMED does not have much predicted consumption correlation with the other zones being measured.

\subsubsection{Post-Retirement with Over-Predicted Consumption}

Table 7 shows the coefficients from the post-retirement with over-predicted consumption model for the six zones. The variables with statistically significant coefficients of at least $10 \%$ 
across a minimum of four of the six zones are $\mathrm{X}_{\mathrm{APS}}, \mathrm{Z}_{\mathrm{APS}}, \mathrm{X}_{\mathrm{ATSI}}, \mathrm{Z}_{\mathrm{ATSI}}, \mathrm{X}_{\mathrm{COMED}}, \mathrm{Z}_{\mathrm{COMED}}, \mathrm{CDD}$ and $\mathrm{CDD}^{2}$, and the intercept term. The dummy variables that experienced, on a consistent basis, statistically significance coefficients across the six zones are: hours 4 and 7 through 23 , days Thursday through Sunday, and months September through February along with April plus May.

The results of $\mathrm{X}_{\mathrm{APS}}, \mathrm{Z}_{\mathrm{APS}}, \mathrm{X}_{\mathrm{ATSI}}, \mathrm{Z}_{\mathrm{ATSI}}$, and $\mathrm{Z}_{\mathrm{COMED}}$ show negative, statistically significant coefficient estimates. These independent variables significantly lower the dependent variable LMP being regressed. The coefficient estimates for $\mathrm{X}_{\mathrm{COMED}}$ are positive. Six of the twelve possible over-predicted and under-predicted consumption errors have significant effects on LMP. Five of the six consumption errors decrease the LMP. These results show a trend of consumption error in zones outside the dependent variable zone leading to decreases in LMP of the dependent variable zone. For these models, only $\mathrm{CDD}$ has a statistically significant non-linear impact on LMP. Degree days do not have a very influential effect on LMP in these regressions. The intercept estimates range between 17 and 20, slightly lower than pre-retirement coefficients.

Tables 12 and 13 displays the cross-correlation data for over-predicted and underpredicted consumption during the post-retirement time period. When over-predicted consumption occurs, the DAY zone has the highest correlation average with the five other zones at 0.394. COMED has the lowest correlation with other zones at 0.235 . When under-predicted consumption occurs, the DAY zone has the highest correlation average with the five other zones at 0.360 . ATSI has the lowest correlation with other zones at 0.202 . These correlation data display how the six zones interact with each other, and how likely a zone is to have a similar forecast error as the five other PJM zones being measured. DUQ is highly correlated with every zone measured. COMED and ATSI do not have much predicted consumption correlation with the other zones being measured. The tables show that predicted consumption correlation 
averages drop from pre-retirement time period to the post-retirement time period. The zones are less interconnected when measuring their over-predicted and under-predicted consumption variables.

\subsubsection{Pre-Retirement with Under-Predicted Consumption}

Table 8 shows the coefficients from the pre-retirement with under-predicted consumption regression models for each of the six zones being evaluated. The variables with statistically significant coefficients of at least $10 \%$ across a minimum of four of the six zones are $\mathrm{Z}_{\mathrm{AEP}}, \mathrm{X}_{\mathrm{APS}}$, $\mathrm{Z}_{\mathrm{APS}}, \mathrm{CDD}, \mathrm{CDD}^{2}$, and intercept term. The dummy variables that experienced, on a consistent basis, statistically significance coefficients across the six zones are: hours 7 through 22, days Thursday and Sunday, and months October, January and February.

The results of $\mathrm{Z}_{\mathrm{AEP}}$ and $\mathrm{X}_{\mathrm{APS}}$ show negative, statistically significant coefficient estimates. These independent variables significantly lower the dependent variable LMP across most of the six zones. No over-predicted or under-predicted consumption variables consistently showed a positive coefficient across the six zones, although the variable $\mathrm{Z}_{\mathrm{APS}}$ has a mixed positive and negative statistically significant coefficient estimates. Only three over-predicted and underpredicted consumption error variables significantly affect the LMPs in these regressions. For these models, like those reported in Table 7, only CDD has a statistically significant non-linear impact on LMP. The intercept estimates vary between 20 and 30, like Table 6 estimates.

\subsubsection{Post-Retirement with Under-Predicted Consumption}

Table 9 shows the coefficients from the post-retirement with under-predicted consumption regression models for the six zones. The variables with statistically significant coefficients of at least $10 \%$ across a minimum of four of the six zones are $\mathrm{X}_{\mathrm{APS}}, \mathrm{Z}_{\mathrm{ATSI}}, \mathrm{Z}_{\mathrm{DAY}}$, and 
intercept term. The dummy variables that experienced, on a consistent basis, statistically significance coefficients across the six zones are: hours 7 through 22, days Friday through Sunday, and only the month of March.

The results of $\mathrm{X}_{\mathrm{APS}}, \mathrm{Z}_{\mathrm{ATSI}}$, and $\mathrm{Z}_{\mathrm{DAY}}$ variables show negative, statistically significant coefficient estimates. These independent variables significantly lower the dependent variable LMP being regressed. There were no independent over-predicted or under-predicted consumption variables with significantly consistent positive coefficients. Only three of the twelve possible over-predicted and under-predicted consumption variables had a significant effect on the LMP in these regressions. Neither HDD or CDD has a consistent, statistically significant linear or non-linear effects across zones. The intercept estimates vary between 15 and 22, like the estimates in Table 7.

\subsubsection{Comparison of Models}

The four models represented in Tables 6, 7, 8 and 9 differ based on time-period and predicted consumption. One of the main differences found between the pre-retirement and postretirement models is in the intercept values. Pre-retirement models have much higher intercepts than the post-retirement models. The difference found between the over-predict and underpredicted consumption models is the number of significant independent variables. The overpredicted consumption models have more variables with statistically significant coefficient estimates affecting the LMP of each zone. There is a total of thirteen consistently negative independent over-predicted and underpredicted consumption coefficients decreasing LMP within the four regression models. Only two consistently positive independent over-predicted and under-predicted consumption coefficients increased LMPs within the four regression models. The significant independent variables of predicted consumption from external zones display 
signs of decreasing the LMPs of the zone being regressed. In other words, when outside zones incorrectly predict consumption, the LMP of the zone in question decreases. Fifteen of the total forty-eight independent over-predicted and under-predicted consumption variables are significant, so it is not reasonable to immediately draw conclusions from the regression information given. The dummy variables for all four zones follow similar significance trends. Hours 7-22, the weekend days Saturday and Sunday, and the winter months January and February are the most significant. The significant hours maintain positive values. The days with statistically significant coefficients on the weekend have negative values. The months with significant coefficients had a mixture of positive and negative impacts on LMP.

\subsection{Analyses}

Twenty-four time-series regressions described above to are used to evaluate real-time locational marginal prices within the AEP, APS, COMED, ATSI, DAY, and DUQ zones. Four different scenario analyses are examined: (1) Early Retirement with Over-Predicted Consumption, (2) No Retirement with Over-Predicted Consumption, (3) Early Retirement with Under-Predicted Consumption, and (4) No Retirement with Under-Predicted Consumption. The Diff results are presented in Tables 20, 21, 22 and 23 (\$/MWH) and Tables 24, 25, 26 and 27 (\% change). A positive Diff value is defined by the observed LMP being larger than the counterfactual LMP. A negative Diff value is defined by the observed LMP being smaller than the counterfactual LMP. Positive Diff values mean that lower projected LMP represents a more cost-efficient generation of electricity than the observed LMP. Negative Diff values are defined as projected LMP being larger than compared to observed LMP within the PJM RTO so that these projections represent less cost-efficient generation than the observed LMP. The results of the four analyses are described below. 


\subsubsection{Early Retirement with Over-Predicted Consumption}

The average difference in LMP results exhibits positive Diff values from an early retirement with over-predicted consumption analysis (Tables 20 and 24). Given an early retirement scenario when over-prediction of consumption has occurred, the average counterfactual LMP is below observed LMPs. The top 5\% difference of average LMP exhibit positive Diff values of an even greater magnitude compared to the average LMP for this analysis. The bottom 5\% difference in LMP data experiences a negative Diff value. In these situations, early retirement raises projected LMP relative to the observed LMP values.

Results show the average price difference of all LMPs, the price difference of the top 5\% of LMP observations, and the price differences of the bottom 5\% of LMP observations for each of the six zones under early retirement with over-predicted consumption conditions (Tables 20 and 24). The average price differences of this simulated early retirement show real-time LMP prices are, on average over the 12 -month period, $\$ 5.33$ to $\$ 8.35$ (16.9\% to $23.7 \%$ ) per $\mathrm{MWH}$ lower than observed prices depending on the zone. The price decrease is amplified when considering the top 5\% of LMPs. The average price decrease in the top 5\% on observations are between $\$ 54.43$ and $\$ 79.49$ (62.5\% to 69.5\%) per MWH. The average and top 5\% difference of LMP show lower prices would have existed during periods of over-prediction of consumption if the coal-fired capacity was retired a year earlier than its official closing date.

Conversely, the bottom 5\% difference in LMP observations showed projected higher prices with retirement. The average price increase for the bottom $5 \%$ in all six zones ranged from $\$ 12.56$ to $\$ 20.48$ (between $106.2 \%$ and $20,060.8 \%$ ) per MWH. The COMED zone had a massive percent decrease, but the average observed LMP of the bottom $5 \%$ of observations was a negative value of $-\$ 0.10$. These price increases in the bottom $5 \%$ are likely the result of less 
baseload capacity availability making it difficult for zones to ramp down their generation to meet consumption levels.

The coal-fired capacity retirements measured in this report focus on the AEP zone's loss of 5,408 MW of capacity. Compared to the surrounding zones, the AEP zone came in $5^{\text {th }}$ for average LMP decrease $\left(4^{\text {th }}\right.$ for $\left.\%\right), 5^{\text {th }}$ for top $5 \%$ of LMP decrease $\left(5^{\text {th }}\right.$ for $\left.\%\right)$, and $6^{\text {th }}$ for bottom $5 \%$ of LMP increase $\left(6^{\text {th }}\right.$ for $\%$ ) out of the six zones evaluated. The analysis shows the AEP would have experienced decreased LMPs from the retirements occurring earlier during overprediction conditions, but zones around the AEP receive a larger magnitude of decreased LMPs from retirement. The AEP was the best performer in reducing LMP increases during the bottom $5 \%$ of observations.

\subsubsection{No Retirement with Over-Predicted Consumption}

The average difference in LMP results exhibits negative Diff values under a noretirement with over-predicted consumption analysis (Tables 21 and 25). The bottom 5\% difference in LMP observations exhibit even more negative Diff values and the average. These results show that when the retirement of coal-fired plants does not occur, the counterfactual LMP are higher than observed prices. The top 5\% of LMP observations experience a positive Diff value. Both early retirement and no retirement over-predicted consumption scenarios experience positive Diff values for the top 5\%. The magnitude of Diff for the top 5\% was much larger in the early retirement analysis than the no retirement analysis.

Tables 21 and 25 shows each zone's average LMP observations, top 5\% of observations, and bottom $5 \%$ of observations under no retirement with over-predicted consumption conditions. The results show that average projected LMPs for the counterfactual were larger compared to the actual observed prices with retirement, between $-\$ 3.97$ and $-\$ 7.15(-15.0 \%--26.9 \%)$ per MWH. 
The bottom 5\% experienced between price increases of $\$ 22.66$ and $-\$ 37.09$ (130.2\% to 208.6\%) per MWH if there was no retirement of coal-fired capacity on June 1st, 2015. For every zone, the average and bottom 5\% showed an average LMP increase under the conditions of overpredicting electricity consumption. Based on this scenario's results, keeping the coal-fired generation capacity in the PJM would drive average LMP up. The baseload coal-fired generation is not helping the bottom 5\% of LMP as expected either. The rise in price is arguably the result of electricity generation capacity that was not retired being inefficient and increasing the LMP.

The top 5\% did not show an LMP increase under the counterfactual, like the average and bottom 5\% of observations. It had an LMP decrease of between $\$ 31.25$ and $\$ 35.03$ (40.6\% to $45.3 \%$ ) per MWH. The top 5\% of observed prices were lower than projected LMP under a no retirement scenario.

The AEP zone came in $4^{\text {th }}$ for average LMP increase $\left(4^{\text {th }}\right.$ for $\left.\%\right), 6^{\text {th }}$ for top $5 \%$ of LMP decrease (Tied $4^{\text {th }}$ for $\left.\%\right)$, and $5^{\text {th }}$ for bottom $5 \%$ of LMP increase $\left(5^{\text {th }}\right.$ for $\left.\%\right)$ out of the six zones evaluated. The consequences of not retiring the coal capacity under over-prediction conditions would lead to the AEP's average LMP increasing more than some zones but less than others.

Based upon the results of Tables 20 and 24, an argument can be made that retiring the coal-fired generation capacity early results in a more stable market with over-predicted consumption. Higher Diff values in the early retirement analysis of Table 20 means that early retirement has led to larger decreases in LMPs than the no retirement analysis. Generation in the early retirement scenario can meet consumption needs at a more effective rate and keep LMPs low compared to the no retirement analysis. The magnitude of positive Diff values for the top $5 \%$ of LMPs is also larger in early retirement compared to no retirement. The early retirement analysis mitigates price spikes more effectively than the no retirement analysis. Larger positive 
Diff values for the average and top 5\% of LMP in early retirement suggests the PJM has become more stable from the early retirement analysis compared to the no retirement analysis when overpredicted consumption occurs.

\subsubsection{Early Retirement with Under-Predicted Consumption}

The average and top 5\% difference in LMP results exhibit positive Diff values from an early retirement with under-predicted consumption analysis, while the bottom $5 \%$ difference in LMP exhibit negative Diff values (Tables 22 and 26). Early retirement with under-prediction of consumption results in much lower projected LMP under the counterfactual than observed LMP during the average and top 5\% of observations. All six zones experience decreased projected LMPs. The top 5\% has positive Diff values that are much larger in magnitude than the early retirement with over-predicted consumption analysis. The bottom 5\% experienced Diff values about the same magnitude than the early retirement with over-predicted consumption analysis.

Tables 22 and 26 results show that early retirement with the under-predicted consumption analysis consistently lowers LMP in all analyses across all six zones. The average LMP decrease with early retirement over all observations ranges from $\$ 5.41$ to $\$ 12.99$ (16.6\% to $29.2 \%$ ) per MWH. The top 5\% of prices showed substantial reductions with early retirement of $\$ 60.54$ to $\$ 126.31$ (65.3\% to $76.1 \%)$ per MWH, while the bottom 5\% of prices are between $-\$ 11.90$ to $\$ 22.78(-71.1 \%$ to $-3817.5 \%)$ per MWH lower for the observed than the counterfactual. The large percent change in COMED is the result of the average observed bottom $5 \%$ of observations being $\$ 0.46$. While the DUQ zone has a large negative value for the bottom $5 \%$, this Diff value is not statistically significant from zero. The reason will be explained further in the t-test section of the results chapter. 
The AEP zone came in $2^{\text {nd }}$ for average LMP decrease $\left(2^{\text {nd }}\right.$ for $\left.\%\right), 2^{\text {nd }}$ for top $5 \%$ of LMP decrease ( $1^{\text {st }}$ for $\%$ ), and $4^{\text {th }}$ for bottom $5 \%$ of LMP decrease ( $3^{\text {rd }}$ for $\%$ ) out of the six zones evaluated. The results from this analysis are very favorable for the AEP zone. Its LMP decrease outperformed most of the surrounding zones. The LMP increase in the bottom 5\% of observations also outperformed most of the surrounding zones.

\subsubsection{No Retirement with Under-Predicted Consumption}

The average difference in LMP results exhibits negative Diff values from a no retirement with under-predicted consumption analysis (Tables 23 and 27). No retirement with underprediction of consumption results in projected LMP under the counterfactual being higher, on average, than the observed LMP. The bottom 5\% of LMP data also experienced substantial negative Diff values. The counterfactual with no retirement of inefficient coal-fired capacity combined with under-predicted consumption leads to increased LMP for the average and bottom $5 \%$ categories. The top 5\% of differences in LMP reveal positive Diff values. All four analyses have positive Diff values for the top 5\% of LMP. The magnitude of positive Diff values for the top $5 \%$ is much larger in the early retirement analyses than the no retirement analyses.

The results of the no retirement analysis with under-predicted consumption are very similar to the over-predicted consumption case. They showed the counterfactual average LMPs are higher over all six zones compared to the observed LMP averages (Table 23 and 27). The average LMP increase in this analysis is between $-\$ 5.16$ and $-\$ 6.56(-17.0 \%$ to $-21.6 \%)$ per MWH. The bottom 5\% of observations had six zones with $-\$ 28.51$ to $-\$ 37.12$ ( $-223.2 \%$ to $1639.6 \%$ ) per MWH increases in LMP attributed to retirement. Each zone's result for the bottom $5 \%$ experiences large percent changes due to their low average observed LMP values. 
The top 5\% of LMP price observations in this analysis continue to show that observed prices are greater than counterfactual LMP prices along with the other three analyses. The top $5 \%$ of LMP show a $\$ 30.09$ to $\$ 59.30$ (35.7\% to 54.9\%) per MWH lower LMP projected to have occurred with no retirement. Even though the no retirement and under-prediction of consumption scenarios are expected to cause the projected LMP under the counterfactual to be higher than the observed LMP, the top 5\% of LMP observations consistently showed the opposite result.

The AEP zone came in $6^{\text {th }}$ for average LMP increase $\left(6^{\text {th }}\right.$ for $\left.\%\right), 3^{\text {rd }}$ for top $5 \%$ of LMP decrease $\left(2^{\text {nd }}\right.$ for $\left.\%\right)$, and $3^{\text {rd }}$ for bottom $5 \%$ of LMP increase $\left(3^{\text {rd }}\right.$ for $\left.\%\right)$ out of the six zones evaluated. The results are scattered within the AEP compared to its neighboring zones. Under this analysis of no retirement and under-predicted consumption, the AEP's LMP change does not stand out in comparison to the surrounding zones.

\section{3 t-Test Results}

Multiple t-tests are performed to compare the statistical significance of different datasets for price, over-predicted consumption, and under-predicted consumption. The initial set of t-tests were performed to compare the Diff values against the zero for each of the four analyses. If the results of the t-test are not significantly different from zero, the Diff values are not experiencing a measurable change in LMPs from the pre-retirement period to the post-retirement period. If the results are significant, the pre-retirement LMPs are measurably different than the post-retirement counterfactual LMPs. (Table 17) The results show that for each zone's average, top 5\%, and bottom 5\%. Diff values are statistically different from zero. The results of this t-test verify that the projected LMPs from the counterfactuals are different than the observed LMPs.

Another t-test was performed to determine how each zone's observed price behaves compared to other U.S. electricity market wholesale prices. The six zones daily price averages 
were compared to the daily price average of following markets: ICE, ERCOT, INDIANA, MID_COLUMBIA, NEPOOL, NP 15, PALO VERDE, PJM and SP 15 (Table 18). The results of the t-test offer further insight into the behavior of these zones in their pre-retirement and postretirement periods. When the zones are compared to the ICE, Intercontinental Exchange, the results show that all zones except COMED had significantly different averages than ICE in the pre-retirement period. The post-retirement period did not have significantly different price averages. After the capacity was retired, the PJM wholesale prices were more resembling of the U.S. averages. A two-year t-test of each zone against the ICE prices displays the wholesale prices of electricity in five zones were significantly different from ICE prices. The PJM portion of Table 18 shows the zones price averages were all significantly different from the PJM price averages in both the pre-retirement and post-retirement periods. The six PJM zones measured are not following the price averages of the RTO they reside in. This observation is likely the result of zones within the eastern portion of the PJM having higher demand and LMPs than the western portion of the PJM.

The final t-test was performed to determine if consumption of electricity was statistically different in between the pre-retirement time period and the post-retirement time period. Table 19 shows the two time periods experience significantly different amounts of electricity consumption. The pre-retirement time period has a larger average consumption of electricity than the post-retirement time period in every zone (Tables 4 and 5). This consumption difference is likely the result of the pre-retirement time period having less favorable weather conditions than the post-retirement time period. 


\section{Chapter 5: Conclusions}

The PJM Interconnect is a regional transmission organization (RTO) which manages and transmits electricity across 13 states within the mid-Atlantic, Midwest, and Northeast regions of the U.S. On June 1, 2015, 5,408 MW of coal-fired electrical generation capacity was retired within the AEP zone of this RTO (Figure 9). The objective of this research was to analyze impacts on wholesale electricity prices based on locational marginal price (LMP) from this retirement using demand-side analyses within the AEP and five surrounding zones within the PJM.

Regression models were utilized to evaluate the effects of over-predicted and underpredicted consumption on observed LMP within six zones over two-time periods. Four models were examined: (1) pre-retirement with over-predicted consumption (Table 6), (2) postretirement with over-predicted consumption (Table 7), (3) pre-retirement with under-predicted consumption (Table 8), and (4) post-retirement with under-predicted consumption (Table 9). The results of these regression analyses show the pre-retirement LMPs are higher than the postretirement LMPs. The models display signs of downward trending LMPs within the six zones. Both pre-retirement models' intercept values are smaller than the post-retirement models' intercept values. This discovery coincides with the downward national trend of the U.S. wholesale electricity market. The results also exhibit more significant independent variables affecting LMP in the over-predicted consumption analyses compared to the under-predicted consumption analyses.

Research results illustrate the effects of coal-fired capacity retirement and predicted consumption error on LMP. Four analyses were created to examine differences between observed LMP versus a counterfactual LMP based upon either early retirement of coal-fired 
electrical generation capacity or no retirement of this capacity. The analyses results were: (a) early retirement with over-predicted consumption (Tables 20 and 24), (b) no retirement with over-predicted consumption (Tables 21 and 25), (c) early retirement with under-predicted consumption (Tables 22 and 26), and (d) no retirement with under-predicted consumption (Tables 23 and 27). In the early retirement analyses, the counterfactual LMP was lower than observed LMP over all six zones for both under-predicted and over-predicted consumption. For the no retirement analyses, average LMP from the counterfactual was higher than observed LMP in each of the six zones for both under-predicted and over-predicted consumption conditions. When differences were computed for the top 5\% and bottom 5\% of observed LMP, the results did not behave in the same manner as the average LMP. The top 5\% difference of LMP showed lower counterfactual prices compared to observed prices under all four analyses. The bottom 5\% difference of LMP showed higher counterfactual prices compared to observed prices in every analysis.

Both the early retirement and no retirement scenarios procured favorable results compared to the observed retirement in 2015 when examining the top 5\% results. When compared, the LMP decreases in the early retirement analyses was greater in magnitude than the decreases for the no retirement analyses. Thus, retiring the coal-fired capacity early leads to more stable LMPs within the PJM. Explanation of these results is likely the product of the entire U.S. electricity industry experiencing decreasing wholesale prices from 2014 to 2016 . The independent variables affect the top $5 \%$ of observations results but are not influential enough to counteract the downward national price trend.

The bottom 5\% of LMP experience the opposite results of the top 5\%. The no retirement scenario has increased prices for every zone in all four analyses. The analyses with no retirement 
of coal-fired capacity resulted in larger LMP increases than the early retirement analyses. Keeping the inefficient baseload power stations increased LMP for the bottom 5\% of data. While both the early and no retirement scenarios increase the bottom 5\% difference of LMP, the early retirement scenario has LMP increases in lower magnitude and is more stable than the increases occurring in the no retirement scenario.

The results of this thesis differ from similar research described in the literature review. Rahmani et al. (2016) argue the coal retirements would lead to increased LMP and congestion within the PJM. Their findings are based on a forecasting model of the PJM. Woo et al. (2014) describe how baseload nuclear generation retirements would also lead to LMP increases. This capacity generation was retired due to the nuclear plant experiencing wear in its tubing and other safety concerns. The research finding here demonstrate no signs that coal-fired capacity retirement leads to increasing LMPs. The analysis used historical data where coal generation was retired from the PJM for its inability to compete within a competitive market for wholesale electricity. While Rahmani et al. (2016) and Woo et al. (2014) are similar in nature to this research, these research findings show price increases because their analysis or reason for generation retirement differ from this report. In addition to the lack of increasing LMP, the LMP in each of the six zones became more stable after the coal-fired capacity retirement. The coalfired capacity retirement does not change the PJM's downward trending wholesale prices. The RTO maintains a similar downward trend in wholesale price averages as the U.S. wholesale price average from June $1^{\text {st }}, 2014$ through June $1^{\text {st }}, 2016$.

The results of this research demonstrate how the PJM electricity market effectively adapted to planned closures of power stations. Aging and inefficient coal-fired power stations were no longer capable of producing energy at a competitive price within the PJM; therefore, 
they were retired. Upon the retirement of over 5,000 MW of coal-fired capacity, the PJM system demonstrated enough electricity generation from other energy producers to continue meeting the consumption of its electricity consumers. There is no evidence of wholesale electricity price increases as a result of retiring the coal-fired capacity for the average LMP or top 5\% of observations within the six zones measured. Since the national price of electricity was trending downward during this period, it cannot be stated that the coal-fired capacity retirements have caused a significant decrease in LMP either. There has been no measurable shift in wholesale electricity prices from the loss of generation capacity.

The following research is limited in scope. Only two years of hourly data are used to analyze the effects of the coal-fired capacity retirements. Measuring one year before and one year after the retirement does not consider all possible weather and demand scenarios within the electricity industry that should be accounted for. If the time period analyzed was increased, there may be different long-term effects. This research also fails to include all zones within the PJM. The PJM does not offer hourly LMP data to the public for every zone, therefore only six zones were included within this report.

Future research on this topic to better understand the effects of capacity retirement in regulated markets should continue. Predictive models such as Vector Autoregressive (VAR) and Spatial Vector Autoregressive (SpVAR) are possible approaches we can use to gain a better understanding as to why some zones LMPs decrease more than others from the coal retirement. Other independent variables such as hourly congestion and marginal loss data can also be added to the current research to improve the research quality.

\subsection{Policy Implications}

These research findings imply that retiring older and inefficient coal power stations results in lower locational marginal prices within the PJM RTO. While the results do not clearly 
show that the analyzed zones were better off in comparison to the national average, the zones did not experience any observed adverse effects on LMP when the coal-fired capacity was retired. The results also displayed more favorable results for the top 5\% of LMP observations when the capacity was retired. The six zones' wholesale prices were more stable as a result of the capacity retirement.

The PJM should continue evolving as an RTO by retiring cost inefficient power stations to make room in the market for newer more efficient electricity generators. State and Federal environmental policies as well as state-run regulated monopolies can be utilized to accelerate or slow down the PJM's transition from aging power stations to newer more efficient forms of electricity generation. The Department of Energy's argument for subsidies on resilient forms of electricity generation is not substantiated by the findings of this thesis. Retaining coal-fired capacity was not stabilizing LMP prices within the PJM. The only advantage of keeping noneconomically efficient resilient forms of energy in the RTO is in case of national emergencies. These research findings validate the Federal Energy Regulatory Commission's stance that grid resiliency was not threatened by the retirement of 5,408 $\mathrm{MW}$ of coal-fired electricity generation capacity in the AEP zone of the PJM region. 


\section{Figures}

\section{Table 2.6 Electric Power Sector Energy Consumption}

Trillion Btu

30,000

20,000

10,000

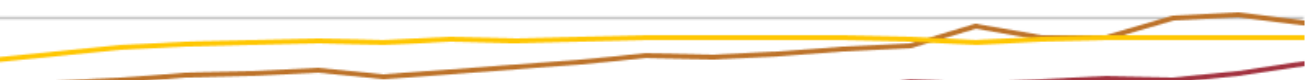

0

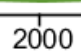

2005

2010

2015

- Coal Consumed by the Electric Power Sector

- Natural Gas Consumed by the Electric Power Sector (Excluding Supplemental Gaseous Fuels)

- Petroleum Consumed by the Electric Power Sector

- Nuclear Electric Power Consumed by the Electric Power Sector

- Total Renewable Energy Consumed by the Electric Power Sector

eia Source: U.S. Energy Information Administration

Figure 1: United States Electric Power Energy Consumption (U.S. Energy Information Administration, 2018) 
U.S. electricity generation by fuel, all sectors million megawatthours per day
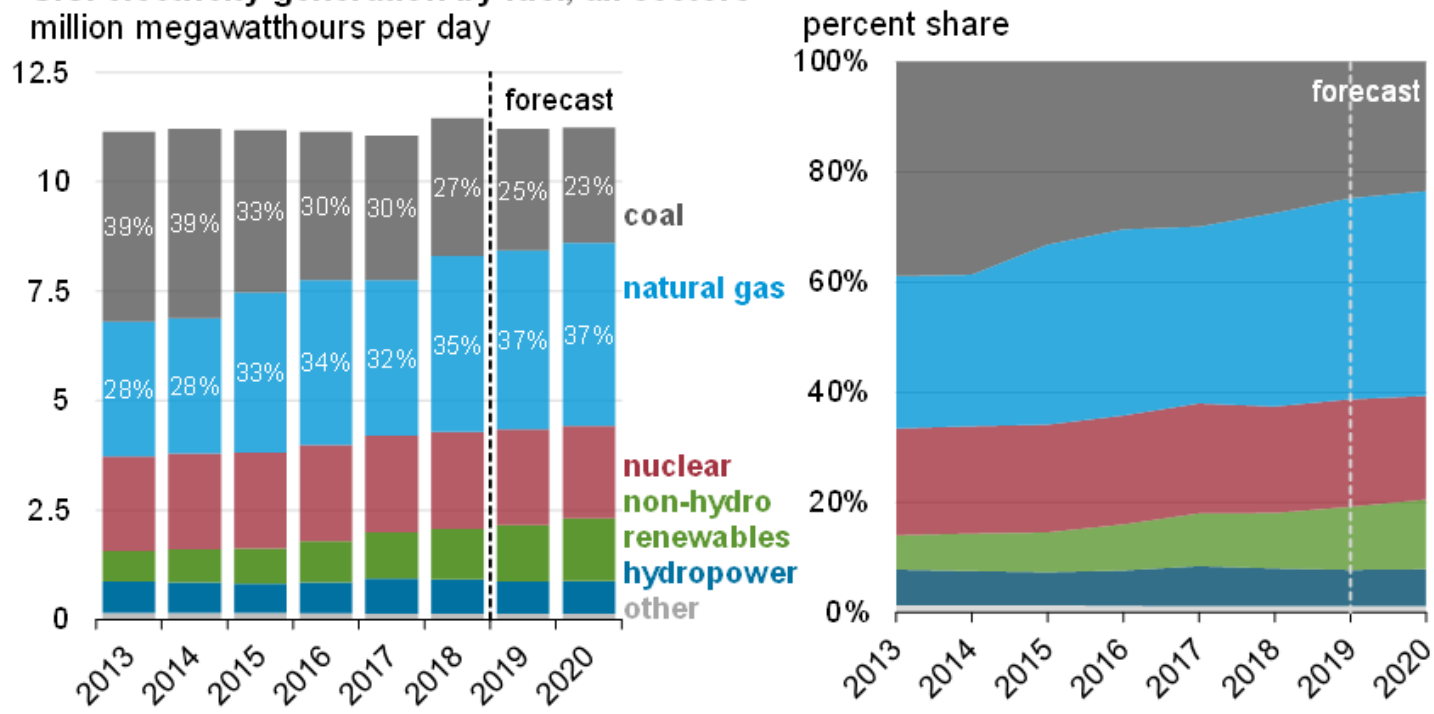

Note: Labels show percentage share of total generation provided by coal and natural gas.

Source: Short-Term Energy Outlook, March 2019

Figure 2: U.S. Electricity Generation by Fuel, All Sectors (U.S. Energy Information Administration, 2019) 
Michael O'Conor

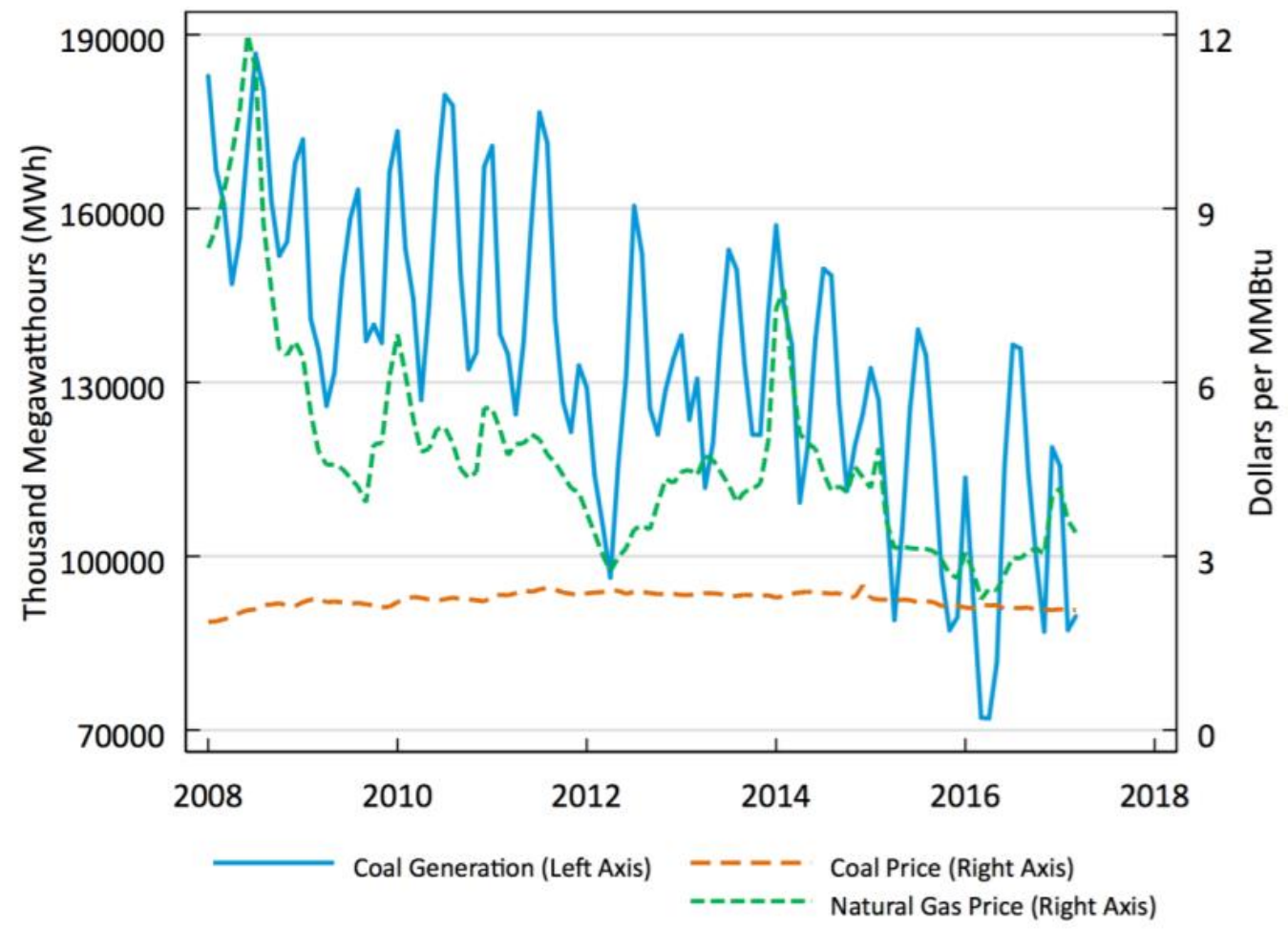

Source: EIA

Figure 3: Electricity Generation from Coal and the Delivered Prices of Coal and Natural Gas (monthly for the United States) (Alexopoulos, 2017) 
U.S. utility-scale electric generating capacity by initial operating year (as of Dec 2016) gigawatts

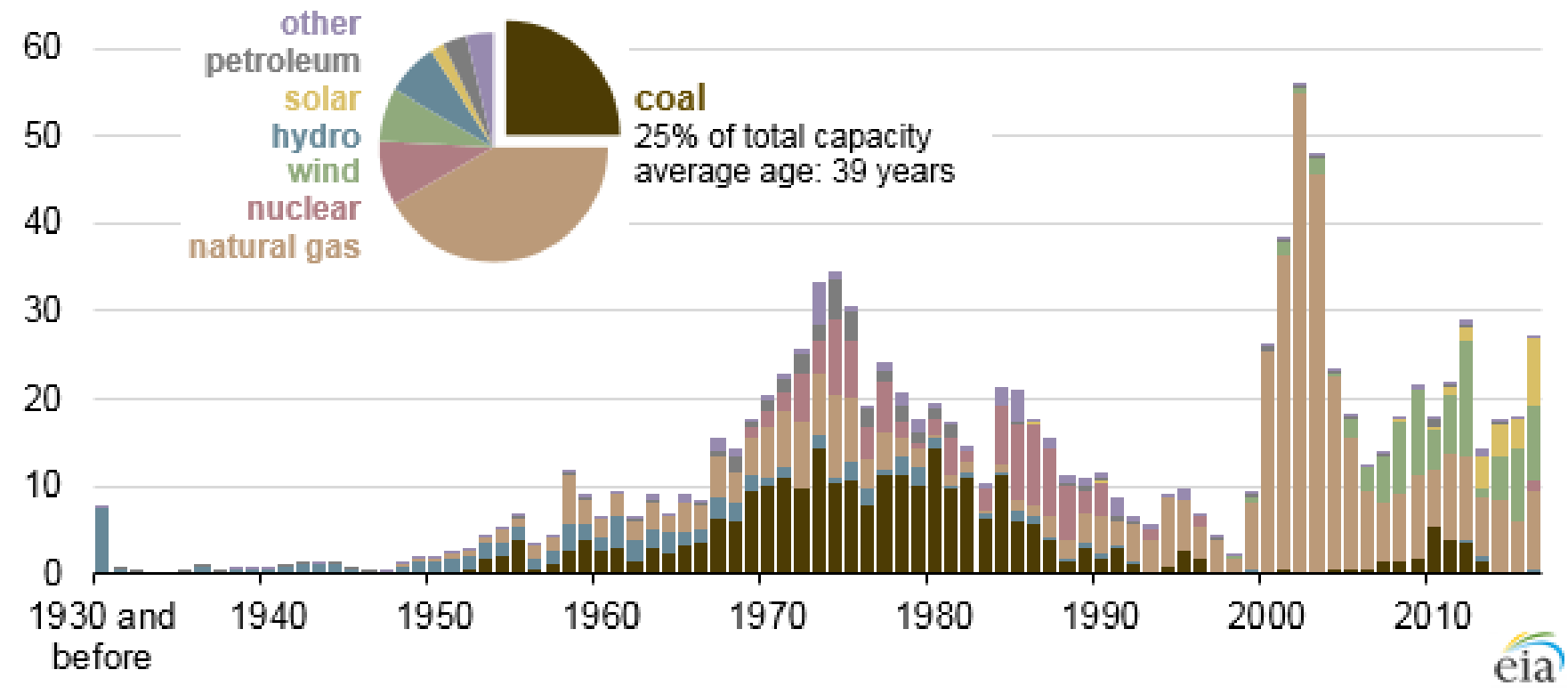

Figure 4: U.S. Utility-Scale Generating Capacity by Initial Opening Year (as of Dec 2016) (Jell, 2017) 


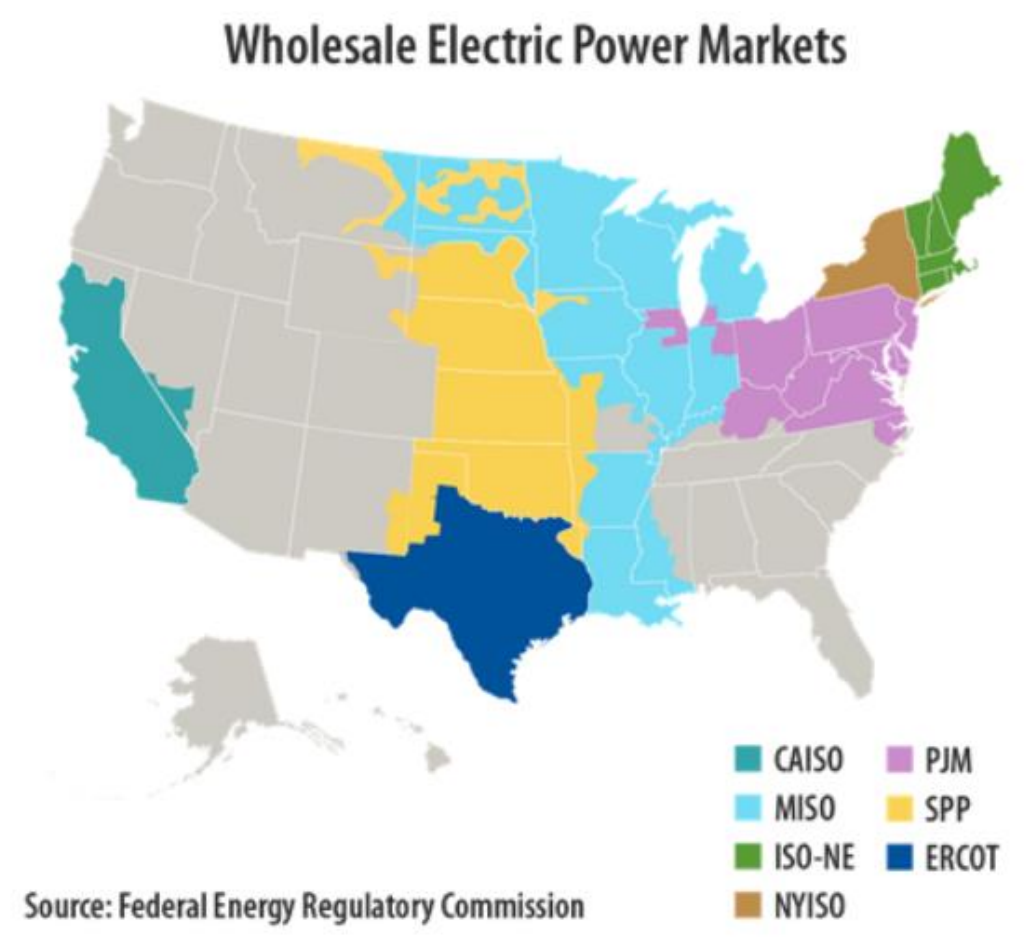

Figure 5: United States

Figure 5. Wholesale Electric Power Markets Map (United States Environmental Protection Agency, 2018) 


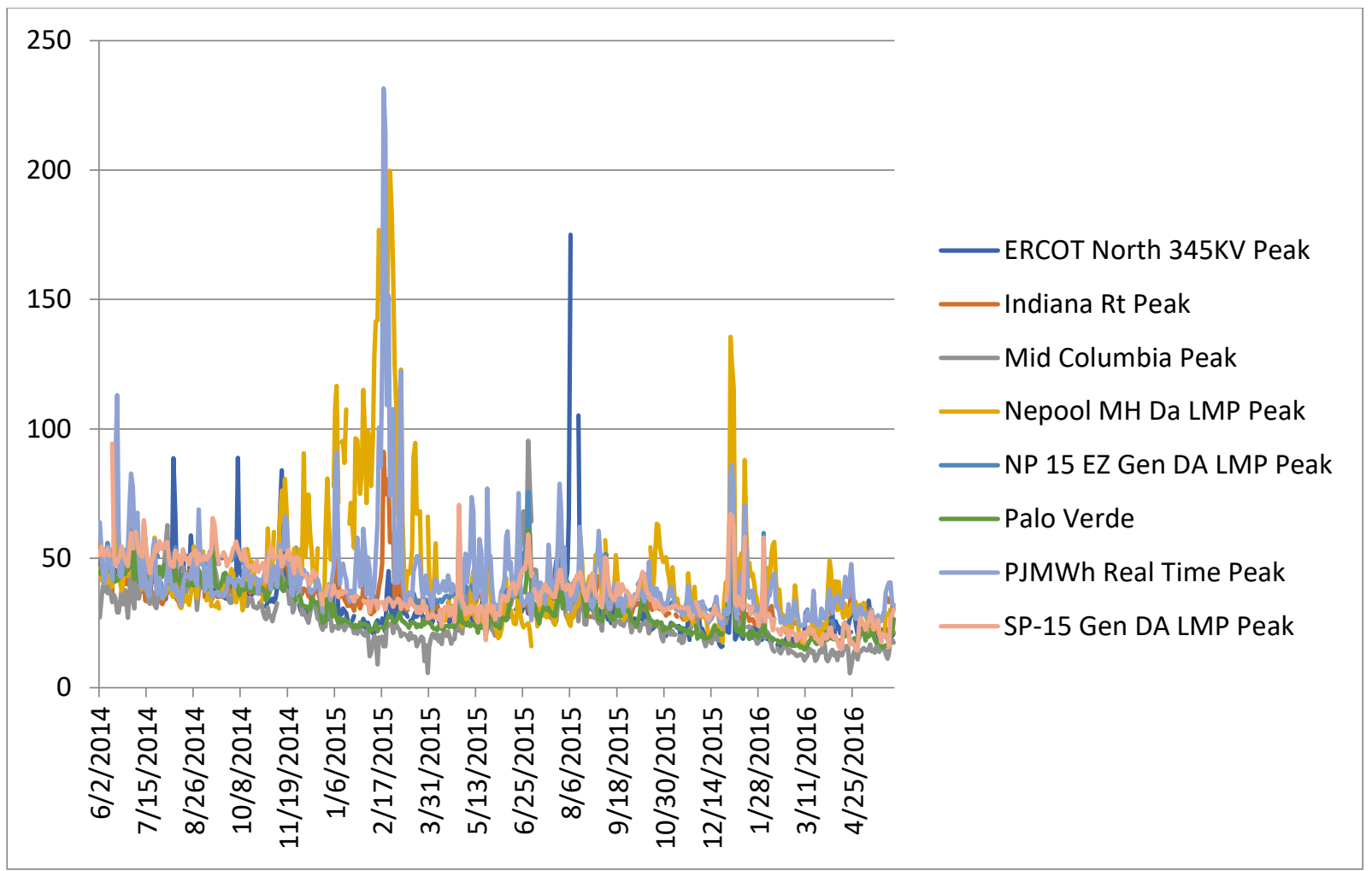

Figure 6: Competitive Market Daily Wholesale Electricity Price (Per MW) (U.S. Energy Information Administration, 2018) 


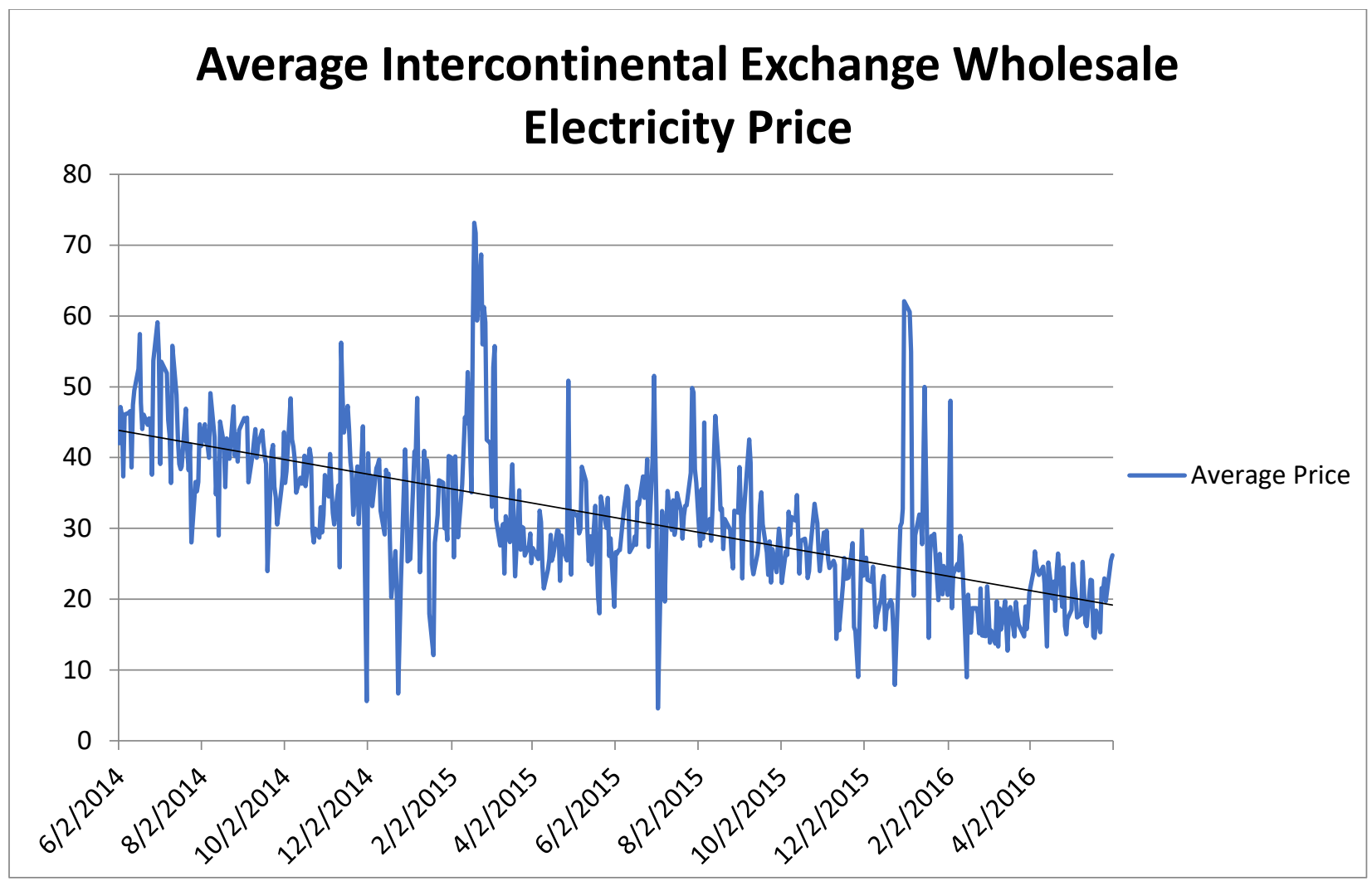

Figure 7: 10-Year United States Competitive Market Average Electricity Price (Per MW) (U.S. Energy Information Administration, 2018) 


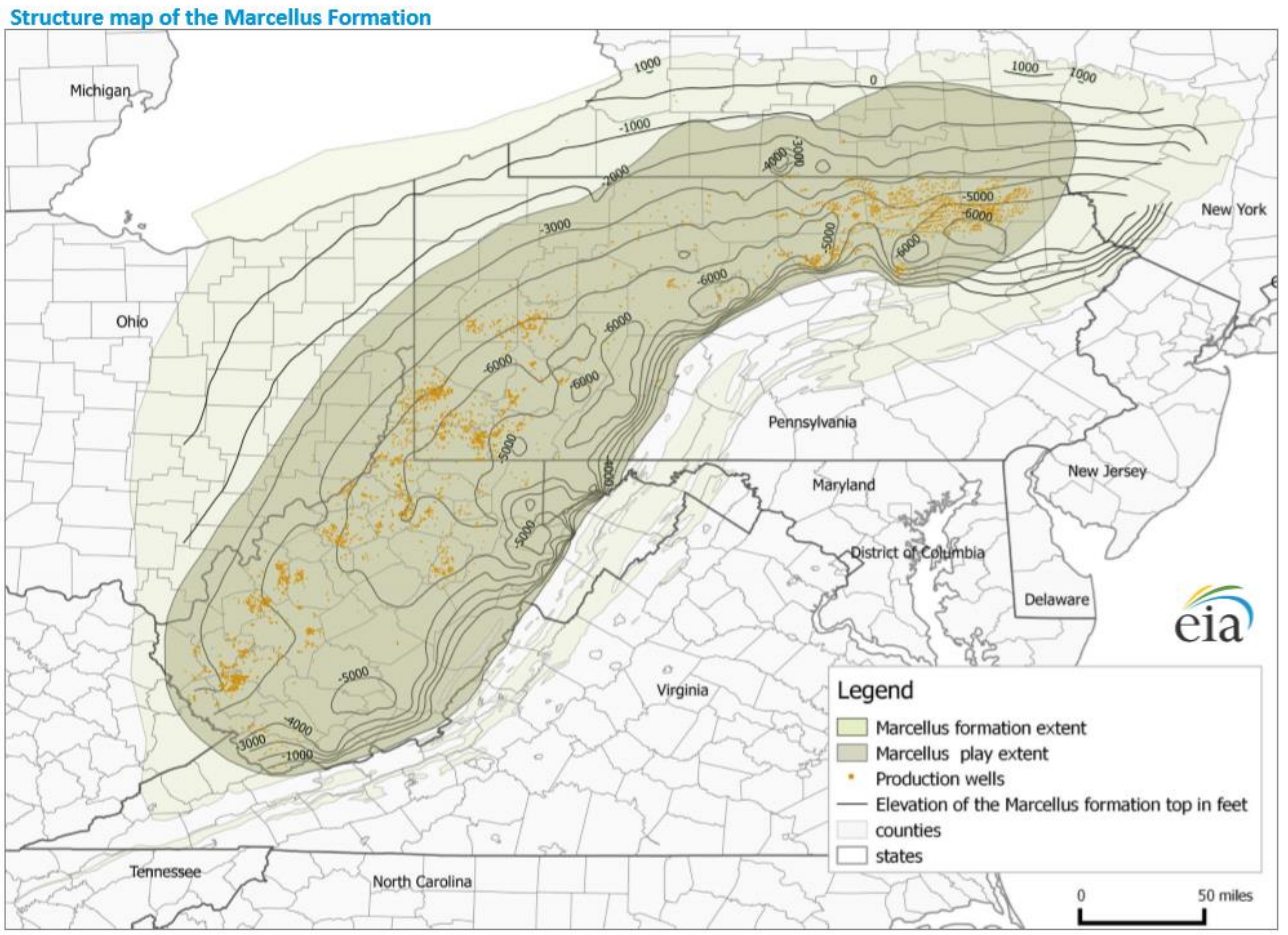

Source: U.S. Energy Information Administration, based on DrillingInfo Inc., New York State Geological Survey, Ohio State Geological Survey, Pennsylvania Bureau of Topographic \& Geologic Survey, West Virginia Geological \& Economic Survey, and U.S. Geological Survey. Note: Mab includes production wells from Januarv 2003 throuah December 2014

Figure 8: Marcellus Shale Formation (U.S. Energy Information Administration, 2018) 


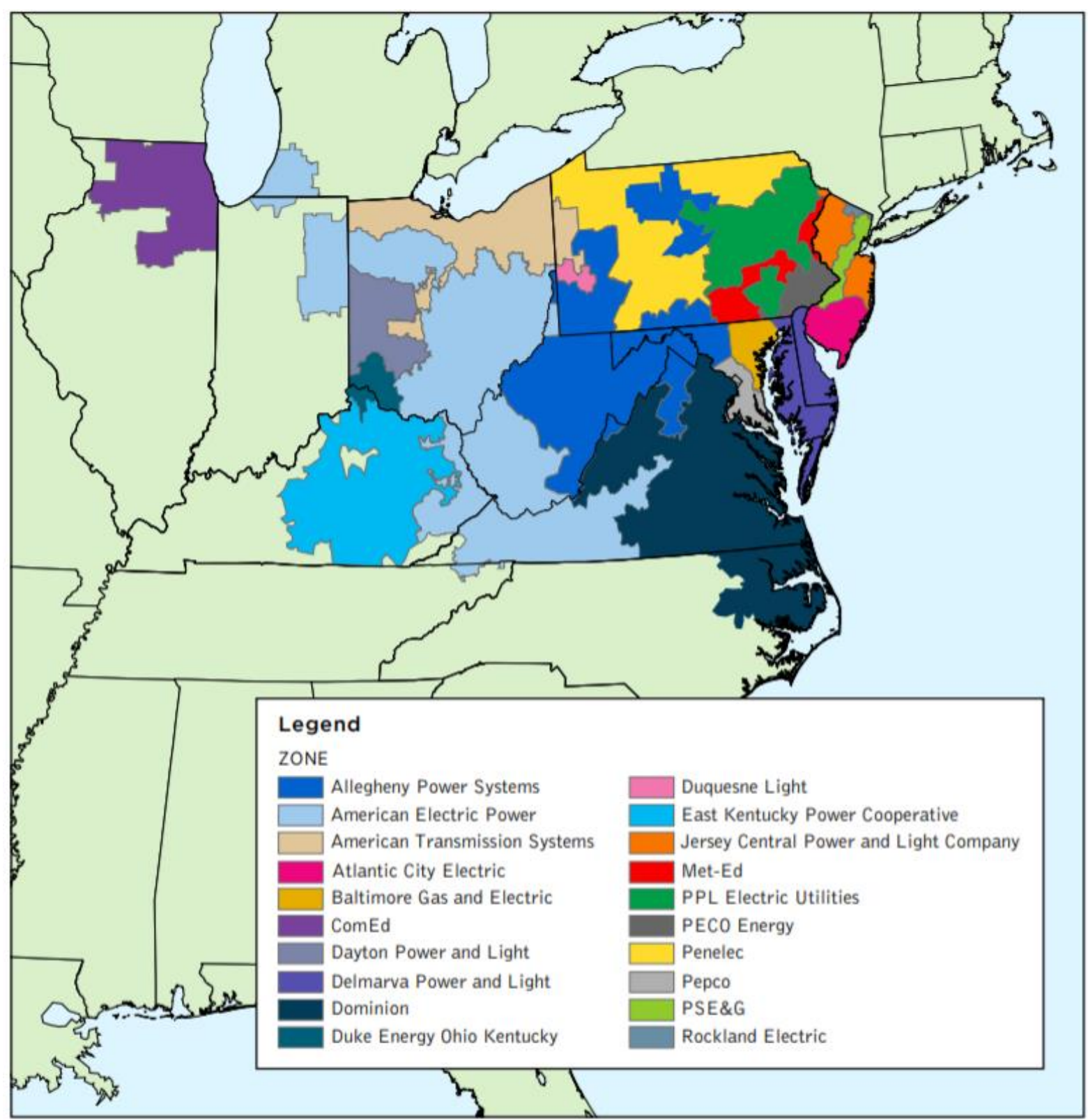

Figure 9: PJM Zones (Current, 2018) 
Michael O’Conor

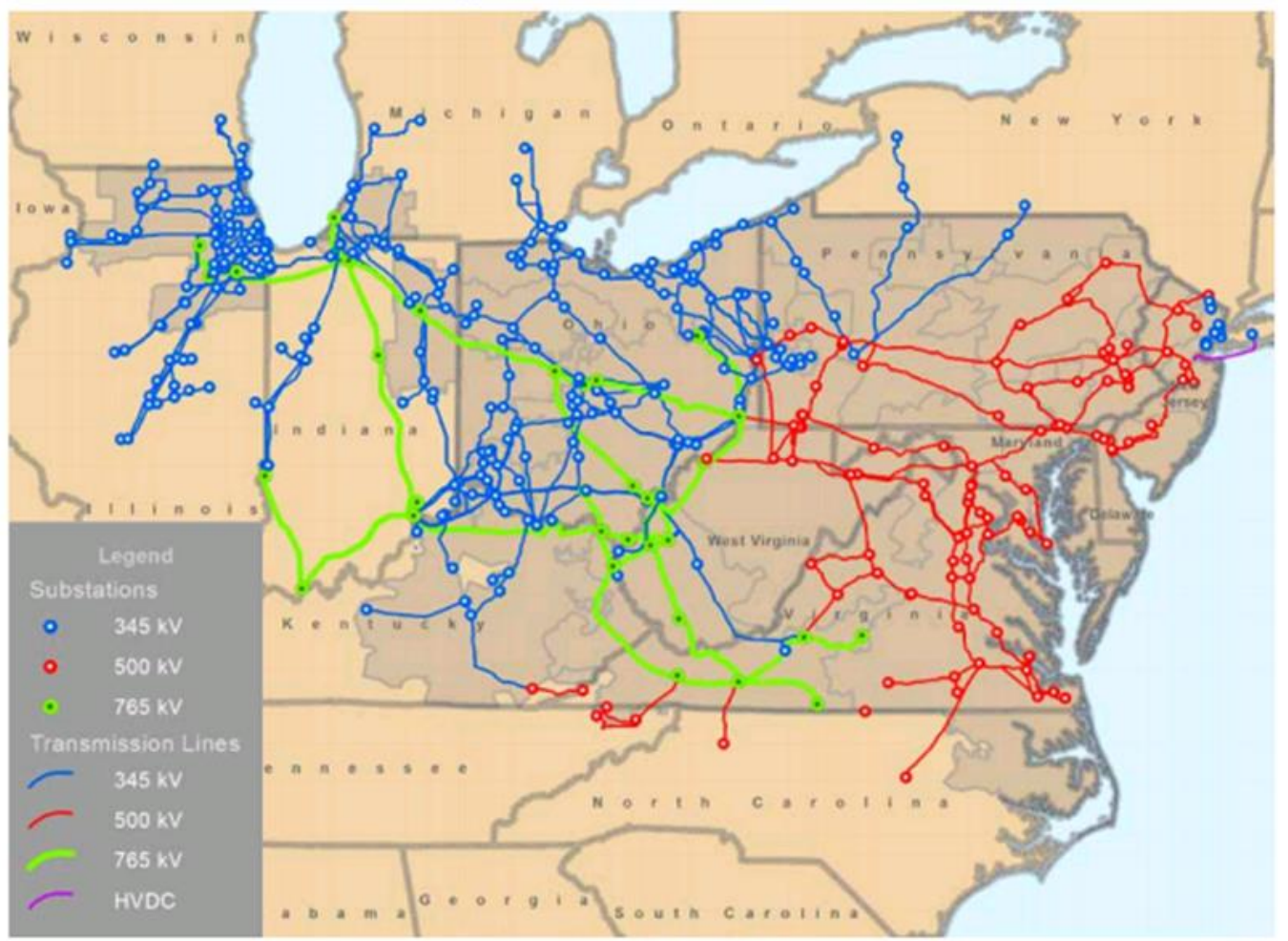

Figure 10: PJM Backbone Transmission System (TEAC, 2018) 


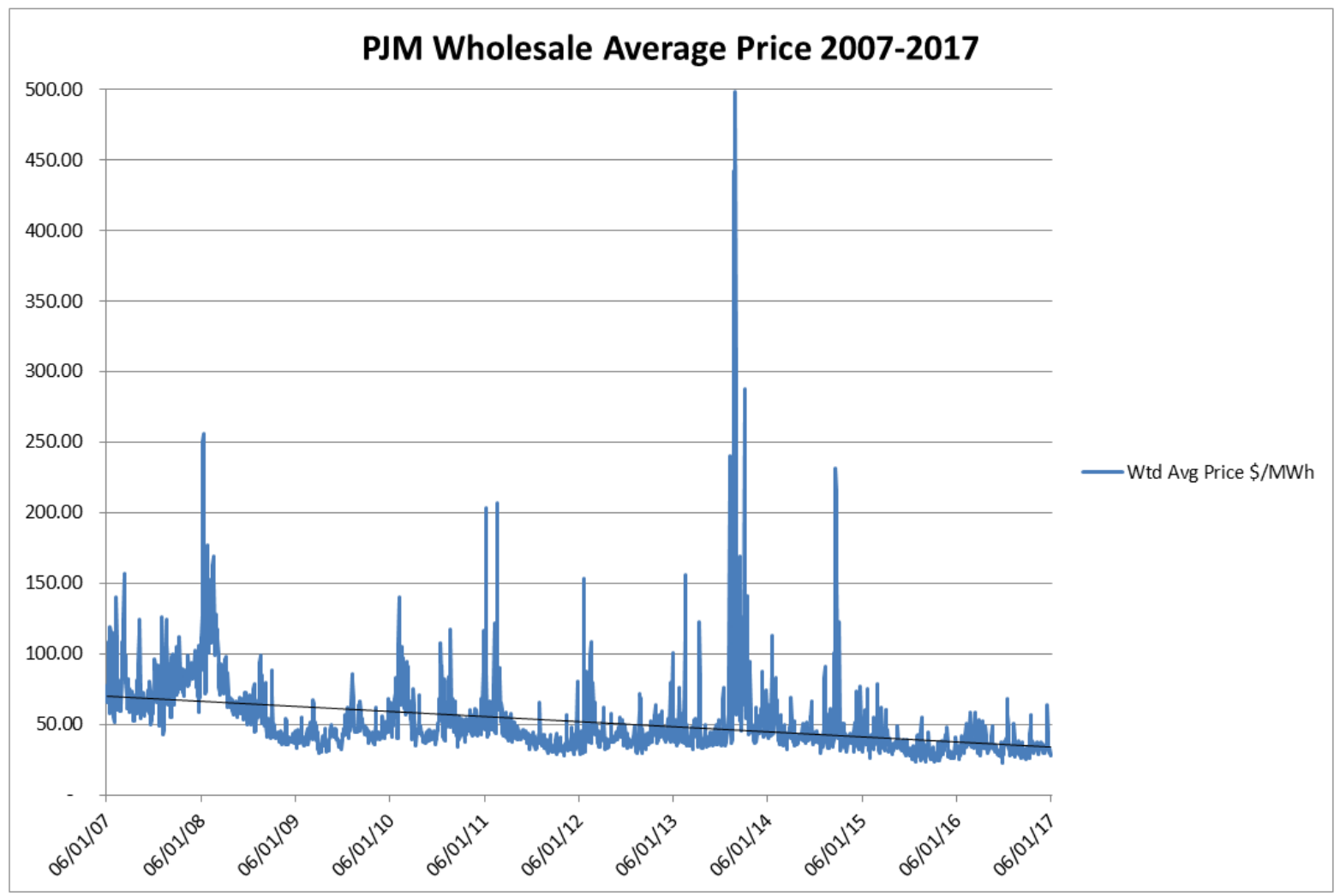

Figure 11: PJM Wholesale Average Daily Price 2007-2017 (PJM, 2018) 


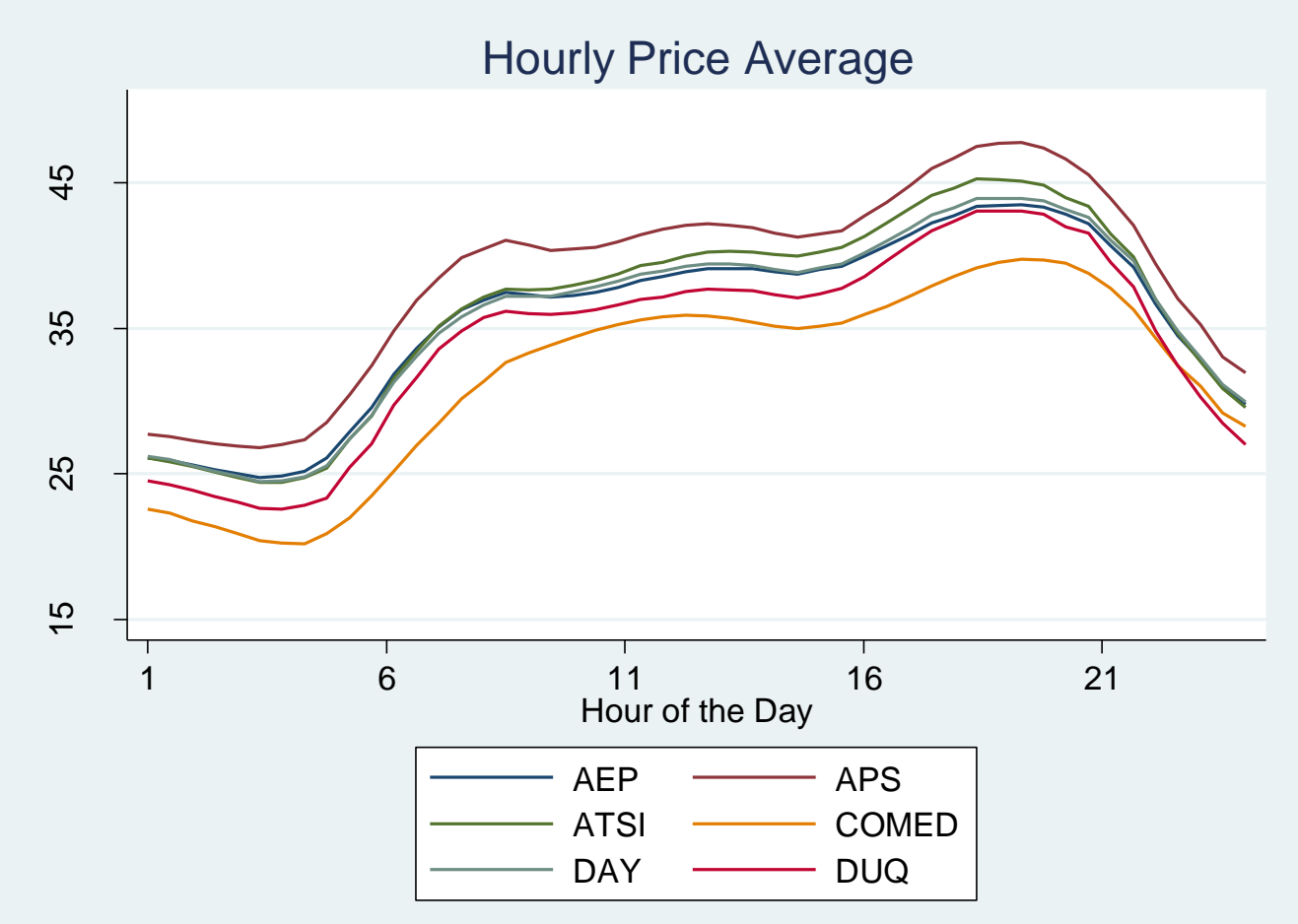

Figure 12: Hourly Price Average Pre-Retirement (PJM, 2018) 


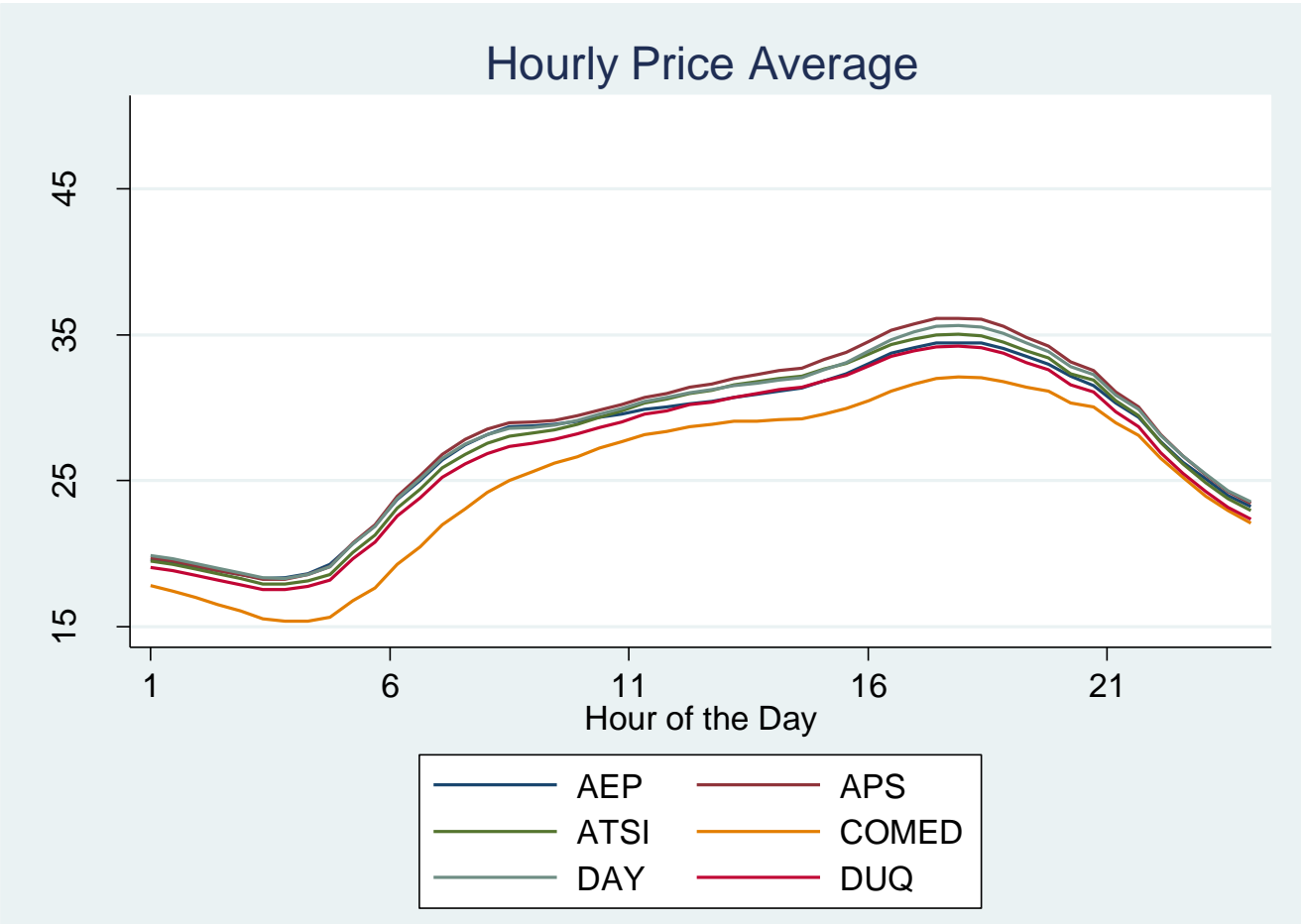

Figure 13: Hourly Price Average Post- Retirement (PJM, 2018) 


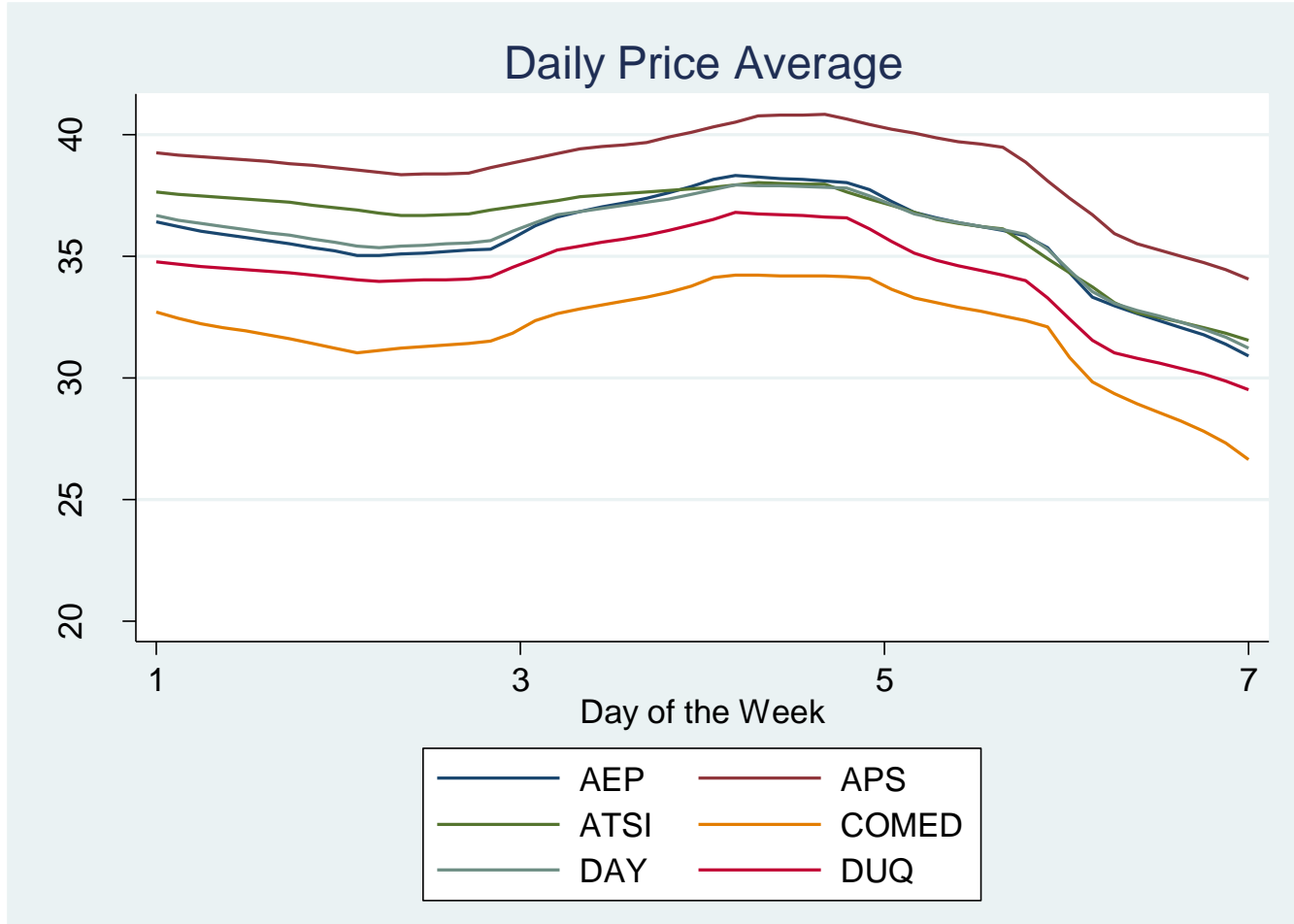

Figure 14: Daily Price Average Pre-Retirement (PJM, 2018) 


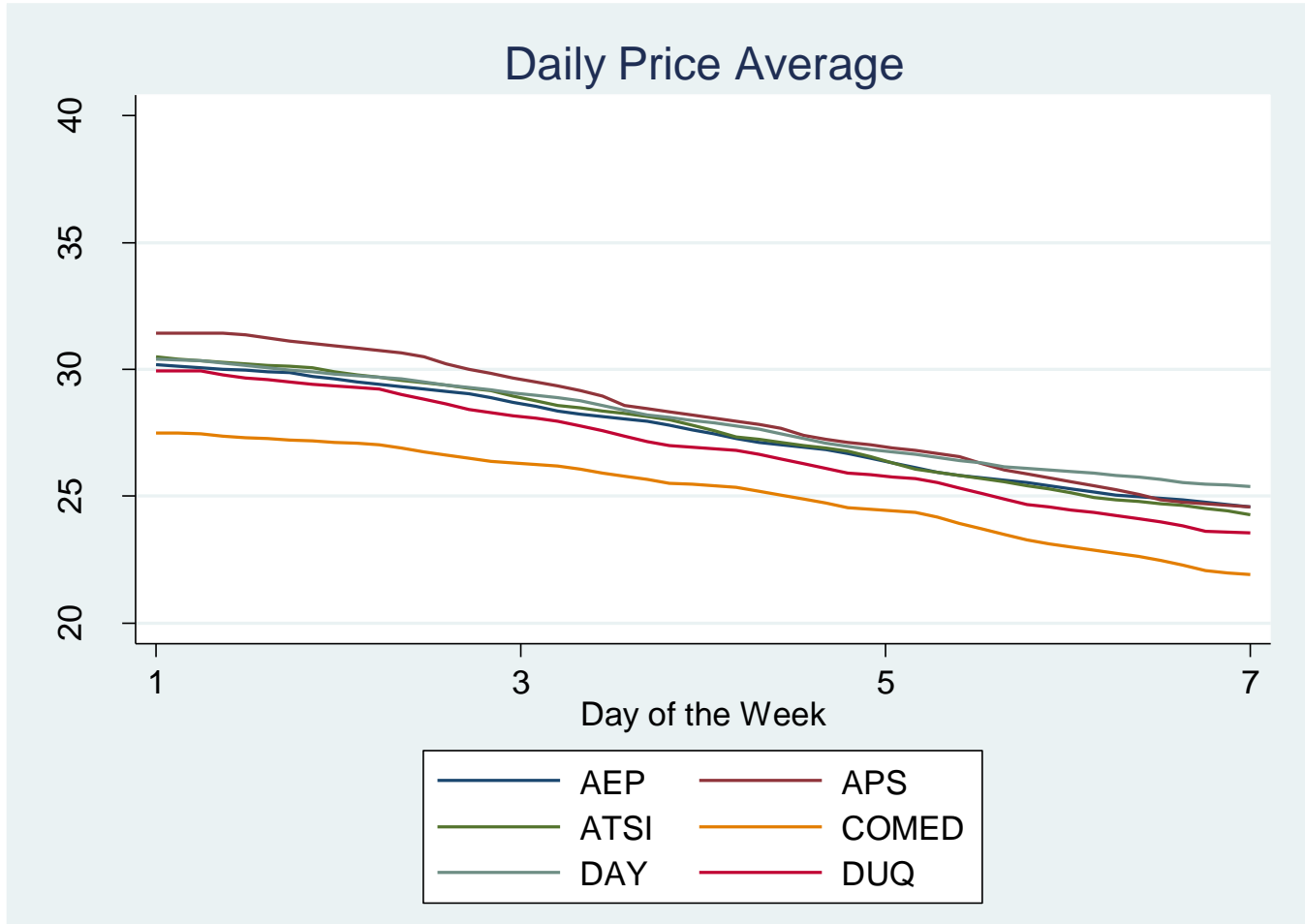

Figure 15: Daily Price Average Post-Retirement (PJM, 2018) 


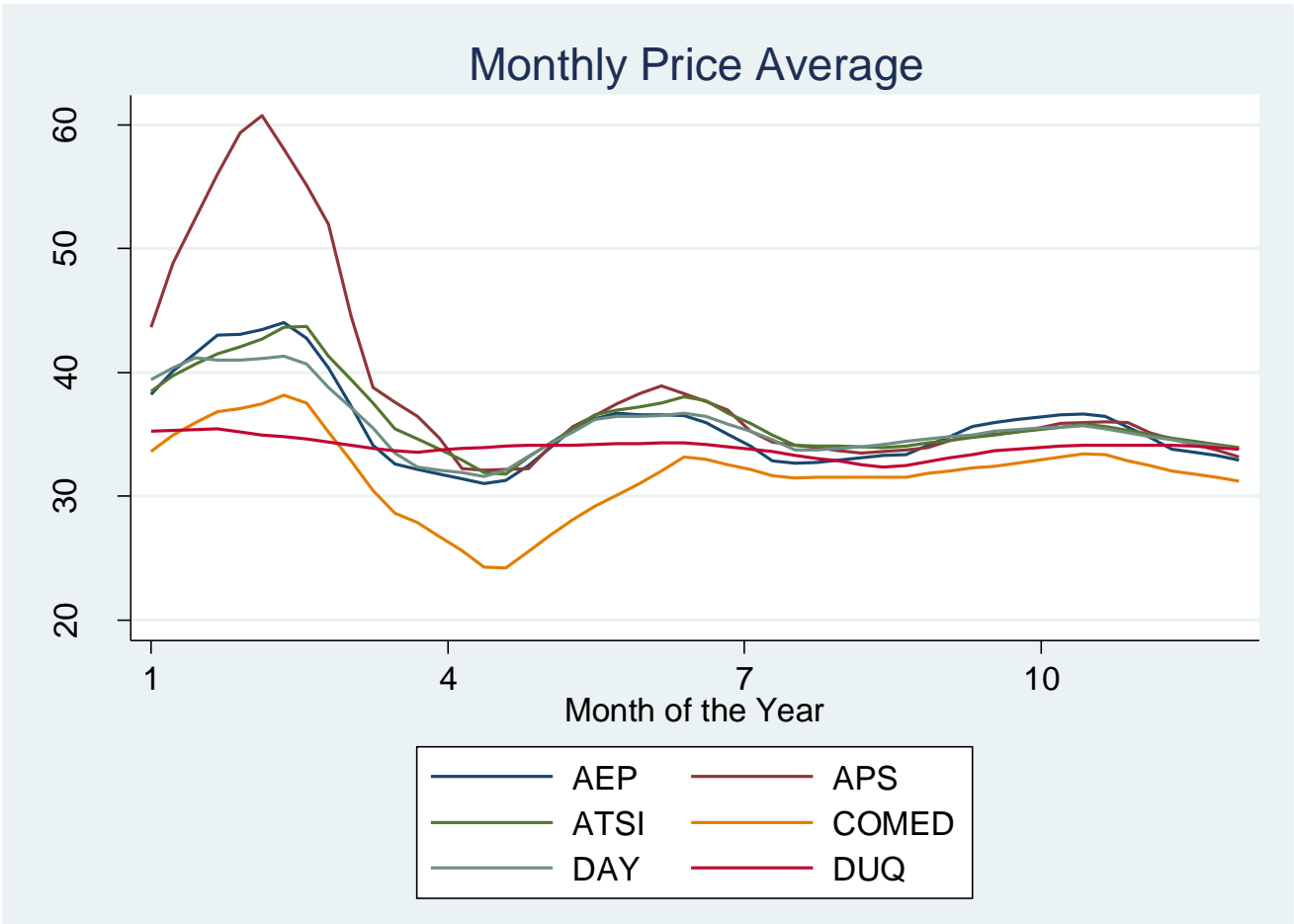

Figure 16: Monthly Price Average Pre-Retirement (PJM, 2018) 


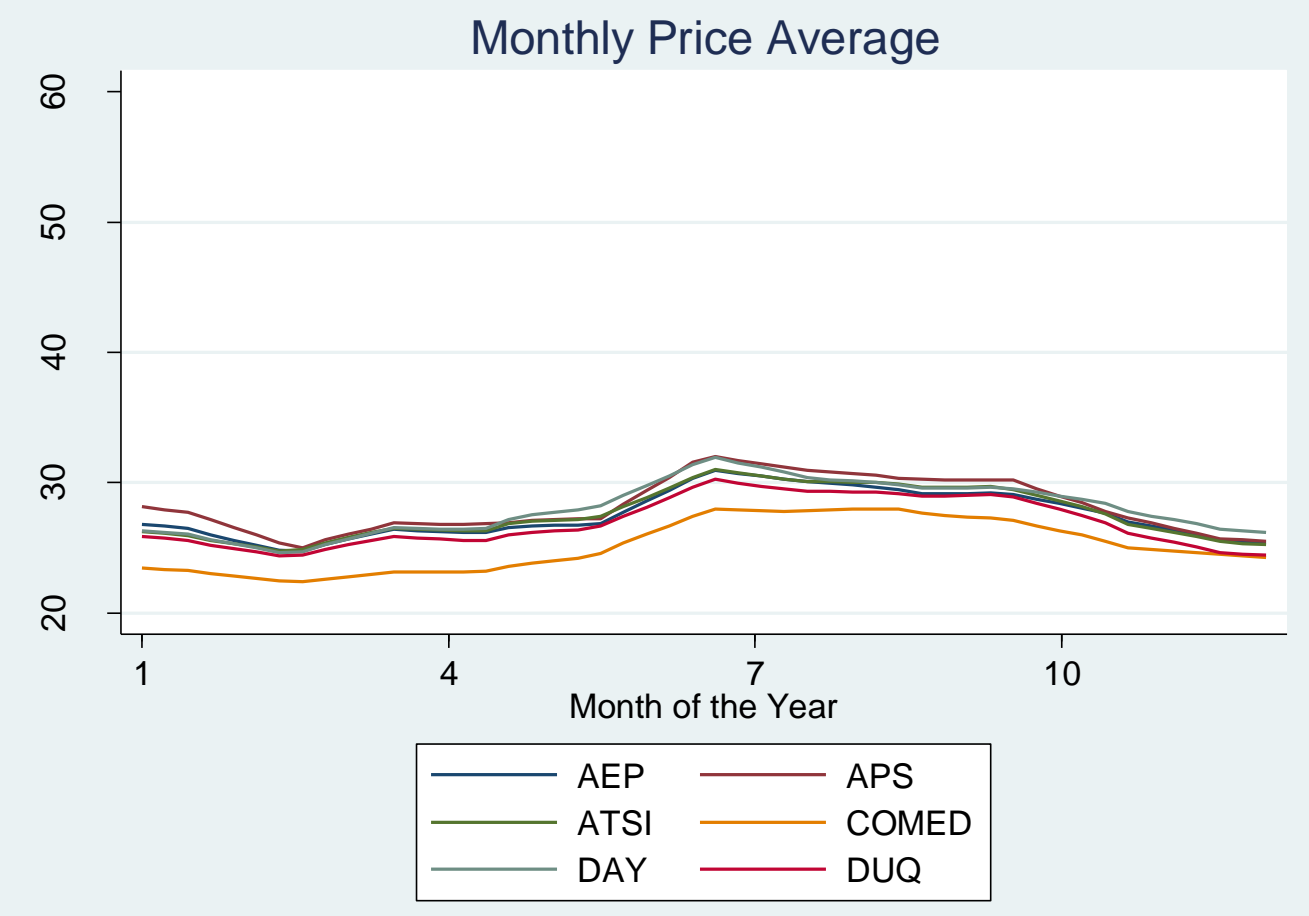

Figure 17: Monthly Price Average Post-Retirement (PJM, 2018) 
Michael O'Conor 
Tables

Table 1: Fuel Mix over the Entire PJM Region (Capacity, 2017)

\begin{tabular}{|c|c|c|c|c|c|c|c|c|c|c|c|c|}
\hline & \multicolumn{2}{|c|}{ January $1^{\text {st }}, 2014$} & \multicolumn{2}{|c|}{ June $1^{\text {st }}, 2014$} & \multicolumn{2}{|c|}{ January $1^{\text {st }}, 2015$} & \multicolumn{2}{|c|}{ June $1^{\text {st }}, 2015$} & \multicolumn{2}{|c|}{ January $1^{\text {st }}, 2016$} & \multicolumn{2}{|c|}{ June $1^{\text {st }}, 2016$} \\
\hline & MW & Percent & MW & Percent & MW & Percent & MW & Percent & MW & Percent & MW & Percent \\
\hline Coal & $75,544.6$ & $41.3 \%$ & $74,785.5$ & $40.6 \%$ & $72,741.3$ & $39.6 \%$ & $66,878.1$ & $37.8 \%$ & $66,674.8$ & $37.5 \%$ & $66,619.9$ & $36.6 \%$ \\
\hline Gas & $53,395.0$ & $29.2 \%$ & $55,041.7$ & $29.9 \%$ & $59,662.6$ & $32.5 \%$ & $59,460.1$ & $33.6 \%$ & $60,487.4$ & $34.0 \%$ & $64,721.7$ & $35.5 \%$ \\
\hline Nuclear & $33,076.7$ & $18.1 \%$ & $32,891.0$ & $17.9 \%$ & $32,947.1$ & $17.9 \%$ & $33,071.5$ & $18.7 \%$ & $33,071.5$ & $18.6 \%$ & $33,050.6$ & $18.2 \%$ \\
\hline Oil & $11,314.2$ & $6.2 \%$ & $11,155.7$ & $6.1 \%$ & $7,907.6$ & $4.3 \%$ & $6,853.4$ & $3.9 \%$ & $6,851.8$ & $3.9 \%$ & $6,779.8$ & $3.7 \%$ \\
\hline Solar & 84.2 & $0.0 \%$ & 94.7 & $0.1 \%$ & 97.5 & $0.1 \%$ & 128.0 & $0.1 \%$ & 128.0 & $0.1 \%$ & 252.4 & $0.1 \%$ \\
\hline Solid Waste & 701.4 & $0.4 \%$ & 780.0 & $0.4 \%$ & 781.9 & $0.4 \%$ & 771.3 & $0.4 \%$ & 769.4 & $0.4 \%$ & 767.5 & $0.4 \%$ \\
\hline
\end{tabular}


Table 2: Coal Consumption and Capacity Retired 2014-2016 (PJM, 2019)

\begin{tabular}{|l|cccccc|}
\hline & AEP & APS & ATSI & COMED & DAY & DUQ \\
$\begin{array}{l}\text { Average Load Consumed (MWH) June 1 } \\
2014-\text { June } 1^{\text {st }}, 2015\end{array}$ & 15,100 & 5,699 & 7,874 & 11,278 & 2,002 & 1,643 \\
$\begin{array}{l}\text { Average Load Consumed (MWH) June } \\
2^{\text {nd }}, 2015-\text { June } 1^{\text {st }}, 2016\end{array}$ & 14,467 & 5,425 & 7,566 & 11,033 & 1,954 & 1,576 \\
Capacity Retired (MWH) June $1^{\text {st }}, 2015$ & 5,408 & 0 & 986 & 251 & 277 & 125 \\
\hline
\end{tabular}


Table 3: Metropolitan Locations (U.S. Census Bureau, 2017)

\begin{tabular}{|c|c|c|}
\hline METROPOLITAN LOCATION & ZONE & POPULATION \\
\hline CHARLESTON, WEST VIRGINIA & AEP & 227,071 \\
\hline COLUMBUS, OHIO & AEP & $1,907,965$ \\
\hline ROANOKE, VIRGINIA & AEP & 308,665 \\
\hline WHEELING, WEST VIRGINIA & AEP & 147,951 \\
\hline CANTON, OHIO & AEP & 404,428 \\
\hline FORT WAYNE, INDIANA & AEP & 416,254 \\
\hline MORGANTOWN, WEST VIRGINIA & APS & 129,709 \\
\hline BECKLEY, WEST VIRGINIA & APS & 124,913 \\
\hline HAGERSTOWN/MARTINSBURG, MARYLAND & APS & 251,602 \\
\hline TOLEDO, OHIO & ATSI & 610,002 \\
\hline CLEVELAND/ ELYRIA, OHIO & ATSI & $2,077,271$ \\
\hline YOUNGSTOWN/WARREN/BOARDMAN, OHIO & ATSI & 565,799 \\
\hline AKRON, OHIO & ATSI & 703,203 \\
\hline CHICAGO, ILLINOIS & COMED & $9,461,541$ \\
\hline DAYTON/MIAMISBURG, OHIO & DAY & 799,251 \\
\hline PITTSBURGH, PENNSYLVANIA & DUQ & $2,356,291$ \\
\hline
\end{tabular}


Table 4: Pre-Retirement Variables Summary

\begin{tabular}{|c|c|c|c|c|c|}
\hline VARIABLE & OBS & MEAN & STD. DEV. & MIN & MAX \\
\hline $\mathrm{C}_{\mathrm{AEP}}$ & 8784 & 15100.42362 & 2542.417116 & 9661.64 & 24738.7 \\
\hline $\mathbf{C}_{\mathrm{APS}}$ & 8784 & 5699.839747 & 1065.001914 & 3356.56 & 9593.56 \\
\hline $\mathbf{C}_{\text {ATSI }}$ & 8784 & 7874.969657 & 1267.302998 & 4941.59 & 12362.1 \\
\hline С Сомеd & 8784 & 11278.49093 & 2012.842568 & 7431.99 & 19721.2 \\
\hline $\mathrm{C}_{\mathrm{DAY}}$ & 8784 & 2002.800717 & 369.0610391 & 1186 & 3192 \\
\hline $\mathrm{C}_{\text {DUQ }}$ & 8784 & 1643.449064 & 369.0610391 & 1186 & 3192 \\
\hline $\mathbf{P}_{\mathrm{AEP}}$ & 8784 & 35.45769 & 23.26487 & -232.429 & 396.397 \\
\hline $\mathbf{P}_{\text {APS }}$ & 8784 & 38.36392 & 29.20088 & -229.843 & 489.441 \\
\hline $\mathbf{P}_{\text {ATSI }}$ & 8784 & 36.05598 & 23.33224 & -230.566 & 390.484 \\
\hline $\mathbf{P}_{\text {COMEd }}$ & 8784 & 31.60538 & 20.99765 & -227.702 & 362.906 \\
\hline $\mathbf{P}_{\text {DAY }}$ & 8784 & 35.56128 & 22.37035 & -238.794 & 378.299 \\
\hline $\mathbf{P}_{\text {DuQ }}$ & 8784 & 33.95292 & 22.65688 & -227.122 & 377.646 \\
\hline $\mathbf{X}_{\mathrm{AEP}}$ & 8784 & 188.9325 & 298.4434 & 0 & 2924.7 \\
\hline $\mathbf{Z}_{\mathrm{AEP}}$ & 8784 & -150.5075 & 288.4576 & -14111.5 & 0 \\
\hline $\mathbf{X}_{\mathrm{APS}}$ & 8784 & 112.7276 & 140.0121 & 0 & 1021.11 \\
\hline $\mathbf{Z}_{\mathrm{APS}}$ & 8784 & -45.94407 & 112.4718 & -5411.67 & 0 \\
\hline $\mathbf{X}_{\mathrm{ATSI}}$ & 8784 & 121.5986 & 173.6496 & 0 & 1384.53 \\
\hline $\mathbf{Z}_{\text {ATSI }}$ & 8784 & -62.30827 & 144.3686 & -6719.76 & 0 \\
\hline $\mathbf{X}_{\text {COMED }}$ & 8784 & 189.7327 & 348.7463 & 0 & 4706.7 \\
\hline$Z_{\text {COMED }}$ & 8784 & -96.40035 & 223.7273 & -9507.77 & 0 \\
\hline $\mathbf{X}_{\text {DAY }}$ & 8784 & 47.44666 & 61.66826 & 0 & 431 \\
\hline $\mathbf{Z}_{\text {DAY }}$ & 8784 & -16.09312 & 38.97655 & -1689 & 0 \\
\hline $\mathbf{X}_{\text {DUQ }}$ & 8784 & 29.22963 & 41.43178 & 0 & 310.31 \\
\hline$Z_{\text {DUQ }}$ & 8784 & -17.24541 & 34.6383 & -1411.44 & 0 \\
\hline HDD $_{\text {AEP }}$ & 8784 & 2.885982 & 4.594865 & 0 & 16.60336 \\
\hline $\mathrm{CDD}_{\mathrm{AEP}}$ & 8784 & -15.04967 & 16.27964 & -60.73278 & 0 \\
\hline HDD $_{\text {APS }}$ & 8784 & 2.619713 & 4.18181 & 0 & 15.00704 \\
\hline CDD $_{\text {APS }}$ & 8784 & -14.28724 & 15.55181 & -59.00488 & 0 \\
\hline HDD $_{\text {ATSI }}$ & 8784 & 1.965156 & 3.695134 & 0 & 16.24206 \\
\hline CDD $_{\text {ATSI }}$ & 8784 & -17.67304 & 17.75399 & -66.47915 & 0 \\
\hline HDDCOMED & 8784 & 2.161202 & 4.055683 & 0 & 19 \\
\hline CDDCOMED & 8784 & -18.47541 & 18.44764 & -67 & 0 \\
\hline HDD $_{D A Y}$ & 8784 & 2.308743 & 4.005727 & 0 & 14 \\
\hline CDD $_{\text {DAY }}$ & 8784 & -16.42896 & 17.23179 & -63 & 0 \\
\hline HDD $_{\text {DUQ }}$ & 8784 & 2.122951 & 3.742406 & 0 & 16 \\
\hline CDDDUQ & 8784 & -16.44809 & 17.29786 & -65 & 0 \\
\hline HDD $^{2}{ }_{\text {AEP }}$ & 8784 & 29.43927 & 56.48161 & 0 & 275.6715 \\
\hline $\mathrm{HDD}^{2}{ }_{\mathrm{APS}}$ & 8784 & 24.34844 & 48.08024 & 0 & 225.2112 \\
\hline HDD $^{2}$ ATSI & 8784 & 17.5143 & 41.36566 & 0 & 263.8045 \\
\hline HDD $^{2}$ СОMED & 8784 & 21.11749 & 49.51475 & 0 & 361 \\
\hline HDD $^{2}$ DAY & 8784 & 21.37432 & 44.55078 & 0 & 196 \\
\hline HDD $^{2}$ DUQ & 8784 & 18.51093 & 40.375 & 0 & 256 \\
\hline $\mathrm{CDD}^{2}{ }_{\mathrm{AEP}}$ & 8784 & -491.4894 & 742.7098 & -3688.471 & 0 \\
\hline $\mathrm{CDD}^{2}{ }_{\mathrm{APS}}$ & 8784 & -445.9567 & 675.3296 & -3481.576 & 0 \\
\hline CDD $^{2}{ }_{\text {ATSI }}$ & 8784 & -627.5047 & 888.9267 & -4419.477 & 0 \\
\hline CDD $^{2}$ СOMED & 8784 & -681.6175 & 960.5125 & -4489 & 0 \\
\hline $\mathrm{CDD}^{2} \mathrm{DAY}$ & 8784 & -566.8115 & 839.281 & -3969 & 0 \\
\hline $\mathrm{CDD}^{2}{ }^{\mathrm{DUQ}}$ & 8784 & -569.7213 & 839.7445 & -4225 & 0 \\
\hline
\end{tabular}


Table 5: Post-Retirement Variables Summary

\begin{tabular}{|c|c|c|c|c|c|}
\hline VARIABLE & OBS & MEAN & STD. DEV. & MIN & MAX \\
\hline $\mathrm{C}_{\mathrm{AEP}}$ & 8784 & 14465.30442 & 2402.461084 & 9708.29 & 22255.7 \\
\hline $\mathbf{C}_{\text {APS }}$ & 8784 & 5424.88442 & 974.5882237 & 3507.47 & 8665.93 \\
\hline $\mathbf{C}_{\text {ATSI }}$ & 8784 & 7564.53378 & 1239.464005 & 4914.95 & 12356.4 \\
\hline С CоMED & 8784 & 11030.84203 & 2093.808668 & 7289.79 & 20162.3 \\
\hline $\mathrm{C}_{\mathrm{DAY}}$ & 8784 & 1953.939373 & 358.374171 & 1199 & 3269 \\
\hline $\mathrm{C}_{\text {DuQ }}$ & 8784 & 1576.196599 & 308.2982831 & 1027.81 & 2804.02 \\
\hline $\mathbf{P}_{\text {AEP }}$ & 8784 & 27.46282 & 16.53671 & -108.558 & 396.509 \\
\hline $\mathbf{P}_{\text {APS }}$ & 8784 & 28.15862 & 17.88457 & -107.67 & 452.131 \\
\hline $\mathbf{P}_{\text {ATSI }}$ & 8784 & 27.53278 & 16.56675 & -108.849 & 409.527 \\
\hline $\mathbf{P}_{\text {COMEd }}$ & 8784 & 25.09165 & 14.97082 & -107.615 & 309.063 \\
\hline $\mathbf{P}_{\mathrm{DAY}}$ & 8784 & 27.90809 & 16.95533 & -110.904 & 356.619 \\
\hline$P_{\text {DuQ }}$ & 8784 & 26.86976 & 16.40035 & -106.155 & 409.372 \\
\hline $\mathbf{X}_{\mathrm{AEP}}$ & 8784 & 274.6992 & 350.9818 & 0 & 5925 \\
\hline $\mathbf{Z}_{\mathrm{AEP}}$ & 8784 & -113.6995 & 244.3614 & -10314.1 & 0 \\
\hline $\mathbf{X}_{\mathrm{APS}}$ & 8784 & 153.5864 & 163.8648 & 0 & 1009.62 \\
\hline $\mathbf{Z}_{\mathrm{APS}}$ & 8784 & -29.418 & 85.72878 & -3899.64 & 0 \\
\hline $\mathbf{X}_{\text {ATSI }}$ & 8784 & 63.74838 & 139.6792 & 0 & 1843.84 \\
\hline $\mathbf{Z}_{\text {ATSI }}$ & 8784 & -179.8229 & 210.2097 & -5704.41 & 0 \\
\hline $\mathbf{X}_{\text {COMED }}$ & 8784 & 161.7304 & 275.0782 & 0 & 3171 \\
\hline $\mathbf{Z}_{\text {COMED }}$ & 8784 & -118.8896 & 273.58 & -8324.65 & 0 \\
\hline $\mathbf{X}_{\text {DAY }}$ & 8784 & 40.96645 & 57.47029 & 0 & 514 \\
\hline $\mathbf{Z}_{\mathrm{DAY}}$ & 8784 & -17.91803 & 54.86237 & -3589 & 0 \\
\hline $\mathbf{X}_{\text {DUQ }}$ & 8784 & 49.62666 & 47.68899 & 0 & 370.72 \\
\hline $\mathbf{Z}_{\text {DUQ }}$ & 8784 & -10.49915 & 50.63043 & -3811 & 0 \\
\hline HDD $_{\text {AEP }}$ & 8784 & 2.730713 & 4.473963 & 0 & 15.82226 \\
\hline CDD $_{\text {AEP }}$ & 8784 & -11.77966 & 13.33259 & -53.08191 & 0 \\
\hline HDD $_{\text {APS }}$ & 8784 & 2.928461 & 4.765366 & 0 & 17.00704 \\
\hline CDD $_{\text {APS }}$ & 8784 & -11.5287 & 13.15386 & -50.75813 & 0 \\
\hline HDD $_{\text {ATSI }}$ & 8784 & 2.29862 & 4.101536 & 0 & 17.13497 \\
\hline CDD $_{\text {ATSI }}$ & 8784 & -13.34989 & 14.00954 & -55.14301 & 0 \\
\hline HDDCOMED & 8784 & 2.275956 & 4.267006 & 0 & 17 \\
\hline CDDCOMED & 8784 & -14.86885 & 15.20258 & -63 & 0 \\
\hline HDD $_{\text {DAY }}$ & 8784 & 2.377049 & 4.084043 & 0 & 16 \\
\hline CDD $_{\text {DAY }}$ & 8784 & -12.76503 & 14.11333 & -57 & 0 \\
\hline HDD $_{\text {DUQ }}$ & 8784 & 2.169399 & 3.903947 & 0 & 15 \\
\hline CDDDUQ & 8784 & -12.39344 & 13.67311 & -55 & 0 \\
\hline HDD $^{2}{ }_{\text {AEP }}$ & 8784 & 27.47086 & 54.31487 & 0 & 250.3439 \\
\hline $\mathrm{HDD}^{2}{ }_{\mathrm{APS}}$ & 8784 & 31.28201 & 60.65058 & 0 & 289.2394 \\
\hline HDD $^{2}{ }_{\text {ATSI }}$ & 8784 & 22.10434 & 49.7689 & 0 & 293.6072 \\
\hline HDD $^{2}$ СOMED & 8784 & 23.38525 & 54.67613 & 0 & 289 \\
\hline HDD $^{2}$ DAY & 8784 & 22.32787 & 47.90212 & 0 & 256 \\
\hline HDD $^{2}$ DUQ & 8784 & 19.94536 & 44.17465 & 0 & 225 \\
\hline $\mathrm{CDD}^{2}{ }_{\mathrm{AEP}}$ & 8784 & -316.4983 & 531.4418 & -2817.689 & 0 \\
\hline $\mathrm{CDD}^{2}{ }_{\mathrm{APS}}$ & 8784 & -305.9151 & 519.1038 & -2576.388 & 0 \\
\hline $\mathrm{CDD}^{2}{ }_{\mathrm{ATSI}}$ & 8784 & -374.4647 & 577.0633 & -3040.751 & 0 \\
\hline $\mathrm{CDD}^{2}$ СОМЕD & 8784 & -452.1749 & 680.3602 & -3969 & 0 \\
\hline $\mathrm{CDD}^{2} \mathrm{DAY}$ & 8784 & -362.1093 & 594.8962 & -3249 & 0 \\
\hline $\mathrm{CDD}^{2}$ DUQ & 8784 & -340.5301 & 573.0701 & -3025 & 0 \\
\hline
\end{tabular}


Table 6: Pre-Retirement with Over-Predicted Consumption Regression Model

\begin{tabular}{|c|c|c|c|c|c|c|}
\hline & AEP & APS & ATSI & COMED & DAY & DUQ \\
\hline \multirow[t]{2}{*}{$\mathbf{X}_{\mathrm{AEP}}$} & -0.002 & 0.001 & -0.001 & $-0.00216^{*}$ & -0.002 & 0.001 \\
\hline & $(-0.001)$ & $(-0.001)$ & $(-0.001)$ & $(-0.001)$ & $(-0.001)$ & $(-0.001)$ \\
\hline \multirow[t]{2}{*}{$\mathbf{Z}_{\mathrm{AEP}}$} & . & $-0.0118 * * *$ & $-0.0187 * * *$ & $-0.0123^{* * *}$ & $-0.0161 * * *$ & $-0.00477 * * *$ \\
\hline & (.) & $(-0.002)$ & $(-0.002)$ & $(-0.001)$ & $(-0.001)$ & $(-0.001)$ \\
\hline \multirow[t]{2}{*}{$\mathbf{X}_{\mathrm{APS}}$} & $-0.00750 * * *$ & $-0.00884 * * *$ & $-0.0112 * * *$ & -0.004 & $-0.00929 * * *$ & $-0.00621 * * *$ \\
\hline & $(-0.002)$ & $(-0.002)$ & $(-0.002)$ & $(-0.002)$ & $(-0.002)$ & $(-0.002)$ \\
\hline \multirow[t]{2}{*}{$\mathbf{Z}_{\mathrm{APS}}$} & -0.007 & . & 0.000 & 0.003 & $-0.0159 * * *$ & $-0.0290 * * *$ \\
\hline & $(-0.004)$ & (.) & $(-0.004)$ & $(-0.003)$ & $(-0.004)$ & $(-0.004)$ \\
\hline \multirow[t]{2}{*}{$\mathbf{X}_{\mathrm{ATSI}}$} & -0.001 & -0.001 & 0.001 & 0.000 & 0.000 & -0.003 \\
\hline & $(-0.002)$ & $(-0.002)$ & $(-0.002)$ & $(-0.002)$ & $(-0.002)$ & $(-0.002)$ \\
\hline \multirow[t]{2}{*}{$\mathbf{Z}_{\mathrm{ATSI}}$} & -0.004 & $-0.00747 *$ & . & $-0.00790 * *$ & $0.0116^{* * *}$ & -0.003 \\
\hline & $(-0.003)$ & $(-0.003)$ & (.) & $(-0.003)$ & $(-0.003)$ & $(-0.003)$ \\
\hline \multirow[t]{2}{*}{$\mathbf{X}_{\text {COMED }}$} & $0.00311 * * *$ & $0.00427 * * *$ & $0.00736^{* * *}$ & $0.00263 * * *$ & $0.00499 * * *$ & $0.00423 * * *$ \\
\hline & $(-0.001)$ & $(-0.001)$ & $(-0.001)$ & $(-0.001)$ & $(-0.001)$ & $(-0.001)$ \\
\hline \multirow[t]{2}{*}{$\mathbf{Z}_{\text {COMED }}$} & $-0.00399 * *$ & -0.001 & $-0.00627 * *$ & . & $-0.00565 * *$ & $-0.00570 * * *$ \\
\hline & $(-0.002)$ & $(-0.002)$ & $(-0.002)$ & (.) & $(-0.002)$ & $(-0.001)$ \\
\hline \multirow[t]{2}{*}{$\mathbf{X}_{\mathbf{D A Y}}$} & -0.007 & -0.008 & $-0.0169 * *$ & $-0.0145^{* *}$ & -0.008 & -0.006 \\
\hline & $(-0.004)$ & $(-0.006)$ & $(-0.006)$ & $(-0.005)$ & $(-0.005)$ & $(-0.005)$ \\
\hline \multirow[t]{2}{*}{$\mathbf{Z}_{\mathrm{DAY}}$} & -0.006 & 0.001 & $0.0688 * * *$ & $0.0479 * * *$ & . & 0.004 \\
\hline & $(-0.011)$ & $(-0.011)$ & $(-0.013)$ & $(-0.011)$ & (.) & $(-0.01)$ \\
\hline \multirow[t]{2}{*}{$\mathbf{X}_{\text {DUQ }}$} & 0.010 & 0.008 & -0.002 & 0.000 & 0.003 & -0.002 \\
\hline & $(-0.006)$ & $(-0.007)$ & $(-0.008)$ & $(-0.007)$ & $(-0.007)$ & $(-0.006)$ \\
\hline \multirow[t]{2}{*}{$\mathbf{Z}_{\mathrm{DUQ}}$} & -0.015 & -0.021 & $-0.0474 * * *$ & $-0.0389 * * *$ & $-0.0546 * * *$ & . \\
\hline & $(-0.01)$ & $(-0.014)$ & $(-0.013)$ & $(-0.01)$ & $(-0.011)$ & (.) \\
\hline \multirow[t]{2}{*}{ HDD $_{i}$} & -0.089 & $-1.744 * * *$ & $-1.543^{* * *}$ & -0.451 & -0.441 & $-0.588 *$ \\
\hline & $(-0.261)$ & $(-0.323)$ & $(-0.329)$ & $(-0.291)$ & $(-0.322)$ & $(-0.246)$ \\
\hline \multirow[t]{2}{*}{$\mathrm{CDD}_{\mathrm{i}}$} & $0.755^{* * *} *$ & $1.797 * * *$ & $1.097 * * *$ & $0.341 * * *$ & $0.796 * * *$ & $0.339 * * *$ \\
\hline & $(-0.094)$ & $(-0.099)$ & $(-0.097)$ & $(-0.084)$ & $(-0.087)$ & $(-0.074)$ \\
\hline \multirow[t]{2}{*}{ HDD $_{i}^{2}$} & $0.0574 * * *$ & $0.168 * * *$ & $0.198 * * *$ & $0.0758 * * *$ & $0.0870 * * *$ & $0.116^{* * *}$ \\
\hline & $(-0.017)$ & $(-0.024)$ & $(-0.026)$ & $(-0.021)$ & $(-0.026)$ & $(-0.02)$ \\
\hline \multirow[t]{2}{*}{$\mathrm{CDD}_{\mathrm{i}}{ }^{2}$} & $-0.0238 * * *$ & $-0.0559 * * *$ & $-0.0283 * * *$ & $-0.0139 * * *$ & $-0.0227 * * *$ & $-0.00968 * * *$ \\
\hline & $(-0.002)$ & $(-0.002)$ & $(-0.002)$ & $(-0.001)$ & $(-0.001)$ & $(-0.001)$ \\
\hline \multirow[t]{2}{*}{$\mathbf{h}_{1}$} & . & . & . & . & . & . \\
\hline & (.) & (.) & (.) & (.) & (.) & (.) \\
\hline \multirow[t]{2}{*}{$\mathbf{h}_{2}$} & -0.825 & 0.152 & 0.245 & -0.663 & -0.428 & -0.433 \\
\hline & $(-1.592)$ & $(-1.653)$ & $(-1.886)$ & $(-1.684)$ & $(-1.601)$ & $(-1.393)$ \\
\hline \multirow[t]{2}{*}{$\mathbf{h}_{3}$} & -2.198 & -1.271 & -1.941 & -2.730 & -2.551 & -2.314 \\
\hline & $(-1.584)$ & $(-1.675)$ & $(-1.852)$ & $(-1.69)$ & $(-1.608)$ & $(-1.396)$ \\
\hline \multirow[t]{2}{*}{$\mathbf{h}_{4}$} & $-3.186^{*}$ & -2.543 & -2.376 & $-4.101 *$ & $-3.743 *$ & $-3.142 *$ \\
\hline & $(-1.586)$ & $(-1.672)$ & $(-1.866)$ & $(-1.696)$ & $(-1.612)$ & $(-1.42)$ \\
\hline $\mathbf{h}_{5}$ & -1.758 & -1.011 & -0.613 & $-3.576^{*}$ & -1.725 & -1.732 \\
\hline
\end{tabular}


Michael O'Conor

\begin{tabular}{|c|c|c|c|c|c|c|}
\hline & $(-1.618)$ & $(-1.662)$ & $(-1.874)$ & $(-1.703)$ & $(-1.613)$ & $(-1.44)$ \\
\hline \multirow[t]{2}{*}{$h_{6}$} & 2.065 & 2.769 & 2.396 & -0.526 & 1.065 & 0.316 \\
\hline & $(-1.604)$ & $(-1.675)$ & $(-1.874)$ & $(-1.704)$ & $(-1.622)$ & $(-1.437)$ \\
\hline \multirow[t]{2}{*}{$\mathbf{h}_{7}$} & $8.816^{* * *}$ & $11.46^{* * *}$ & $12.55^{* * *}$ & $9.965 * * *$ & $9.326 * * *$ & $9.032 * * *$ \\
\hline & $(-1.604)$ & $(-1.721)$ & $(-1.886)$ & $(-1.722)$ & $(-1.642)$ & $(-1.465)$ \\
\hline \multirow[t]{2}{*}{$\mathbf{h}_{8}$} & $10.60 * * *$ & $13.02 * * *$ & $12.62 * * *$ & $9.966 * * *$ & $9.683 * * *$ & $9.689 * * *$ \\
\hline & $(-1.584)$ & $(-1.714)$ & $(-1.847)$ & $(-1.733)$ & $(-1.631)$ & $(-1.454)$ \\
\hline \multirow[t]{2}{*}{$\mathbf{h}_{9}$} & $9.218 * * *$ & $11.15^{* * *}$ & $9.694 * * *$ & $9.599 * * *$ & $8.342 * * *$ & $8.272 * * *$ \\
\hline & $(-1.555)$ & $(-1.708)$ & $(-1.822)$ & $(-1.702)$ & $(-1.618)$ & $(-1.427)$ \\
\hline \multirow[t]{2}{*}{$\mathbf{h}_{10}$} & $12.37 * * *$ & $12.98 * * *$ & $11.61 * * *$ & $12.35^{* * *}$ & $11.33 * * *$ & $11.02 * * *$ \\
\hline & $(-1.546)$ & $(-1.706)$ & $(-1.819)$ & $(-1.679)$ & $(-1.624)$ & $(-1.442)$ \\
\hline \multirow[t]{2}{*}{$\mathbf{h}_{11}$} & $10.87 * * *$ & $12.21 * * *$ & $12.37 * * *$ & $12.54 * * *$ & $11.38 * * *$ & $9.272 * * *$ \\
\hline & $(-1.555)$ & $(-1.69)$ & $(-1.822)$ & $(-1.686)$ & $(-1.619)$ & $(-1.427)$ \\
\hline \multirow[t]{2}{*}{$\mathbf{h}_{12}$} & $10.64 * * *$ & $12.29 * * *$ & $12.61 * * *$ & $12.99 * * *$ & $11.78 * * *$ & $10.83 * * *$ \\
\hline & $(-1.541)$ & $(-1.702)$ & $(-1.815)$ & $(-1.7)$ & $(-1.63)$ & $(-1.418)$ \\
\hline \multirow[t]{2}{*}{$\mathbf{h}_{13}$} & $11.33 * * *$ & $13.07 * * *$ & $11.10 * * *$ & $12.52 * * *$ & $9.391 * * *$ & $10.00 * * *$ \\
\hline & $(-1.549)$ & $(-1.714)$ & $(-1.819)$ & $(-1.707)$ & $(-1.638)$ & $(-1.439)$ \\
\hline \multirow[t]{2}{*}{$h_{14}$} & $12.46^{* * *}$ & $10.37 * * *$ & $13.90 * * *$ & $12.75^{* * *}$ & $11.02 * * *$ & $11.93 * * *$ \\
\hline & $(-1.553)$ & $(-1.725)$ & $(-1.842)$ & $(-1.708)$ & $(-1.663)$ & $(-1.441)$ \\
\hline \multirow[t]{2}{*}{$\mathbf{h}_{15}$} & $9.745^{* * *}$ & $7.116^{* * *}$ & $11.55^{* * *}$ & $9.488 * * *$ & $8.215^{* * *}$ & $7.703 * * *$ \\
\hline & $(-1.555)$ & $(-1.73)$ & $(-1.856)$ & $(-1.714)$ & $(-1.681)$ & $(-1.423)$ \\
\hline \multirow[t]{2}{*}{$\mathbf{h}_{16}$} & $10.36^{* * *}$ & $7.354 * * *$ & $11.46^{* * *}$ & $9.332 * * *$ & $8.054 * * *$ & $8.864 * * *$ \\
\hline & $(-1.559)$ & $(-1.731)$ & $(-1.867)$ & $(-1.745)$ & $(-1.686)$ & $(-1.445)$ \\
\hline \multirow[t]{2}{*}{$\mathbf{h}_{17}$} & $16.52 * * *$ & $12.64 * * *$ & $15.53 * * *$ & $13.40 * * *$ & $14.80 * * *$ & $13.89 * * *$ \\
\hline & $(-1.577)$ & $(-1.76)$ & $(-1.888)$ & $(-1.757)$ & $(-1.704)$ & $(-1.45)$ \\
\hline \multirow[t]{2}{*}{$\mathbf{h}_{18}$} & $16.43 * * *$ & $16.96 * * *$ & $16.58 * * *$ & $13.59 * * *$ & $15.70 * * *$ & $14.32 * * *$ \\
\hline & $(-1.593)$ & $(-1.768)$ & $(-1.909)$ & $(-1.738)$ & $(-1.695)$ & $(-1.444)$ \\
\hline \multirow[t]{2}{*}{$\mathbf{h}_{19}$} & $14.84 * * *$ & $15.89 * * *$ & $15.81 * * *$ & $14.59 * * *$ & $14.56 * * *$ & $12.39 * * *$ \\
\hline & $(-1.567)$ & $(-1.749)$ & $(-1.899)$ & $(-1.737)$ & $(-1.683)$ & $(-1.444)$ \\
\hline \multirow[t]{2}{*}{$\mathbf{h}_{20}$} & $17.58 * * *$ & $20.40 * * *$ & $19.64 * * *$ & $16.77 * * *$ & $16.85 * * *$ & $15.46 * * *$ \\
\hline & $(-1.559)$ & $(-1.757)$ & $(-1.885)$ & $(-1.744)$ & $(-1.685)$ & $(-1.433)$ \\
\hline \multirow[t]{2}{*}{$\mathbf{h}_{21}$} & $17.51 * * *$ & $20.07 * * *$ & $19.02 * * *$ & $17.95^{* * *}$ & $17.80 * * *$ & $15.17 * * *$ \\
\hline & $(-1.535)$ & $(-1.713)$ & $(-1.838)$ & $(-1.699)$ & $(-1.665)$ & $(-1.398)$ \\
\hline \multirow[t]{2}{*}{$\mathbf{h}_{22}$} & $11.58 * * *$ & $11.75^{* * *}$ & $12.16^{* * * *}$ & $13.95 * * *$ & $12.58 * * *$ & $8.201 * * *$ \\
\hline & $(-1.531)$ & $(-1.699)$ & $(-1.835)$ & $(-1.69)$ & $(-1.638)$ & $(-1.39)$ \\
\hline \multirow[t]{2}{*}{$\mathbf{h}_{23}$} & $4.497 * *$ & $3.688^{*}$ & $4.259^{*}$ & $6.195^{* * *}$ & $3.899 *$ & 2.327 \\
\hline & $(-1.517)$ & $(-1.686)$ & $(-1.838)$ & $(-1.685)$ & $(-1.627)$ & $(-1.373)$ \\
\hline \multirow[t]{2}{*}{$\mathbf{h}_{24}$} & 0.987 & 0.689 & 0.730 & 2.160 & -0.252 & -0.705 \\
\hline & $(-1.515)$ & $(-1.686)$ & $(-1.831)$ & $(-1.678)$ & $(-1.625)$ & $(-1.367)$ \\
\hline \multirow[t]{2}{*}{$d_{1}$} & -0.248 & 1.618 & -0.468 & 1.579 & -0.901 & $1.739^{*}$ \\
\hline & $(-0.81)$ & $(-0.94)$ & $(-1)$ & $(-0.941)$ & $(-0.925)$ & $(-0.808)$ \\
\hline \multirow[t]{2}{*}{$\mathbf{d}_{2}$} & $-2.071^{*}$ & -1.652 & -1.894 & -0.604 & $-2.799 * *$ & $-1.627 *$ \\
\hline & $(-0.807)$ & $(-0.945)$ & $(-1.029)$ & $(-0.973)$ & $(-0.915)$ & $(-0.802)$ \\
\hline \multirow[t]{2}{*}{$d_{3}$} & . & . & . & . & . & . \\
\hline & (.) & (.) & (.) & (.) & (.) & (.) \\
\hline
\end{tabular}


Michael O'Conor

\begin{tabular}{|c|c|c|c|c|c|c|}
\hline \multirow[t]{2}{*}{$d_{4}$} & 0.906 & 1.144 & -0.538 & 1.539 & -0.774 & $-2.329 * *$ \\
\hline & $(-0.826)$ & $(-0.955)$ & $(-1)$ & $(-0.929)$ & $(-0.923)$ & $(-0.814)$ \\
\hline \multirow[t]{2}{*}{$d_{5}$} & -1.386 & $-1.970^{*}$ & -1.508 & $1.866^{*}$ & -1.159 & -0.614 \\
\hline & $(-0.869)$ & $(-0.971)$ & $(-1.014)$ & $(-0.922)$ & $(-0.934)$ & $(-0.836)$ \\
\hline \multirow[t]{2}{*}{$d_{6}$} & $-3.087 * * *$ & $-4.056^{* * *}$ & $-2.285^{*}$ & -0.064 & $-2.705^{* *}$ & $-1.568 *$ \\
\hline & $(-0.861)$ & $(-0.957)$ & $(-1.027)$ & $(-0.963)$ & $(-0.902)$ & $(-0.799)$ \\
\hline \multirow[t]{2}{*}{$\mathbf{d}_{7}$} & $-3.753 * * *$ & $-2.007 *$ & $-4.406^{* * *}$ & $-4.994 * * *$ & $-5.275^{* * *}$ & $-3.480 * * *$ \\
\hline & $(-0.818)$ & $(-0.929)$ & $(-0.998)$ & $(-0.954)$ & $(-0.887)$ & $(-0.772)$ \\
\hline \multirow[t]{2}{*}{$\mathbf{m}_{1}$} & $-5.868 * * *$ & $-8.031 * * *$ & $-7.157 * * *$ & $-4.896 * * *$ & -1.997 & 0.431 \\
\hline & $(-1.235)$ & $(-1.349)$ & $(-1.434)$ & $(-1.197)$ & $(-1.225)$ & $(-1.203)$ \\
\hline \multirow[t]{2}{*}{$\mathbf{m}_{2}$} & -0.956 & $4.363 * *$ & $-5.296 * *$ & 1.557 & $6.850 * * *$ & -0.086 \\
\hline & $(-1.321)$ & $(-1.465)$ & $(-1.689)$ & $(-1.402)$ & $(-1.423)$ & $(-1.309)$ \\
\hline \multirow[t]{2}{*}{$\mathbf{m}_{3}$} & $5.819 * * *$ & $8.849 * * *$ & $7.204 * * *$ & $4.394 * * *$ & $5.290 * * *$ & $6.987 * * *$ \\
\hline & $(-1.2)$ & $(-1.289)$ & $(-1.273)$ & $(-1.187)$ & $(-1.182)$ & $(-1.103)$ \\
\hline \multirow[t]{2}{*}{$\mathbf{m}_{4}$} & 2.205 & $6.660 * * *$ & $3.646^{*}$ & 2.453 & $2.997 *$ & $4.199 * * *$ \\
\hline & $(-1.378)$ & $(-1.458)$ & $(-1.459)$ & $(-1.377)$ & $(-1.385)$ & $(-1.234)$ \\
\hline \multirow[t]{2}{*}{$\mathbf{m}_{5}$} & 0.959 & -0.471 & -3.209 & 1.145 & 1.728 & 1.316 \\
\hline & $(-1.752)$ & $(-1.799)$ & $(-1.814)$ & $(-1.659)$ & $(-1.656)$ & $(-1.602)$ \\
\hline \multirow[t]{2}{*}{$\mathbf{m}_{6}$} & 0.523 & -1.239 & 0.763 & $7.840 * * *$ & 1.704 & 2.726 \\
\hline & $(-1.91)$ & $(-2.112)$ & $(-2.065)$ & $(-1.959)$ & $(-1.85)$ & $(-1.606)$ \\
\hline \multirow[t]{2}{*}{$\mathbf{m}_{7}$} & $-3.769 *$ & -2.242 & -3.260 & $5.889 * *$ & -0.980 & -1.630 \\
\hline & $(-1.843)$ & $(-1.976)$ & $(-2.063)$ & $(-1.974)$ & $(-1.795)$ & $(-1.572)$ \\
\hline \multirow[t]{2}{*}{$\mathbf{m}_{8}$} & -3.293 & -1.365 & $-4.495^{*}$ & 2.027 & -1.412 & 0.166 \\
\hline & $(-2.001)$ & $(-2.058)$ & $(-2.162)$ & $(-2.121)$ & $(-1.933)$ & $(-1.61)$ \\
\hline \multirow[t]{2}{*}{$\mathbf{m}_{9}$} & 1.143 & 1.475 & 0.029 & $7.839 * * *$ & $4.068 *$ & 2.679 \\
\hline & $(-1.707)$ & $(-1.821)$ & $(-1.864)$ & $(-1.733)$ & $(-1.642)$ & $(-1.472)$ \\
\hline \multirow[t]{2}{*}{$\mathbf{m}_{10}$} & $9.562 * * *$ & $9.705^{* * *}$ & $6.334 * * *$ & $10.06^{* * *}$ & $9.125 * * *$ & $6.077 * * *$ \\
\hline & $(-1.448)$ & $(-1.539)$ & $(-1.484)$ & $(-1.489)$ & $(-1.393)$ & $(-1.323)$ \\
\hline \multirow[t]{2}{*}{$\mathbf{m}_{11}$} & $5.047 * * *$ & $6.790 * * *$ & $6.204 * * *$ & $3.503 * *$ & $5.495 * * *$ & $6.672 * * *$ \\
\hline & $(-1.196)$ & $(-1.247)$ & $(-1.357)$ & $(-1.323)$ & $(-1.185)$ & $(-1.131)$ \\
\hline \multirow[t]{2}{*}{$\mathbf{m}_{12}$} & . & . & . & . & . & . \\
\hline & (.) & (.) & (.) & (.) & (.) & (.) \\
\hline \multirow[t]{2}{*}{ intercept } & $23.92 * * *$ & $26.39 * * *$ & $27.55^{* * *}$ & $15.07 * * *$ & $24.29 * * *$ & $22.16 * * *$ \\
\hline & $(-2.167)$ & $(-2.278)$ & $(-2.492)$ & $(-2.304)$ & $(-2.193)$ & $(-1.865)$ \\
\hline R-SQ & 0.316 & 0.410 & 0.302 & 0.276 & 0.303 & 0.232 \\
\hline ADJ R-SQ & 0.308 & 0.404 & 0.295 & 0.269 & 0.296 & 0.223 \\
\hline AIC & 38560.000 & 50884.900 & 47263.400 & 46558.900 & 51128.800 & 41604.700 \\
\hline BIC & 38921.200 & 51258.400 & 47632.500 & 46928.200 & 51503.100 & 41970.300 \\
\hline F-TEST & 38.780 & 72.850 & 41.940 & 36.920 & 46.250 & 27.450 \\
\hline $\mathbf{N}$ & 4677 & 5818 & 5386 & 5395 & 5903 & 5051 \\
\hline
\end{tabular}


Table 7: Post-Retirement with Over-Predicted Consumption Regression Model

\begin{tabular}{|c|c|c|c|c|c|c|}
\hline & AEP & APS & ATSI & COMED & DAY & DUQ \\
\hline \multirow[t]{2}{*}{$\mathbf{X}_{\mathrm{AEP}}$} & 0.000 & 0.000 & 0.000 & 0.001 & 0.001 & -0.001 \\
\hline & $(-0.001)$ & $(-0.001)$ & $(-0.001)$ & $(-0.001)$ & $(-0.001)$ & $(-0.001)$ \\
\hline \multirow[t]{2}{*}{$\mathbf{Z}_{\mathrm{AEP}}$} & . & $-0.00526 * * *$ & -0.001 & -0.002 & $-0.00517 * * *$ & $-0.00435 * * *$ \\
\hline & . & $(-0.001)$ & $(-0.001)$ & $(-0.001)$ & $(-0.001)$ & $(-0.001)$ \\
\hline \multirow[t]{2}{*}{$\mathbf{X}_{\mathrm{APS}}$} & $-0.00622 * * *$ & $-0.00892 * * *$ & $-0.0106 * * *$ & $-0.00515 * * *$ & $-0.00917 * * *$ & $-0.00601 * * *$ \\
\hline & $(-0.001)$ & $(-0.001)$ & $(-0.002)$ & $(-0.001)$ & $(-0.001)$ & $(-0.001)$ \\
\hline \multirow[t]{2}{*}{$\mathbf{Z}_{\mathrm{APS}}$} & $-0.0193 * * *$ & . & -0.005 & $-0.0121 * * *$ & $-0.0191 * * *$ & $-0.0134 * * *$ \\
\hline & $(-0.003)$ & . & $(-0.005)$ & $(-0.003)$ & $(-0.003)$ & $(-0.003)$ \\
\hline \multirow[t]{2}{*}{$\mathbf{X}_{\text {ATSI }}$} & $-0.00404 * *$ & $-0.00370 *$ & $-0.00437 * *$ & $-0.00469 * *$ & $-0.00329 *$ & $-0.00280 *$ \\
\hline & $(-0.001)$ & $(-0.001)$ & $(-0.002)$ & $(-0.001)$ & $(-0.001)$ & $(-0.001)$ \\
\hline \multirow[t]{2}{*}{$\mathbf{Z}_{\text {ATSI }}$} & $-0.00434 * * *$ & $-0.00722 * * *$ & . & $-0.00848 * * *$ & 0.000 & $-0.00574 * * *$ \\
\hline & $(-0.001)$ & $(-0.001)$ & 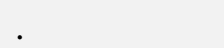 & $(-0.001)$ & $(-0.001)$ & $(-0.001)$ \\
\hline \multirow[t]{2}{*}{ ХСОМЕD } & $0.00358 * * *$ & $0.00431 * * *$ & $0.00487 * * *$ & $0.00227 * * *$ & $0.00410 * * *$ & $0.00528 * * *$ \\
\hline & $(-0.001)$ & $(-0.001)$ & $(-0.001)$ & $(-0.001)$ & $(-0.001)$ & $(-0.001)$ \\
\hline \multirow[t]{2}{*}{$\mathbf{Z}_{\text {COMED }}$} & -0.001 & $-0.00321 * * *$ & $-0.00514 * * *$ & . & $-0.00773 * * *$ & $-0.00334 * * *$ \\
\hline & $(-0.001)$ & $(-0.001)$ & $(-0.001)$ & . & $(-0.001)$ & $(-0.001)$ \\
\hline \multirow[t]{2}{*}{$\mathbf{X}_{\mathbf{D A Y}}$} & -0.002 & 0.006 & 0.000 & $-0.0103 * *$ & 0.001 & -0.003 \\
\hline & $(-0.003)$ & $(-0.004)$ & $(-0.005)$ & $(-0.004)$ & $(-0.004)$ & $(-0.004)$ \\
\hline \multirow[t]{2}{*}{$\mathbf{Z}_{\text {DAY }}$} & 0.001 & $-0.0160 * *$ & -0.001 & $-0.0153 * *$ & . & $-0.0139 *$ \\
\hline & $(-0.006)$ & $(-0.006)$ & $(-0.008)$ & $(-0.005)$ & . & $(-0.005)$ \\
\hline \multirow[t]{2}{*}{$\mathbf{X}_{\text {DuQ }}$} & -0.001 & 0.005 & -0.002 & -0.002 & -0.004 & 0.004 \\
\hline & $(-0.004)$ & $(-0.004)$ & $(-0.006)$ & $(-0.005)$ & $(-0.004)$ & $(-0.004)$ \\
\hline \multirow[t]{2}{*}{$Z_{\text {DUQ }}$} & 0.003 & -0.011 & 0.004 & $0.0162 * *$ & 0.009 & . \\
\hline & $(-0.006)$ & $(-0.009)$ & $(-0.007)$ & $(-0.005)$ & $(-0.008)$ & . \\
\hline \multirow[t]{2}{*}{ HDD $_{\mathrm{i}}$} & -0.019 & 0.273 & $0.691 * *$ & $0.835^{* * *}$ & 0.262 & -0.119 \\
\hline & $(-0.21)$ & $(-0.199)$ & $(-0.256)$ & $(-0.18)$ & $(-0.203)$ & $(-0.205)$ \\
\hline \multirow[t]{2}{*}{ CDD $_{i}$} & $0.121^{*}$ & $0.215^{* * *}$ & $0.290 * *$ & 0.068 & $0.122 *$ & $0.151 * * *$ \\
\hline & $(-0.048)$ & $(-0.054)$ & $(-0.095)$ & $(-0.056)$ & $(-0.051)$ & $(-0.042)$ \\
\hline \multirow[t]{2}{*}{$H D D_{i}^{2}$} & $0.0381 *$ & 0.023 & 0.005 & -0.024 & 0.024 & $0.0538 * *$ \\
\hline & $(-0.016)$ & $(-0.013)$ & $(-0.018)$ & $(-0.013)$ & $(-0.015)$ & $(-0.016)$ \\
\hline \multirow[t]{2}{*}{$\mathrm{CDD}_{\mathrm{i}}^{2}$} & $-0.00714 * * *$ & $-0.0125 * * *$ & $-0.0135 * * *$ & $-0.00378 * * *$ & $-0.00738 * * *$ & $-0.00753 * * *$ \\
\hline & $(-0.001)$ & $(-0.001)$ & $(-0.002)$ & $(-0.001)$ & $(-0.001)$ & $(-0.001)$ \\
\hline \multirow[t]{2}{*}{$h_{1}$} & . & . & . & . & . & . \\
\hline & . & . & . & . & - & . \\
\hline \multirow[t]{2}{*}{$\mathbf{h}_{2}$} & -0.919 & -0.643 & -1.256 & -1.058 & -1.188 & -0.896 \\
\hline & $(-1.029)$ & $(-1.053)$ & $(-1.612)$ & $(-1.105)$ & $(-1.073)$ & $(-0.943)$ \\
\hline \multirow[t]{2}{*}{ h3 } & -1.734 & -1.851 & -2.767 & $-3.100 * *$ & $-2.349 *$ & $-1.962 *$ \\
\hline & $(-1.035)$ & $(-1.062)$ & $(-1.589)$ & $(-1.116)$ & $(-1.076)$ & $(-0.938)$ \\
\hline \multirow[t]{2}{*}{ h4 } & $-2.419^{*}$ & $-2.373^{*}$ & $-3.742 *$ & $-3.564 * *$ & $-3.353 * *$ & $-2.496 * *$ \\
\hline & $(-1.047)$ & $(-1.058)$ & $(-1.589)$ & $(-1.111)$ & $(-1.074)$ & $(-0.945)$ \\
\hline$h_{5}$ & -1.364 & -0.974 & -1.962 & $-3.220 * *$ & $-2.288^{*}$ & -1.321 \\
\hline
\end{tabular}




\begin{tabular}{|c|c|c|c|c|c|c|}
\hline & $(-1.039)$ & $(-1.067)$ & $(-1.615)$ & $(-1.121)$ & $(-1.072)$ & $(-0.948)$ \\
\hline \multirow[t]{2}{*}{$\mathbf{h}_{6}$} & $2.172 *$ & 1.951 & 0.389 & -0.158 & 1.417 & $1.889^{*}$ \\
\hline & $(-1.043)$ & $(-1.063)$ & $(-1.591)$ & $(-1.115)$ & $(-1.072)$ & $(-0.951)$ \\
\hline \multirow[t]{2}{*}{$\mathbf{h}_{7}$} & $9.474 * * *$ & $9.219 * * *$ & $8.402 * * *$ & $4.610 * * *$ & $7.008 * * *$ & $10.42 * * *$ \\
\hline & $(-1.03)$ & $(-1.073)$ & $(-1.62)$ & $(-1.138)$ & $(-1.094)$ & $(-0.957)$ \\
\hline \multirow[t]{2}{*}{$\mathbf{h}_{8}$} & $9.582 * * *$ & $9.194 * * *$ & $8.622 * * *$ & $6.119 * * *$ & $7.250 * * *$ & $9.016 * * *$ \\
\hline & $(-1.039)$ & $(-1.064)$ & $(-1.628)$ & $(-1.15)$ & $(-1.075)$ & $(-0.962)$ \\
\hline \multirow[t]{2}{*}{ h9 } & $8.659 * * *$ & $7.873 * * *$ & $7.660 * * *$ & $7.035^{* * *}$ & $7.181 * * *$ & $7.901 * * *$ \\
\hline & $(-1.025)$ & $(-1.056)$ & $(-1.571)$ & $(-1.144)$ & $(-1.063)$ & $(-0.952)$ \\
\hline \multirow[t]{2}{*}{$\mathbf{h}_{10}$} & $8.778 * * *$ & $9.132 * * *$ & $8.238 * * *$ & $7.319 * * *$ & $7.310 * * *$ & $8.908 * * *$ \\
\hline & $(-1.019)$ & $(-1.054)$ & $(-1.554)$ & $(-1.121)$ & $(-1.061)$ & $(-0.952)$ \\
\hline \multirow[t]{2}{*}{$\mathbf{h}_{11}$} & $8.373 * * *$ & $10.10 * * *$ & $10.27 * * *$ & $8.241 * * *$ & $8.454 * * *$ & $9.696 * * *$ \\
\hline & $(-1.013)$ & $(-1.053)$ & $(-1.543)$ & $(-1.118)$ & $(-1.066)$ & $(-0.958)$ \\
\hline \multirow[t]{2}{*}{$\mathbf{h}_{12}$} & $8.683^{* * *}$ & $11.05^{* * *}$ & $11.02 * * *$ & $9.120 * * *$ & $9.823^{* * *}$ & $9.559 * * *$ \\
\hline & $(-1.014)$ & $(-1.064)$ & $(-1.546)$ & $(-1.121)$ & $(-1.073)$ & $(-0.959)$ \\
\hline \multirow[t]{2}{*}{$\mathbf{h}_{13}$} & $8.408 * * *$ & $10.71 * * *$ & $11.30 * * *$ & $8.389 * * *$ & $8.994 * * *$ & $9.067 * * *$ \\
\hline & $(-1.029)$ & $(-1.066)$ & $(-1.542)$ & $(-1.113)$ & $(-1.084)$ & $(-0.957)$ \\
\hline \multirow[t]{2}{*}{$\mathbf{h}_{14}$} & $8.233 * * *$ & $9.986 * * *$ & $10.33 * * *$ & $8.640 * * *$ & $8.517 * * *$ & $8.461 * * *$ \\
\hline & $(-1.032)$ & $(-1.071)$ & $(-1.553)$ & $(-1.125)$ & $(-1.102)$ & $(-0.965)$ \\
\hline \multirow[t]{2}{*}{$\mathbf{h}_{15}$} & 7.490 *** & $11.08 * * *$ & $11.97 * * *$ & $9.996 * * *$ & $8.956 * * *$ & $8.894 * * *$ \\
\hline & $(-1.036)$ & $(-1.07)$ & $(-1.568)$ & $(-1.132)$ & $(-1.095)$ & $(-0.961)$ \\
\hline \multirow[t]{2}{*}{$\mathbf{h}_{16}$} & $7.355^{* * *}$ & $10.24 * * *$ & $11.98 * * *$ & $8.260 * * *$ & $8.912 * * *$ & $8.393 * * *$ \\
\hline & $(-1.033)$ & $(-1.079)$ & $(-1.552)$ & $(-1.141)$ & $(-1.102)$ & $(-0.969)$ \\
\hline \multirow[t]{2}{*}{$\mathbf{h}_{17}$} & $9.600 * * *$ & $12.14 * * *$ & $13.71 * * *$ & $11.82 * * *$ & $10.48 * * *$ & $10.44 * * *$ \\
\hline & $(-1.037)$ & $(-1.092)$ & $(-1.553)$ & $(-1.149)$ & $(-1.102)$ & $(-0.975)$ \\
\hline \multirow[t]{2}{*}{$\mathbf{h}_{18}$} & $12.41 * * *$ & $15.56 * * *$ & $16.73 * * *$ & $11.68 * * *$ & $14.38 * * *$ & $13.19 * * *$ \\
\hline & $(-1.042)$ & $(-1.102)$ & $(-1.569)$ & $(-1.158)$ & $(-1.112)$ & $(-0.987)$ \\
\hline \multirow[t]{2}{*}{$\mathbf{h}_{19}$} & $10.23 * * *$ & $11.65^{* * *}$ & $13.65^{* * *}$ & $11.75 * * *$ & $11.74 * * *$ & $10.78 * * *$ \\
\hline & $(-1.032)$ & $(-1.091)$ & $(-1.583)$ & $(-1.156)$ & $(-1.101)$ & $(-0.98)$ \\
\hline \multirow[t]{2}{*}{$\mathbf{h}_{20}$} & $9.622 * * *$ & $10.87 * * *$ & $11.03 * * *$ & $9.618 * * *$ & $9.710 * * *$ & $10.22 * * *$ \\
\hline & $(-1.026)$ & $(-1.086)$ & $(-1.585)$ & $(-1.148)$ & $(-1.099)$ & $(-0.975)$ \\
\hline \multirow[t]{2}{*}{$\mathbf{h}_{21}$} & $10.88 * * *$ & $11.77 * * *$ & $12.47 * * *$ & $11.17 * * *$ & $11.12 * * *$ & $10.93 * * *$ \\
\hline & $(-1.011)$ & $(-1.074)$ & $(-1.557)$ & $(-1.12)$ & $(-1.077)$ & $(-0.967)$ \\
\hline \multirow[t]{2}{*}{$\mathbf{h}_{22}$} & $7.937 * * *$ & $8.113 * * *$ & $7.566 * * *$ & $8.681 * * *$ & $7.688 * * *$ & $7.575^{*} * *$ \\
\hline & $(-1.012)$ & $(-1.06)$ & $(-1.532)$ & $(-1.11)$ & $(-1.065)$ & $(-0.955)$ \\
\hline \multirow[t]{2}{*}{$\mathbf{h}_{23}$} & $3.494 * * *$ & $3.637 * * *$ & $3.649 *$ & $4.511 * * *$ & $3.335^{* *}$ & $3.170 * * *$ \\
\hline & $(-1.013)$ & $(-1.053)$ & $(-1.555)$ & $(-1.096)$ & $(-1.059)$ & $(-0.951)$ \\
\hline \multirow[t]{2}{*}{$\mathbf{h}_{24}$} & 0.997 & 1.176 & 0.916 & 1.669 & 0.947 & 0.841 \\
\hline & $(-1.018)$ & $(-1.047)$ & $(-1.551)$ & $(-1.093)$ & $(-1.065)$ & $(-0.943)$ \\
\hline \multirow[t]{2}{*}{$\mathbf{d}_{1}$} & 0.225 & -0.051 & -1.079 & 0.245 & 0.627 & 0.111 \\
\hline & $(-0.578)$ & $(-0.61)$ & $(-0.861)$ & $(-0.629)$ & $(-0.601)$ & $(-0.525)$ \\
\hline \multirow[t]{2}{*}{$d_{2}$} & 0.205 & $1.431 *$ & 1.131 & -0.859 & $2.019 * * *$ & 0.772 \\
\hline & $(-0.562)$ & $(-0.587)$ & $(-0.845)$ & $(-0.624)$ & $(-0.597)$ & $(-0.516)$ \\
\hline \multirow[t]{2}{*}{$\mathbf{d}_{3}$} & . & . & . & . & . & . \\
\hline & & & & & & \\
\hline
\end{tabular}


Michael O'Conor

\begin{tabular}{|c|c|c|c|c|c|c|}
\hline \multirow[t]{2}{*}{$d_{4}$} & $-1.099 *$ & -0.331 & $-2.412 * *$ & $-2.010 * *$ & $-1.252 *$ & -0.652 \\
\hline & $(-0.558)$ & $(-0.579)$ & $(-0.822)$ & $(-0.613)$ & $(-0.595)$ & $(-0.516)$ \\
\hline \multirow[t]{2}{*}{$d_{5}$} & $-2.990 * * *$ & $-2.203 * * *$ & $-4.368 * * *$ & $-2.573 * * *$ & $-2.828 * * *$ & $-1.666^{* *}$ \\
\hline & $(-0.573)$ & $(-0.59)$ & $(-0.84)$ & $(-0.61)$ & $(-0.605)$ & $(-0.522)$ \\
\hline \multirow[t]{2}{*}{$d_{6}$} & $-3.222 * * *$ & $-2.955 * * *$ & $-4.403 * * *$ & $-3.342 * * *$ & $-2.385^{* * *}$ & $-2.654 * * *$ \\
\hline & $(-0.536)$ & $(-0.585)$ & $(-0.834)$ & $(-0.608)$ & $(-0.569)$ & $(-0.536)$ \\
\hline \multirow[t]{2}{*}{$d_{7}$} & $-4.948 * * *$ & $-5.395 * * *$ & $-6.097 * * *$ & $-6.345^{* * *}$ & $-4.657 * * *$ & $-4.777 * * *$ \\
\hline & $(-0.558)$ & $(-0.597)$ & $(-0.888)$ & $(-0.641)$ & $(-0.595)$ & $(-0.537)$ \\
\hline \multirow[t]{2}{*}{$\mathbf{m}_{1}$} & -1.615 & $-3.857 * * *$ & $-4.551 * *$ & $-2.072 *$ & 0.896 & $-1.574^{*}$ \\
\hline & $(-0.872)$ & $(-0.936)$ & $(-1.57)$ & $(-0.937)$ & $(-0.91)$ & $(-0.802)$ \\
\hline \multirow[t]{2}{*}{$\mathbf{m}_{2}$} & $-3.341 * * *$ & $-6.085^{* * *}$ & $-4.542 *$ & $-5.685^{* * *}$ & -1.782 & $-3.555^{*} * *$ \\
\hline & $(-0.904)$ & $(-0.979)$ & $(-2.043)$ & $(-0.98)$ & $(-0.937)$ & $(-0.82)$ \\
\hline \multirow[t]{2}{*}{$\mathbf{m}_{3}$} & $-1.900^{*}$ & $-2.026^{*}$ & -2.422 & $-3.534 * * *$ & -0.377 & -0.951 \\
\hline & $(-0.827)$ & $(-0.909)$ & $(-2.654)$ & $(-0.927)$ & $(-0.868)$ & $(-0.766)$ \\
\hline \multirow[t]{2}{*}{$\mathbf{m}_{4}$} & $5.385 * * *$ & $4.686 * * *$ & -3.908 & 0.318 & $7.440 * * *$ & $4.241 * * *$ \\
\hline & $(-0.867)$ & $(-0.938)$ & $(-4.689)$ & $(-1.045)$ & $(-0.966)$ & $(-0.781)$ \\
\hline \multirow[t]{2}{*}{$\mathbf{m}_{5}$} & $-2.126^{*}$ & $-2.027 *$ & $-6.159 * *$ & $-3.287 * *$ & 0.492 & $-1.691 *$ \\
\hline & $(-0.839)$ & $(-0.923)$ & $(-2.024)$ & $(-1.044)$ & $(-0.938)$ & $(-0.763)$ \\
\hline \multirow[t]{2}{*}{$\mathbf{m}_{6}$} & 1.871 & 0.264 & 2.674 & 0.252 & $2.460 *$ & $2.349^{*}$ \\
\hline & $(-1.079)$ & $(-1.12)$ & $(-1.431)$ & $(-1.177)$ & $(-1.025)$ & $(-0.944)$ \\
\hline \multirow[t]{2}{*}{$\mathbf{m}_{7}$} & 1.839 & 0.552 & -1.070 & 0.345 & $2.332 *$ & $2.424 *$ \\
\hline & $(-1.15)$ & $(-1.179)$ & $(-1.441)$ & $(-1.176)$ & $(-1.08)$ & $(-1.026)$ \\
\hline \multirow[t]{2}{*}{$\mathbf{m}_{8}$} & -1.201 & -1.713 & -2.100 & -2.148 & -0.666 & -0.513 \\
\hline & $(-1.132)$ & $(-1.127)$ & $(-1.441)$ & $(-1.174)$ & $(-1.031)$ & $(-0.886)$ \\
\hline \multirow[t]{2}{*}{ m9 } & $4.609 * * *$ & $4.140 * * *$ & 2.608 & $3.150 * *$ & $4.703 * * *$ & $3.576 * * *$ \\
\hline & $(-0.971)$ & $(-0.991)$ & $(-1.361)$ & $(-1.169)$ & $(-0.959)$ & $(-0.826)$ \\
\hline \multirow[t]{2}{*}{$\mathbf{m}_{10}$} & $4.396 * * *$ & $5.592 * * *$ & $6.002 * * *$ & $3.591 * * *$ & $7.349 * * *$ & $5.499 * * *$ \\
\hline & $(-0.791)$ & $(-0.831)$ & $(-0.972)$ & $(-0.951)$ & $(-0.776)$ & $(-0.667)$ \\
\hline \multirow[t]{2}{*}{$\mathbf{m}_{11}$} & $3.718 * * *$ & $4.314 * * *$ & $4.581 * * *$ & $4.152 * * *$ & $6.216^{* * *}$ & $3.777 * * *$ \\
\hline & $(-0.752)$ & $(-0.774)$ & $(-0.878)$ & $(-0.872)$ & $(-0.723)$ & $(-0.708)$ \\
\hline \multirow[t]{2}{*}{$\mathbf{m}_{12}$} & . & . & . & . & . & . \\
\hline & . & . & . & . & . & . \\
\hline \multirow[t]{2}{*}{ intercept } & $19.17 * * *$ & $17.00 * * *$ & $19.67 * * *$ & $18.70 * * *$ & $17.23 * * *$ & $17.04 * * *$ \\
\hline & $(-1.13)$ & $(-1.163)$ & $(-1.735)$ & $(-1.402)$ & $(-1.168)$ & $(-0.998)$ \\
\hline R-SQ & 0.242 & 0.281 & 0.308 & 0.254 & 0.293 & 0.265 \\
\hline ADJ R-SQ & 0.235 & 0.275 & 0.295 & 0.246 & 0.286 & 0.259 \\
\hline AIC & 43072.900 & 52248.200 & 23650.900 & 39295.900 & 43669.900 & 52905.000 \\
\hline BIC & 43444.400 & 52628.700 & 23987.500 & 39661.500 & 44041.500 & 53287.500 \\
\hline F-TEST & 32.310 & 46.450 & 23.920 & 30.980 & 41.980 & 44.540 \\
\hline $\mathbf{N}$ & 5623 & 6599 & 3015 & 5060 & 5627 & 6843 \\
\hline
\end{tabular}

F-CRITICAL AT $1 \%=1.49,5 \%=1.33,10 \%=1.25$ 
Table 8: Pre-Retirement with Under-Predicted Consumption Regression Model

\begin{tabular}{|c|c|c|c|c|c|c|}
\hline & AEP & APS & ATSI & COMED & DAY & DUQ \\
\hline \multirow[t]{2}{*}{$\mathbf{X}_{\mathrm{AEP}}$} & . & -0.004 & -0.004 & $-0.00345^{*}$ & -0.003 & $-0.00878 * * *$ \\
\hline & . & $(-0.003)$ & $(-0.002)$ & $(-0.002)$ & $(-0.002)$ & $(-0.002)$ \\
\hline \multirow{2}{*}{$\mathbf{Z}_{\mathrm{AEP}}$} & $-0.0105 * * *$ & $-0.0107 * * *$ & $-0.00407 * *$ & -0.002 & $-0.00543 * * *$ & $-0.0119 * * *$ \\
\hline & $(-0.002)$ & $(-0.002)$ & $(-0.001)$ & $(-0.001)$ & $(-0.001)$ & $(-0.002)$ \\
\hline \multirow{2}{*}{$\mathbf{X}_{\mathrm{APS}}$} & $-0.0151 * * *$ & . & $-0.0183 * * *$ & $-0.0174 * * *$ & $-0.0182 * * *$ & -0.005 \\
\hline & $(-0.004)$ & . & $(-0.004)$ & $(-0.003)$ & $(-0.004)$ & $(-0.004)$ \\
\hline \multirow[t]{2}{*}{$\mathbf{Z}_{\mathrm{APS}}$} & 0.004 & $-0.0139 * *$ & $-0.00783^{*}$ & -0.001 & $0.00750 *$ & $0.0122 * *$ \\
\hline & $(-0.004)$ & $(-0.005)$ & $(-0.003)$ & $(-0.003)$ & $(-0.004)$ & $(-0.004)$ \\
\hline \multirow[t]{2}{*}{$\mathbf{X}_{\mathrm{ATSI}}$} & -0.004 & -0.006 & . & 0.000 & -0.003 & $0.00696^{*}$ \\
\hline & $(-0.004)$ & $(-0.005)$ & . & $(-0.003)$ & $(-0.004)$ & $(-0.004)$ \\
\hline \multirow[t]{2}{*}{$\mathbf{Z}_{\mathrm{ATSI}}$} & 0.000 & 0.000 & -0.003 & $-0.00630^{*}$ & $-0.00942 * * *$ & 0.002 \\
\hline & $(-0.003)$ & $(-0.004)$ & $(-0.003)$ & $(-0.002)$ & $(-0.003)$ & $(-0.003)$ \\
\hline \multirow[t]{2}{*}{$\mathbf{X}_{\text {COMED }}$} & 0.002 & -0.003 & -0.001 & . & 0.000 & $0.00524 * *$ \\
\hline & $(-0.002)$ & $(-0.002)$ & $(-0.001)$ & . & $(-0.001)$ & $(-0.002)$ \\
\hline \multirow[t]{2}{*}{$\mathbf{Z}_{\text {COMED }}$} & $0.00470 * *$ & 0.000 & 0.002 & -0.001 & $0.00415^{*}$ & 0.000 \\
\hline & $(-0.002)$ & $(-0.003)$ & $(-0.002)$ & $(-0.001)$ & $(-0.002)$ & $(-0.002)$ \\
\hline \multirow{2}{*}{$\mathbf{X}_{\mathrm{DAY}}$} & -0.003 & 0.021 & 0.014 & 0.014 & . & -0.017 \\
\hline & $(-0.011)$ & $(-0.013)$ & $(-0.01)$ & $(-0.008)$ & . & $(-0.01)$ \\
\hline \multirow[t]{2}{*}{$\mathbf{Z}_{\mathrm{DAY}}$} & $0.0279^{*}$ & $0.0469 * *$ & -0.009 & -0.002 & 0.012 & $0.0437 * * *$ \\
\hline & $(-0.011)$ & $(-0.016)$ & $(-0.01)$ & $(-0.009)$ & $(-0.01)$ & $(-0.012)$ \\
\hline \multirow[t]{2}{*}{$\mathbf{X}_{\mathrm{DUQ}}$} & 0.020 & 0.001 & 0.007 & 0.009 & $0.0297 *$ & . \\
\hline & $(-0.013)$ & $(-0.021)$ & $(-0.013)$ & $(-0.01)$ & $(-0.012)$ & . \\
\hline \multirow[t]{2}{*}{$\mathbf{Z}_{\text {DUQ }}$} & $-0.0307^{*}$ & 0.027 & 0.007 & 0.009 & -0.014 & $-0.0330 * *$ \\
\hline & $(-0.013)$ & $(-0.016)$ & $(-0.011)$ & $(-0.01)$ & $(-0.012)$ & $(-0.012)$ \\
\hline \multirow[t]{2}{*}{ HDD $_{\mathrm{i}}$} & -0.298 & 0.831 & 0.782 & $1.284 * * *$ & $0.940 *$ & 0.860 \\
\hline & $(-0.438)$ & $(-0.723)$ & $(-0.437)$ & $(-0.286)$ & $(-0.464)$ & $(-0.446)$ \\
\hline \multirow[t]{2}{*}{$\mathrm{CDD}_{\mathrm{i}}$} & $1.467 * * *$ & $1.278 * * *$ & 0.235 & -0.080 & $0.629 * * *$ & $0.556 * * *$ \\
\hline & $(-0.145)$ & $(-0.284)$ & $(-0.145)$ & $(-0.105)$ & $(-0.161)$ & $(-0.148)$ \\
\hline \multirow[t]{2}{*}{ HDD $_{i}^{2}$} & $0.0744^{*}$ & 0.016 & 0.016 & -0.025 & 0.007 & 0.044 \\
\hline & $(-0.03)$ & $(-0.048)$ & $(-0.033)$ & $(-0.019)$ & $(-0.034)$ & $(-0.035)$ \\
\hline \multirow[t]{2}{*}{$\mathrm{CDD}_{\mathrm{i}}^{2}$} & $-0.0392 * * *$ & $-0.0441 * * *$ & $-0.00847 * * *$ & -0.002 & $-0.0190 * * *$ & $-0.0173 * * *$ \\
\hline & $(-0.002)$ & $(-0.004)$ & $(-0.002)$ & $(-0.002)$ & $(-0.002)$ & $(-0.002)$ \\
\hline \multirow[t]{2}{*}{$\mathbf{h}_{1}$} & . & . & . & . & . & . \\
\hline & . & . & . & . & . & . \\
\hline \multirow[t]{2}{*}{$\mathbf{h}_{2}$} & -0.039 & -1.569 & -2.426 & -1.443 & -1.302 & -2.288 \\
\hline & $(-2.322)$ & $(-4.011)$ & $(-2.216)$ & $(-1.913)$ & $(-2.603)$ & $(-2.835)$ \\
\hline \multirow[t]{2}{*}{$\mathbf{h}_{3}$} & -1.575 & -1.767 & -3.060 & -3.491 & -2.519 & -3.377 \\
\hline & $(-2.334)$ & $(-3.896)$ & $(-2.267)$ & $(-1.902)$ & $(-2.589)$ & $(-2.825)$ \\
\hline \multirow[t]{2}{*}{$\mathbf{h}_{4}$} & -2.234 & 0.062 & -4.103 & $-4.449 *$ & -3.095 & -4.147 \\
\hline & $(-2.332)$ & $(-3.916)$ & $(-2.248)$ & $(-1.893)$ & $(-2.577)$ & $(-2.773)$ \\
\hline $\mathbf{h}_{5}$ & -0.050 & 1.747 & -2.850 & -3.125 & -1.594 & -2.299 \\
\hline
\end{tabular}


Michael O'Conor

\begin{tabular}{|c|c|c|c|c|c|c|}
\hline & $(-2.295)$ & $(-3.967)$ & $(-2.24)$ & $(-1.885)$ & $(-2.561)$ & $(-2.736)$ \\
\hline \multirow[t]{2}{*}{$\mathbf{h}_{6}$} & 3.585 & 5.123 & 0.654 & -0.440 & 3.775 & 2.174 \\
\hline & $(-2.313)$ & $(-3.91)$ & $(-2.24)$ & $(-1.884)$ & $(-2.541)$ & $(-2.748)$ \\
\hline \multirow[t]{2}{*}{$\mathbf{h}_{7}$} & $18.74 * * *$ & $26.59 * * *$ & $14.59 * * *$ & $5.791 * *$ & $18.53 * * *$ & $17.61 * * *$ \\
\hline & $(-2.323)$ & $(-3.772)$ & $(-2.234)$ & $(-1.867)$ & $(-2.497)$ & $(-2.712)$ \\
\hline \multirow[t]{2}{*}{$\mathbf{h}_{8}$} & $14.91 * * *$ & $18.93 * * *$ & $11.88 * * *$ & $8.233 * * *$ & $14.69 * * *$ & $14.78 * * *$ \\
\hline & $(-2.354)$ & $(-3.789)$ & $(-2.3)$ & $(-1.859)$ & $(-2.538)$ & $(-2.727)$ \\
\hline \multirow[t]{2}{*}{$h_{9}$} & $9.388 * * *$ & $8.622 *$ & $7.503 * *$ & $7.543 * * *$ & $7.998 * *$ & $11.23 * * *$ \\
\hline & $(-2.401)$ & $(-3.801)$ & $(-2.35)$ & $(-1.9)$ & $(-2.561)$ & $(-2.77)$ \\
\hline \multirow[t]{2}{*}{$\mathbf{h}_{10}$} & $11.51 * * *$ & $12.91 * * *$ & $12.31 * * *$ & $11.45^{* * *}$ & $11.39 * * *$ & $11.31 * * *$ \\
\hline & $(-2.416)$ & $(-3.811)$ & $(-2.352)$ & $(-1.94)$ & $(-2.55)$ & $(-2.743)$ \\
\hline \multirow[t]{2}{*}{$\mathbf{h}_{11}$} & $13.18 * * *$ & $14.53 * * *$ & $13.72 * * *$ & $11.15^{* * *}$ & $12.27 * * *$ & $14.22 * * *$ \\
\hline & $(-2.403)$ & $(-3.874)$ & $(-2.353)$ & $(-1.927)$ & $(-2.568)$ & $(-2.776)$ \\
\hline \multirow[t]{2}{*}{$h_{12}$} & $15.30 * * *$ & $18.81 * * *$ & $14.86^{* * *}$ & $12.08 * * *$ & $13.70 * * *$ & $14.67 * * *$ \\
\hline & $(-2.441)$ & $(-3.844)$ & $(-2.385)$ & $(-1.908)$ & $(-2.558)$ & $(-2.807)$ \\
\hline \multirow[t]{2}{*}{$\mathbf{h}_{13}$} & $14.76^{* * *}$ & $17.12 * * *$ & $17.18 * * *$ & $12.29 * * *$ & $17.62 * * *$ & $15.14 * * *$ \\
\hline & $(-2.437)$ & $(-3.83)$ & $(-2.39)$ & $(-1.91)$ & $(-2.54)$ & $(-2.772)$ \\
\hline \multirow[t]{2}{*}{$h_{14}$} & $16.67 * * *$ & $23.97 * * *$ & $18.07 * * *$ & $14.12 * * *$ & $19.29 * * *$ & $16.09 * * *$ \\
\hline & $(-2.443)$ & $(-3.816)$ & $(-2.35)$ & $(-1.923)$ & $(-2.498)$ & $(-2.784)$ \\
\hline \multirow[t]{2}{*}{$\mathbf{h}_{15}$} & $13.00 * * *$ & $18.10 * * *$ & $12.84 * * *$ & $10.63 * * *$ & $14.68 * * *$ & $15.44 * * *$ \\
\hline & $(-2.449)$ & $(-3.819)$ & $(-2.338)$ & $(-1.924)$ & $(-2.469)$ & $(-2.836)$ \\
\hline \multirow[t]{2}{*}{$\mathbf{h}_{16}$} & $13.27 * * *$ & $20.29 * * *$ & $14.05 * * *$ & $11.92 * * *$ & $16.16^{* * *}$ & $13.70 * * *$ \\
\hline & $(-2.457)$ & $(-3.85)$ & $(-2.334)$ & $(-1.887)$ & $(-2.486)$ & $(-2.805)$ \\
\hline \multirow[t]{2}{*}{$\mathbf{h}_{17}$} & $17.60 * * *$ & $26.55^{* * *}$ & $22.08 * * *$ & $17.68 * * *$ & $19.65^{* * *}$ & $20.38 * * *$ \\
\hline & $(-2.436)$ & $(-3.782)$ & $(-2.31)$ & $(-1.879)$ & $(-2.467)$ & $(-2.815)$ \\
\hline \multirow[t]{2}{*}{$\mathbf{h}_{18}$} & $20.89 * * *$ & $30.56^{* * *}$ & $26.38 * * *$ & $20.34 * * *$ & $22.76^{* * *}$ & $27.35 * * *$ \\
\hline & $(-2.417)$ & $(-3.784)$ & $(-2.289)$ & $(-1.913)$ & $(-2.495)$ & $(-2.844)$ \\
\hline \multirow[t]{2}{*}{$\mathbf{h}_{19}$} & $17.34 * * *$ & $22.43 * * *$ & $18.51 * * *$ & $14.99 * * *$ & $16.92 * * *$ & $21.08 * * *$ \\
\hline & $(-2.451)$ & $(-3.806)$ & $(-2.291)$ & $(-1.905)$ & $(-2.488)$ & $(-2.833)$ \\
\hline \multirow[t]{2}{*}{$\mathbf{h}_{20}$} & $18.98 * * *$ & $20.02 * * *$ & $17.65 * * *$ & $17.12 * * *$ & $18.63^{* * *}$ & $22.17 * * *$ \\
\hline & $(-2.442)$ & $(-3.754)$ & $(-2.289)$ & $(-1.882)$ & $(-2.464)$ & $(-2.827)$ \\
\hline \multirow[t]{2}{*}{$\mathbf{h}_{21}$} & $18.47 * * *$ & $20.76^{* * *}$ & $17.25 * * *$ & $16.35^{* * *}$ & $17.79 * * *$ & $20.73 * * *$ \\
\hline & $(-2.479)$ & $(-3.848)$ & $(-2.359)$ & $(-1.936)$ & $(-2.491)$ & $(-2.895)$ \\
\hline \multirow[t]{2}{*}{$\mathbf{h}_{22}$} & $14.56 * * *$ & $17.21 * * *$ & $13.72 * * *$ & $12.20 * * *$ & $12.95 * * *$ & $18.40 * * *$ \\
\hline & $(-2.487)$ & $(-3.892)$ & $(-2.356)$ & $(-1.947)$ & $(-2.552)$ & $(-2.912)$ \\
\hline \multirow[t]{2}{*}{$\mathbf{h}_{23}$} & 3.339 & 5.553 & 3.397 & $4.416^{*}$ & 3.600 & 3.786 \\
\hline & $(-2.514)$ & $(-3.924)$ & $(-2.34)$ & $(-1.947)$ & $(-2.575)$ & $(-2.965)$ \\
\hline \multirow[t]{2}{*}{$\mathbf{h}_{24}$} & 0.257 & 0.626 & -0.226 & 0.230 & 0.911 & -0.536 \\
\hline & $(-2.51)$ & $(-3.898)$ & $(-2.341)$ & $(-1.952)$ & $(-2.574)$ & $(-2.974)$ \\
\hline \multirow[t]{2}{*}{$d_{1}$} & 2.386 & 1.313 & 0.943 & -0.644 & 2.069 & -2.268 \\
\hline & $(-1.403)$ & $(-2.058)$ & $(-1.311)$ & $(-1.081)$ & $(-1.319)$ & $(-1.47)$ \\
\hline \multirow[t]{2}{*}{$\mathbf{d}_{2}$} & -1.478 & -3.010 & -1.289 & $-3.676^{* * *}$ & -1.191 & -2.273 \\
\hline & $(-1.422)$ & $(-2.01)$ & $(-1.243)$ & $(-1.004)$ & $(-1.33)$ & $(-1.467)$ \\
\hline \multirow[t]{2}{*}{$\mathbf{d}_{\mathbf{3}}$} & . & . & . & . & . & . \\
\hline & 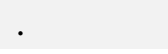 & . & . & . & . & . \\
\hline
\end{tabular}


Michael O'Conor

\begin{tabular}{|c|c|c|c|c|c|c|}
\hline \multirow[t]{2}{*}{$\mathrm{d}_{4}$} & $2.887^{*}$ & 1.514 & 1.107 & $2.701 * *$ & $4.686^{* * *}$ & $6.878 * * *$ \\
\hline & $(-1.406)$ & $(-2.051)$ & $(-1.327)$ & $(-1.04)$ & $(-1.311)$ & $(-1.444)$ \\
\hline \multirow[t]{2}{*}{$d_{5}$} & 1.585 & 0.650 & 0.727 & -0.010 & $2.655^{*}$ & 2.052 \\
\hline & $(-1.332)$ & $(-2.006)$ & $(-1.288)$ & $(-1.068)$ & $(-1.305)$ & $(-1.422)$ \\
\hline \multirow[t]{2}{*}{$d_{6}$} & 1.232 & 3.268 & -1.183 & -0.069 & 1.061 & $-4.740 * *$ \\
\hline & $(-1.329)$ & $(-1.993)$ & $(-1.253)$ & $(-1.021)$ & $(-1.386)$ & $(-1.488)$ \\
\hline \multirow[t]{2}{*}{$\mathbf{d}_{7}$} & $-2.830 *$ & $-5.101 *$ & $-6.743 * * *$ & $-5.159 * * *$ & -2.761 & $-8.430 * * *$ \\
\hline & $(-1.385)$ & $(-2.105)$ & $(-1.303)$ & $(-1.037)$ & $(-1.453)$ & $(-1.607)$ \\
\hline \multirow[t]{2}{*}{$\mathbf{m}_{1}$} & $-11.31 * * *$ & $-11.93 * * *$ & $-8.847 * * *$ & $-7.565 * * *$ & $-13.82 * * *$ & -2.427 \\
\hline & $(-1.73)$ & $(-2.591)$ & $(-1.8)$ & $(-1.698)$ & $(-1.861)$ & $(-1.912)$ \\
\hline \multirow[t]{2}{*}{$\mathbf{m}_{2}$} & $7.181 * * *$ & $19.88 * * *$ & $8.221 * * *$ & $7.960 * * *$ & -3.312 & $-10.38 * * *$ \\
\hline & $(-2.181)$ & $(-3.218)$ & $(-2.393)$ & $(-1.795)$ & $(-1.994)$ & $(-2.383)$ \\
\hline \multirow[t]{2}{*}{$\mathbf{m}_{3}$} & 2.411 & $13.04 * * *$ & $3.919 *$ & 1.313 & 0.765 & $5.136 * *$ \\
\hline & $(-1.617)$ & $(-2.443)$ & $(-1.749)$ & $(-1.43)$ & $(-1.793)$ & $(-1.873)$ \\
\hline \multirow[t]{2}{*}{$\mathbf{m}_{4}$} & -2.396 & 4.141 & 0.222 & -2.950 & -1.710 & -2.357 \\
\hline & $(-2.126)$ & $(-3.815)$ & $(-1.988)$ & $(-1.659)$ & $(-2.378)$ & $(-2.505)$ \\
\hline \multirow[t]{2}{*}{$\mathbf{m}_{5}$} & $-7.182 * *$ & -0.564 & -2.546 & -3.660 & $-10.47 * * *$ & -2.426 \\
\hline & $(-2.68)$ & $(-5.34)$ & $(-2.663)$ & $(-1.957)$ & $(-3.063)$ & $(-2.751)$ \\
\hline \multirow[t]{2}{*}{$\mathbf{m}_{6}$} & -4.632 & 3.560 & 2.234 & 3.030 & 0.639 & 1.942 \\
\hline & $(-2.987)$ & $(-5.407)$ & $(-2.873)$ & $(-2.278)$ & $(-3.188)$ & $(-3.207)$ \\
\hline \multirow[t]{2}{*}{$\mathbf{m}_{7}$} & $-10.54 * * *$ & -5.278 & -2.886 & -0.726 & $-6.702 *$ & $-7.144 *$ \\
\hline & $(-3.136)$ & $(-5.531)$ & $(-2.927)$ & $(-2.316)$ & $(-3.264)$ & $(-3.246)$ \\
\hline \multirow[t]{2}{*}{$\mathbf{m}_{8}$} & $-14.64 * * *$ & -7.801 & $-5.823^{*}$ & $-5.515^{*}$ & $-12.17 * * *$ & $-8.841 * *$ \\
\hline & $(-3.041)$ & $(-5.565)$ & $(-2.964)$ & $(-2.37)$ & $(-3.271)$ & $(-3.306)$ \\
\hline \multirow[t]{2}{*}{$\mathbf{m}_{9}$} & $-7.453^{*}$ & -2.657 & 0.508 & 1.663 & -3.087 & -3.111 \\
\hline & $(-3.09)$ & $(-5.302)$ & $(-2.799)$ & $(-2.285)$ & $(-3.27)$ & $(-3.065)$ \\
\hline \multirow[t]{2}{*}{$\mathbf{m}_{10}$} & $6.588 * *$ & $8.430 *$ & $5.998 *$ & $6.077 * * *$ & 2.107 & $5.798 *$ \\
\hline & $(-2.076)$ & $(-3.874)$ & $(-2.343)$ & $(-1.597)$ & $(-2.267)$ & $(-2.286)$ \\
\hline \multirow[t]{2}{*}{$\mathbf{m}_{11}$} & 1.432 & -4.225 & 2.346 & $4.731 * * *$ & 1.001 & $5.328 * *$ \\
\hline & $(-1.687)$ & $(-3.015)$ & $(-1.674)$ & $(-1.297)$ & $(-1.895)$ & $(-1.957)$ \\
\hline \multirow[t]{2}{*}{$\mathbf{m}_{12}$} & . & . & . & . & . & . \\
\hline & . & . & . & . & . & . \\
\hline \multirow[t]{2}{*}{ intercept } & $30.43 * * *$ & $20.82 * * *$ & $25.41 * * *$ & $20.25 * * *$ & $26.11 * * *$ & $22.63 * * *$ \\
\hline & $(-3.372)$ & $(-5.965)$ & $(-3.512)$ & $(-2.683)$ & $(-3.846)$ & $(-3.822)$ \\
\hline R-SQ & 0.314 & 0.358 & 0.268 & 0.275 & 0.283 & 0.241 \\
\hline ADJ R-SQ & 0.305 & 0.346 & 0.260 & 0.263 & 0.269 & 0.229 \\
\hline AIC & 37355.800 & 28263.800 & 29851.400 & 28380.600 & 24605.600 & 34258.200 \\
\hline BIC & 37709.800 & 28599.500 & 30194.700 & 28723.700 & 24938.600 & 34606.800 \\
\hline F-TEST & 33.720 & 29.440 & 22.240 & 22.980 & 19.910 & 21.200 \\
\hline $\mathbf{N}$ & 4106 & 2966 & 3398 & 3389 & 2829 & 3732 \\
\hline
\end{tabular}


Table 9: Post-Retirement with Under-Predicted Consumption Regression Model

\begin{tabular}{|c|c|c|c|c|c|c|}
\hline & AEP & APS & ATSI & COMED & DAY & DUQ \\
\hline \multirow[t]{2}{*}{$\mathbf{X}_{\mathrm{AEP}}$} & . & 0.002 & 0.001 & 0.000 & -0.001 & $0.00486^{*}$ \\
\hline & . & $(-0.003)$ & $(-0.001)$ & $(-0.001)$ & $(-0.002)$ & $(-0.002)$ \\
\hline \multirow{2}{*}{$\mathbf{Z}_{\mathrm{AEP}}$} & -0.002 & -0.003 & $-0.00323 * *$ & -0.002 & -0.001 & -0.003 \\
\hline & $(-0.001)$ & $(-0.002)$ & $(-0.001)$ & $(-0.001)$ & $(-0.001)$ & $(-0.002)$ \\
\hline \multirow[t]{2}{*}{$\mathbf{X}_{\mathrm{APS}}$} & $-0.00757^{*}$ & . & $-0.00940 * * *$ & $-0.0109 * * *$ & $-0.0133 * * *$ & $-0.00911^{*}$ \\
\hline & $(-0.004)$ & . & $(-0.002)$ & $(-0.002)$ & $(-0.003)$ & $(-0.005)$ \\
\hline \multirow[t]{2}{*}{$\mathbf{Z}_{\mathrm{APS}}$} & -0.004 & $-0.0111^{*}$ & $-0.00640 *$ & 0.001 & 0.007 & -0.001 \\
\hline & $(-0.004)$ & $(-0.005)$ & $(-0.003)$ & $(-0.003)$ & $(-0.004)$ & $(-0.005)$ \\
\hline \multirow[t]{2}{*}{$\mathbf{X}_{\mathrm{ATSI}}$} & 0.002 & -0.002 & . & $0.00806^{* *}$ & -0.003 & -0.009 \\
\hline & $(-0.005)$ & $(-0.006)$ & . & $(-0.003)$ & $(-0.005)$ & $(-0.006)$ \\
\hline \multirow[t]{2}{*}{$\mathbf{Z}_{\mathrm{ATSI}}$} & $-0.0121 * * *$ & -0.005 & $-0.00515 * * *$ & -0.001 & $-0.0131 * * *$ & $-0.00867 * *$ \\
\hline & $(-0.003)$ & $(-0.003)$ & $(-0.001)$ & $(-0.002)$ & $(-0.002)$ & $(-0.003)$ \\
\hline \multirow[t]{2}{*}{$\mathbf{X}_{\text {COMED }}$} & -0.001 & -0.003 & 0.001 & . & 0.000 & -0.003 \\
\hline & $(-0.001)$ & $(-0.002)$ & $(-0.001)$ & . & $(-0.002)$ & $(-0.001)$ \\
\hline \multirow{2}{*}{$\mathbf{Z}_{\text {COMED }}$} & 0.001 & 0.003 & 0.002 & $-0.00206^{*}$ & 0.001 & $0.00367 *$ \\
\hline & $(-0.001)$ & $(-0.002)$ & $(-0.001)$ & $(-0.001)$ & $(-0.001)$ & $(-0.002)$ \\
\hline \multirow[t]{2}{*}{$\mathbf{X}_{\mathbf{D A Y}}$} & 0.000 & -0.021 & -0.010 & -0.009 & . & $-0.0193^{*}$ \\
\hline & $(-0.011)$ & $(-0.012)$ & $(-0.006)$ & $(-0.006)$ & . & $(-0.01)$ \\
\hline \multirow[t]{2}{*}{$\mathbf{Z}_{\mathrm{DAY}}$} & $-0.0206^{*}$ & -0.019 & $-0.0277 * * *$ & $-0.0264 * * *$ & $-0.0176^{*}$ & $-0.0269 * *$ \\
\hline & $(-0.008)$ & $(-0.011)$ & $(-0.006)$ & $(-0.006)$ & $(-0.008)$ & $(-0.009)$ \\
\hline \multirow[t]{2}{*}{$\mathbf{X}_{\mathrm{DUQ}}$} & -0.018 & -0.018 & -0.002 & -0.005 & -0.001 & . \\
\hline & $(-0.011)$ & $(-0.018)$ & $(-0.006)$ & $(-0.007)$ & $(-0.011)$ & . \\
\hline \multirow[t]{2}{*}{$\mathbf{Z}_{\mathrm{DUQ}}$} & 0.014 & 0.018 & 0.003 & -0.007 & 0.006 & $0.0261 * *$ \\
\hline & $(-0.012)$ & $(-0.012)$ & $(-0.009)$ & $(-0.01)$ & $(-0.009)$ & $(-0.009)$ \\
\hline \multirow[t]{2}{*}{ HDD $_{i}$} & 0.659 & -0.283 & 0.485 & $0.755^{* *}$ & 0.461 & $1.492 * *$ \\
\hline & $(-0.39)$ & $(-0.491)$ & $(-0.273)$ & $(-0.241)$ & $(-0.416)$ & $(-0.535)$ \\
\hline \multirow[t]{2}{*}{$\mathrm{CDD}_{\mathrm{i}}$} & -0.134 & 0.229 & 0.119 & -0.081 & -0.050 & 0.101 \\
\hline & $(-0.147)$ & $(-0.181)$ & $(-0.069)$ & $(-0.075)$ & $(-0.113)$ & $(-0.255)$ \\
\hline \multirow[t]{2}{*}{ HDD $_{i}^{2}$} & -0.003 & $0.0957 * *$ & 0.030 & -0.014 & 0.052 & -0.025 \\
\hline & $(-0.024)$ & $(-0.031)$ & $(-0.019)$ & $(-0.015)$ & $(-0.028)$ & $(-0.036)$ \\
\hline \multirow[t]{2}{*}{$\mathrm{CDD}_{\mathrm{i}}^{2}$} & 0.001 & $-0.0125^{* * *}$ & $-0.00609 * * *$ & 0.000 & -0.003 & -0.010 \\
\hline & $(-0.003)$ & $(-0.004)$ & $(-0.001)$ & $(-0.001)$ & $(-0.002)$ & $(-0.006)$ \\
\hline \multirow[t]{2}{*}{$\mathbf{h}_{1}$} & . & . & . & . & . & . \\
\hline & . & . & . & . & . & . \\
\hline \multirow[t]{2}{*}{$\mathbf{h}_{2}$} & -1.134 & -3.033 & -0.961 & -1.589 & -0.872 & -1.685 \\
\hline & $(-2.279)$ & $(-3.413)$ & $(-1.331)$ & $(-1.613)$ & $(-2.326)$ & $(-3.388)$ \\
\hline \multirow[t]{2}{*}{$\mathbf{h}_{3}$} & -2.237 & -3.230 & -1.805 & -2.619 & -1.865 & -3.747 \\
\hline & $(-2.255)$ & $(-3.321)$ & $(-1.339)$ & $(-1.589)$ & $(-2.314)$ & $(-3.462)$ \\
\hline \multirow[t]{2}{*}{$\mathbf{h}_{4}$} & -2.738 & -4.838 & -2.454 & $-3.224 *$ & -2.205 & -4.923 \\
\hline & $(-2.224)$ & $(-3.358)$ & $(-1.339)$ & $(-1.599)$ & $(-2.316)$ & $(-3.363)$ \\
\hline $\mathbf{h}_{5}$ & -1.722 & -4.217 & -1.921 & -2.264 & -1.603 & -4.561 \\
\hline
\end{tabular}


Michael O'Conor

\begin{tabular}{|c|c|c|c|c|c|c|}
\hline & $(-2.247)$ & $(-3.29)$ & $(-1.33)$ & $(-1.583)$ & $(-2.358)$ & $(-3.323)$ \\
\hline \multirow[t]{2}{*}{$\mathbf{h}_{6}$} & 1.800 & 0.951 & 1.716 & -0.724 & 1.457 & -1.915 \\
\hline & $(-2.242)$ & $(-3.322)$ & $(-1.34)$ & $(-1.596)$ & $(-2.335)$ & $(-3.307)$ \\
\hline \multirow[t]{2}{*}{$\mathbf{h}_{7}$} & $10.18 * * *$ & $12.58 * * *$ & $9.217 * * *$ & $6.541 * * *$ & $13.58 * * *$ & 1.479 \\
\hline & $(-2.29)$ & $(-3.269)$ & $(-1.333)$ & $(-1.567)$ & $(-2.273)$ & $(-3.26)$ \\
\hline \multirow[t]{2}{*}{$\mathbf{h}_{8}$} & $6.747 * *$ & $6.964^{*}$ & $7.708 * * *$ & $6.915^{* * *}$ & $8.502 * * *$ & 3.021 \\
\hline & $(-2.267)$ & $(-3.342)$ & $(-1.331)$ & $(-1.555)$ & $(-2.338)$ & $(-3.21)$ \\
\hline \multirow[t]{2}{*}{$h_{9}$} & $7.331 * *$ & $8.408^{*}$ & $7.453 * * *$ & $6.627 * * *$ & $7.205^{* *}$ & 4.316 \\
\hline & $(-2.312)$ & $(-3.4)$ & $(-1.351)$ & $(-1.56)$ & $(-2.4)$ & $(-3.312)$ \\
\hline \multirow[t]{2}{*}{$\mathbf{h}_{10}$} & $9.956 * * *$ & $8.207 *$ & $9.212 * * *$ & $10.25^{* * *}$ & $9.998 * * *$ & $7.079 *$ \\
\hline & $(-2.334)$ & $(-3.422)$ & $(-1.359)$ & $(-1.591)$ & $(-2.393)$ & $(-3.292)$ \\
\hline \multirow[t]{2}{*}{$\mathbf{h}_{11}$} & $10.83 * * *$ & $9.665 * *$ & $9.549 * * *$ & $9.965 * * *$ & $10.57 * * *$ & $10.19 * *$ \\
\hline & $(-2.363)$ & $(-3.444)$ & $(-1.367)$ & $(-1.596)$ & $(-2.363)$ & $(-3.241)$ \\
\hline \multirow[t]{2}{*}{$\mathbf{h}_{12}$} & $13.26 * * *$ & $9.894 * *$ & $10.49 * * *$ & $11.54 * * *$ & $10.74 * * *$ & $11.41 * * *$ \\
\hline & $(-2.36)$ & $(-3.347)$ & $(-1.365)$ & $(-1.593)$ & $(-2.34)$ & $(-3.248)$ \\
\hline \multirow[t]{2}{*}{$\mathbf{h}_{13}$} & $13.82 * * *$ & $11.75 * * *$ & $10.78 * * *$ & $12.48 * * *$ & $12.39 * * *$ & $15.78 * * *$ \\
\hline & $(-2.311)$ & $(-3.356)$ & $(-1.372)$ & $(-1.615)$ & $(-2.311)$ & $(-3.292)$ \\
\hline \multirow[t]{2}{*}{$\mathbf{h}_{14}$} & $14.74 * * *$ & $16.07 * * *$ & $11.61 * * *$ & $12.29 * * *$ & $13.30 * * *$ & $18.83 * * *$ \\
\hline & $(-2.309)$ & $(-3.338)$ & $(-1.367)$ & $(-1.598)$ & $(-2.261)$ & $(-3.225)$ \\
\hline \multirow[t]{2}{*}{$\mathbf{h}_{15}$} & $18.14 * * *$ & $16.64 * * *$ & $12.49 * * *$ & $10.41 * * *$ & $14.76^{* * * *}$ & $22.78 * * *$ \\
\hline & $(-2.303)$ & $(-3.356)$ & $(-1.361)$ & $(-1.591)$ & $(-2.305)$ & $(-3.282)$ \\
\hline \multirow[t]{2}{*}{$h_{16}$} & $19.74 * * *$ & $16.92 * * *$ & $11.89 * * *$ & $13.63 * * *$ & $15.41 * * *$ & $21.19 * * *$ \\
\hline & $(-2.326)$ & $(-3.303)$ & $(-1.374)$ & $(-1.582)$ & $(-2.288)$ & $(-3.234)$ \\
\hline \multirow[t]{2}{*}{$\mathbf{h}_{17}$} & $23.53 * * *$ & $25.69 * * *$ & $15.57 * * *$ & $14.69 * * *$ & $21.19 * * *$ & $27.24 * * *$ \\
\hline & $(-2.327)$ & $(-3.256)$ & $(-1.379)$ & $(-1.579)$ & $(-2.291)$ & $(-3.211)$ \\
\hline \multirow[t]{2}{*}{$\mathbf{h}_{18}$} & $22.97 * * *$ & $22.78 * * *$ & $16.44 * * *$ & $18.09 * * *$ & $19.90 * * *$ & $25.42 * * *$ \\
\hline & $(-2.328)$ & $(-3.225)$ & $(-1.376)$ & $(-1.571)$ & $(-2.273)$ & $(-3.154)$ \\
\hline \multirow[t]{2}{*}{$\mathbf{h}_{19}$} & $17.61 * * *$ & $17.60 * * *$ & $12.47 * * *$ & $12.25^{* * *}$ & $14.25^{* * *}$ & $17.22 * * *$ \\
\hline & $(-2.364)$ & $(-3.264)$ & $(-1.367)$ & $(-1.572)$ & $(-2.306)$ & $(-3.179)$ \\
\hline \multirow[t]{2}{*}{$\mathbf{h}_{20}$} & $17.37 * * *$ & $19.06 * * *$ & $13.29 * * *$ & $14.13 * * *$ & $15.64 * * *$ & $18.12 * * *$ \\
\hline & $(-2.358)$ & $(-3.27)$ & $(-1.359)$ & $(-1.572)$ & $(-2.299)$ & $(-3.182)$ \\
\hline \multirow[t]{2}{*}{$\mathbf{h}_{21}$} & $14.30 * * *$ & $14.63 * * *$ & $12.10 * * *$ & $13.00 * * *$ & $13.17 * * *$ & $14.48 * * *$ \\
\hline & $(-2.415)$ & $(-3.332)$ & $(-1.369)$ & $(-1.614)$ & $(-2.364)$ & $(-3.223)$ \\
\hline \multirow[t]{2}{*}{$\mathbf{h}_{22}$} & $10.90 * * *$ & $12.19 * * *$ & $9.239 * * *$ & $9.562 * * *$ & $9.532 * * *$ & $11.25^{* * *}$ \\
\hline & $(-2.397)$ & $(-3.426)$ & $(-1.38)$ & $(-1.626)$ & $(-2.408)$ & $(-3.323)$ \\
\hline \multirow[t]{2}{*}{$\mathbf{h}_{23}$} & 4.657 & 4.354 & $3.469 *$ & $4.379 * *$ & 3.584 & 4.253 \\
\hline & $(-2.384)$ & $(-3.487)$ & $(-1.365)$ & $(-1.653)$ & $(-2.415)$ & $(-3.36)$ \\
\hline \multirow[t]{2}{*}{$\mathbf{h}_{24}$} & 1.987 & 0.891 & 0.993 & 1.365 & 0.770 & 1.178 \\
\hline & $(-2.349)$ & $(-3.52)$ & $(-1.363)$ & $(-1.655)$ & $(-2.376)$ & $(-3.45)$ \\
\hline \multirow[t]{2}{*}{$d_{1}$} & 1.606 & 1.006 & $1.671 *$ & -0.163 & 0.593 & 2.350 \\
\hline & $(-1.245)$ & $(-1.679)$ & $(-0.755)$ & $(-0.867)$ & $(-1.278)$ & $(-1.891)$ \\
\hline \multirow[t]{2}{*}{$d_{2}$} & 1.087 & -0.555 & 0.562 & 1.084 & -2.051 & 1.403 \\
\hline & $(-1.238)$ & $(-1.712)$ & $(-0.744)$ & $(-0.84)$ & $(-1.223)$ & $(-1.811)$ \\
\hline \multirow[t]{2}{*}{$\mathbf{d}_{3}$} & . & . & . & . & . & . \\
\hline & & . & ${ }^{\circ}$ & . & . & . \\
\hline
\end{tabular}


Michael O'Conor

\begin{tabular}{|c|c|c|c|c|c|c|}
\hline \multirow[t]{2}{*}{$d_{4}$} & -2.204 & $-4.497 *$ & -0.309 & 0.832 & -1.636 & -2.471 \\
\hline & $(-1.28)$ & $(-1.829)$ & $(-0.761)$ & $(-0.872)$ & $(-1.249)$ & $(-1.876)$ \\
\hline \multirow[t]{2}{*}{$d_{5}$} & $-4.241 * * *$ & $-5.816 * *$ & $-1.609 *$ & -1.499 & $-2.836^{*}$ & $-5.526 * *$ \\
\hline & $(-1.278)$ & $(-1.813)$ & $(-0.76)$ & $(-0.901)$ & $(-1.254)$ & $(-1.862)$ \\
\hline \multirow[t]{2}{*}{$d_{6}$} & $-5.522 * * *$ & $-6.005 * *$ & $-3.298 * * *$ & $-2.267 *$ & $-6.521 * * *$ & $-5.635 * *$ \\
\hline & $(-1.494)$ & $(-1.909)$ & $(-0.79)$ & $(-0.911)$ & $(-1.491)$ & $(-1.815)$ \\
\hline \multirow[t]{2}{*}{$\mathbf{d}_{7}$} & $-8.787 * * *$ & $-7.954 * * *$ & $-5.830 * * *$ & $-5.074 * * *$ & $-7.202 * * *$ & $-7.537 * * *$ \\
\hline & $(-1.33)$ & $(-1.715)$ & $(-0.743)$ & $(-0.843)$ & $(-1.304)$ & $(-1.847)$ \\
\hline \multirow[t]{2}{*}{$\mathbf{m}_{1}$} & 1.572 & -1.887 & $-2.564 *$ & -2.061 & $-9.189 * * *$ & $-11.44 * *$ \\
\hline & $(-2.259)$ & $(-3.383)$ & $(-1.23)$ & $(-1.432)$ & $(-2.105)$ & $(-3.612)$ \\
\hline \multirow[t]{2}{*}{$\mathbf{m}_{2}$} & -2.514 & -3.165 & $-4.681 * * *$ & -0.692 & $-11.05^{* * *}$ & $-16.59 * *$ \\
\hline & $(-2.441)$ & $(-3.087)$ & $(-1.26)$ & $(-1.458)$ & $(-2.214)$ & $(-6.352)$ \\
\hline \multirow[t]{2}{*}{$\mathbf{m}_{3}$} & $-6.427 *$ & -2.908 & $-3.247 * *$ & -2.596 & $-9.236 * * *$ & $-12.26^{* *}$ \\
\hline & $(-2.537)$ & $(-2.709)$ & $(-1.161)$ & $(-1.404)$ & $(-2.115)$ & $(-3.876)$ \\
\hline \multirow[t]{2}{*}{$\mathbf{m}_{4}$} & -1.916 & 5.231 & $3.267 * *$ & -0.758 & -2.060 & -6.449 \\
\hline & $(-2.37)$ & $(-2.886)$ & $(-1.164)$ & $(-1.285)$ & $(-1.944)$ & $(-4.593)$ \\
\hline \multirow[t]{2}{*}{$\mathbf{m}_{5}$} & -5.754 & -1.999 & $-3.839 * *$ & $-3.174 *$ & $-8.452 * * *$ & -3.869 \\
\hline & $(-3.184)$ & $(-2.927)$ & $(-1.191)$ & $(-1.379)$ & $(-2.053)$ & $(-4.3)$ \\
\hline \multirow[t]{2}{*}{$\mathbf{m}_{6}$} & 1.713 & 1.587 & -0.244 & 0.789 & -2.043 & 1.682 \\
\hline & $(-2.629)$ & $(-2.986)$ & $(-1.515)$ & $(-1.538)$ & $(-2.578)$ & $(-3.814)$ \\
\hline \multirow[t]{2}{*}{$\mathbf{m}_{7}$} & 4.225 & 2.823 & 2.345 & 2.524 & -2.517 & 0.952 \\
\hline & $(-2.719)$ & $(-3.174)$ & $(-1.599)$ & $(-1.677)$ & $(-2.537)$ & $(-3.824)$ \\
\hline \multirow[t]{2}{*}{$\mathbf{m}_{8}$} & 1.081 & -2.211 & -3.019 & 0.792 & -2.020 & -2.193 \\
\hline & $(-2.614)$ & $(-3.172)$ & $(-1.543)$ & $(-1.659)$ & $(-2.458)$ & $(-4.004)$ \\
\hline \multirow[t]{2}{*}{$\mathbf{m}_{9}$} & 4.206 & $6.779 *$ & 2.346 & $3.992 * *$ & -0.986 & $9.087 *$ \\
\hline & $(-2.397)$ & $(-3.083)$ & $(-1.464)$ & $(-1.46)$ & $(-2.382)$ & $(-3.744)$ \\
\hline \multirow[t]{2}{*}{$\mathbf{m}_{10}$} & $6.475^{* * *}$ & $6.935 * *$ & $3.248^{*}$ & 1.168 & 0.116 & 4.749 \\
\hline & $(-1.883)$ & $(-2.298)$ & $(-1.316)$ & $(-1.245)$ & $(-2.116)$ & $(-3.787)$ \\
\hline \multirow[t]{2}{*}{$\mathbf{m}_{11}$} & 2.081 & 0.879 & 0.503 & 2.088 & $-4.467 *$ & 1.897 \\
\hline & $(-1.732)$ & $(-2.616)$ & $(-1.335)$ & $(-1.116)$ & $(-2.096)$ & $(-2.467)$ \\
\hline \multirow[t]{2}{*}{$\mathbf{m}_{12}$} & . & . & . & . & . & . \\
\hline & . & . & . & . & . & . \\
\hline \multirow[t]{2}{*}{$\alpha$} & $15.82 * * *$ & $18.55^{* * *}$ & $19.14 * * *$ & $16.38 * * *$ & $21.57 * * *$ & $16.43 * * *$ \\
\hline & $(-2.799)$ & $(-3.848)$ & $(-1.604)$ & $(-1.815)$ & $(-2.775)$ & $(-4.614)$ \\
\hline R-SQ & 0.235 & 0.232 & 0.257 & 0.285 & 0.235 & 0.292 \\
\hline ADJ R-SQ & 0.221 & 0.212 & 0.250 & 0.274 & 0.221 & 0.271 \\
\hline AIC & 27483.000 & 19587.300 & 47628.000 & 30023.000 & 26927.200 & 17114.600 \\
\hline BIC & 27822.200 & 19905.900 & 48000.900 & 30371.400 & 27265.400 & 17426.500 \\
\hline F-TEST & 17.380 & 11.700 & 35.870 & 26.620 & 17.010 & 14.100 \\
\hline $\mathbf{N}$ & 3161 & 2185 & 5769 & 3723 & 3101 & 1939 \\
\hline
\end{tabular}


Table 10: Pre-Retirement with Over-Predicted Consumption Correlation

\begin{tabular}{|lcccccc|c|}
\hline & AEP & APS & ATSI & COMED & DAY & DUQ & Average \\
AEP & 1.000 & 0.457 & 0.504 & 0.304 & 0.550 & 0.301 & 0.432 \\
APS & & 1.000 & 0.367 & 0.153 & 0.360 & 0.395 & 0.346 \\
ATSI & & & 1.000 & 0.294 & 0.538 & 0.392 & 0.419 \\
COMED & & & & 1.000 & 0.361 & 0.197 & 0.262 \\
DAY & & & & & 1.000 & 0.284 & 0.419 \\
DUQ & & & & & & 1.000 & 0.314 \\
\hline
\end{tabular}

Table 11: Pre-Retirement with Under-Predicted Consumption Correlation

\begin{tabular}{|lcccccc|c|}
\hline & AEP & APS & ATSI & COMED & DAY & DUQ & Average \\
AEP & 1.000 & 0.563 & 0.518 & 0.365 & 0.510 & 0.448 & 0.481 \\
APS & & 1.000 & 0.456 & 0.295 & 0.446 & 0.505 & 0.453 \\
ATSI & & & 1.000 & 0.459 & 0.564 & 0.506 & 0.501 \\
COMED & & & & 1.000 & 0.432 & 0.351 & 0.380 \\
DAY & & & & & 1.000 & 0.450 & 0.480 \\
DUQ & & & & & & 1.000 & 0.452 \\
\hline
\end{tabular}

Table 12: Post-Retirement with Over-Predicted Consumption Correlation

\begin{tabular}{|lccrrrr|c|}
\hline & AEP & \multicolumn{1}{c}{ APS } & \multicolumn{1}{c}{ ATSI } & COMED & \multicolumn{1}{c}{ DAY } & \multicolumn{1}{c|}{ DUQ } & Average \\
AEP & 1.000 & 0.478 & 0.292 & 0.244 & 0.472 & 0.392 & 0.376 \\
APS & & 1.000 & 0.322 & 0.155 & 0.381 & 0.450 & 0.357 \\
ATSI & & & 1.000 & 0.316 & 0.525 & 0.275 & 0.346 \\
COMED & & & & 1.000 & 0.317 & 0.143 & 0.235 \\
DAY & & & & & 1.000 & 0.276 & 0.394 \\
DUQ & & & & & & 1.000 & 0.307 \\
\hline
\end{tabular}

Table 13: Post-Retirement with Under-Predicted Consumption Correlation

\begin{tabular}{|lcccccc|c|}
\hline & AEP & APS & ATSI & COMED & DAY & DUQ & Average \\
AEP & 1.000 & 0.466 & 0.205 & 0.403 & 0.300 & 0.246 & 0.324 \\
APS & & 1.000 & 0.249 & 0.207 & 0.292 & 0.346 & 0.312 \\
ATSI & & & 1.000 & 0.227 & 0.243 & 0.088 & 0.202 \\
COMED & & & & 1.000 & 0.267 & 0.167 & 0.254 \\
DAY & & & & & 1.000 & 0.697 & 0.360 \\
DUQ & & & & & & 1.000 & 0.309 \\
\hline
\end{tabular}


Table 14: Structural Break Chow Test Caused by Capacity Retirement

\begin{tabular}{|l|rrrrrr|}
\hline & AEP & APS & ATSI & COMED & DAY & DUQ \\
RSS $_{\mathrm{P}}$ & 5545697.88 & 7383710.09 & 5582167.77 & 4599496.13 & 5386662.79 & 5559016.32 \\
$\mathrm{RSS}_{1}$ & 3370733.72 & 4730727.30 & 3541527.60 & 2912172.70 & 3230878.42 & 3594620.77 \\
$\mathrm{RSS}_{2}$ & 1865012.06 & 2092201.61 & 1791994.06 & 1474580.50 & 1910876.88 & 1774784.42 \\
$\mathrm{k}$ & 57 & 57 & 57 & 57 & 57 & 57 \\
$\mathrm{n}$ & 17568 & 17568 & 17568 & 17568 & 17568 & 17568 \\
& & & & & & \\
F-test & 18.13 & 25.17 & 14.28 & 14.85 & 14.59 & 10.81 \\
\hline
\end{tabular}

F-Critical at $1 \%=1.49,5 \%=1.33,10 \%=1.25$ 
Table 15: Structural Break Chow Test Caused by Predicted Consumption

Over-Predicting Consumption during Pre-Retirement

\begin{tabular}{|l|rrrrrr|}
\hline & \multicolumn{1}{|c}{ AEP } & \multicolumn{1}{c}{ APS } & \multicolumn{1}{c|}{ ATSI } & COMED & DAY & DUQ \\
RSS $_{\text {P }}$ & 3197002.13 & 4558086.66 & 3368245.70 & 2638665.70 & 3052150.25 & 3286498.96 \\
RSS $_{\text {pos }}$ & 1017836.1 & 2100543.47 & 1998923.43 & 1731689.57 & 1958841.26 & 1092762.93 \\
RSS $_{\text {nonpos }}$ & 2090546.39 & 2300409.85 & 1258073.06 & 832078.35 & 984883.80 & 2056241.17 \\
$\mathrm{~K}$ & 57 & 57 & 57 & 57 & 57 & 57 \\
$\mathrm{~N}$ & 8784 & 8784 & 8784 & 8784 & 8784 & 8784 \\
& & & & & & \\
F-Test & 4.33 & 10.93 & 5.19 & 4.44 & 5.6 & 6.64 \\
\hline
\end{tabular}

F-Critical at $1 \%=1.49,5 \%=1.33,10 \%=1.25$

Over-Predicting Consumption during Post-Retirement

\begin{tabular}{|l|rrrrrr|}
\hline & \multicolumn{1}{|c}{ AEP } & \multicolumn{1}{c}{ APS } & \multicolumn{1}{c}{ ATSI } & COMED & DAY & DUQ \\
RSS $_{\text {P }}$ & 1809439.95 & 2038277.62 & 1730512.74 & 1385309.74 & 1851004.60 & 1716817.38 \\
RSS $_{\text {pos }}$ & 684846.80 & 1042791.50 & 433975.40 & 683579.47 & 757918.69 & 898064.87 \\
RSS $_{\text {nonpos }}$ & 1066320.16 & 950428.94 & 1275445.32 & 672374.61 & 1038327.40 & 730185.81 \\
$\mathrm{~K}$ & 57 & 57 & 57 & 57 & 57 & 57 \\
$\mathrm{~N}$ & 8784 & 8784 & 8784 & 8784 & 8784 & 8784 \\
& & & & & & \\
F-Test & 5.06 & 3.44 & 1.88 & 3.29 & 4.64 & 8.27 \\
\hline
\end{tabular}

F-Critical at $1 \%=1.49,5 \%=1.33,10 \%=1.25$

Under-Predicting Consumption during Pre-Retirement

\begin{tabular}{|l|rrrrrr|}
\hline & \multicolumn{1}{|c}{ AEP } & \multicolumn{1}{c}{ APS } & \multicolumn{1}{c}{ ATSI } & COMED & DAY & DUQ \\
RSS $_{\text {P }}$ & 3197002.13 & 4558086.66 & 3368245.70 & 2638665.70 & 3052150.82 & 3286498.96 \\
RSS $_{\text {neg }}$ & 2090504.19 & 2300409.85 & 1258073.06 & 832078.35 & 953442.32 & 2056239.52 \\
RSS $_{\text {nonneg }}$ & 1017837.99 & 2100543.47 & 1998923.43 & 1731689.57 & 1992901.56 & 1092763.01 \\
$\mathrm{~K}$ & 57 & 57 & 57 & 57 & 57 & 57 \\
$\mathrm{~N}$ & 8784 & 8784 & 8784 & 8784 & 8784 & 8784 \\
& & & & & & \\
F-Test & 4.33 & 5.43 & 5.19 & 4.44 & 5.46 & 6.64 \\
\hline
\end{tabular}

F-Critical at $1 \%=1.49,5 \%=1.33,10 \%=1.25$

Under-Predicting Consumption during Pre-Retirement

\begin{tabular}{|l|rrrrrr|}
\hline & \multicolumn{1}{|c}{ AEP } & \multicolumn{1}{c}{ APS } & \multicolumn{1}{c}{ ATSI } & COMED & DAY & DUQ \\
RSS $_{\text {P }}$ & 1809439.95 & 2038277.62 & 1730512.74 & 1385309.74 & 1851004.60 & 1716817.38 \\
RSS $_{\text {neg }}$ & 1066320.16 & 950428.94 & 1275445.32 & 672338.67 & 1033940.66 & 729993.10 \\
RSS $_{\text {nonneg }}$ & 684846.80 & 1042791.50 & 433975.40 & 683660.15 & 761735.87 & 898093.77 \\
$\mathrm{~K}$ & 57 & 57 & 57 & 57 & 57 & 57 \\
$\mathrm{~N}$ & 8784 & 8784 & 8784 & 8784 & 8784 & 8784 \\
& & & & & & \\
F-Test & 5.06 & 3.44 & 1.88 & 3.29 & 4.69 & 8.29 \\
\hline
\end{tabular}

F-Critical at $1 \%=1.49,5 \%=1.33,10 \%=1.25$ 
Table 16: LR-Test to Split Predicted Consumption

Likelihood Ratio Single Predicted Consumption

\begin{tabular}{|c|c|cccccc|}
\hline \multirow{3}{*}{ Chi-Squared } & & AEP & APS & ATSI & COMED & DAY & DUQ \\
& pre-retirement & 41.47 & 38.69 & 47.65 & 48.46 & 44.33 & 42.64 \\
& post-retirement & 44.45 & 35 & 39.87 & 38.54 & 52.5 & 37.46 \\
& two years & 50.2 & 76.97 & 50.96 & 55.61 & 45.98 & 41.17 \\
\hline F-Test & pre-retirement & 6.88 & 6.42 & 7.91 & 8.05 & 7.36 & 7.08 \\
& post-retirement & 7.38 & 5.81 & 6.62 & 6.40 & 7.65 & 6.22 \\
& two years & 8.35 & 12.82 & 8.48 & 9.25 & 8.72 & 6.85 \\
\hline
\end{tabular}

F-Critical at $1 \%=1.49,5 \%=1.33,10 \%=1.25$

Likelihood Ratio Over-Predicted Consumption

\begin{tabular}{|c|c|cccccc|}
\hline \multirow{3}{*}{ Chi-Squared } & AEP & APS & ATSI & COMED & DAY & DUQ \\
& pre-retirement & 23.17 & 57.73 & 116.91 & 56.17 & 104.03 & 78.31 \\
& post-retirement & 21.21 & 97.34 & 35.25 & 20.33 & 114.40 & 89.48 \\
& two years & 39.39 & 116.42 & 124.37 & 59.02 & 187.56 & 144.07 \\
\hline \multirow{2}{*}{ F-Test } & pre-retirement & 4.59 & 11.49 & 23.39 & 11.18 & 20.79 & 15.61 \\
& post-retirement & 4.21 & 19.45 & 6.96 & 4.03 & 22.88 & 17.87 \\
& two years & 7.85 & 23.29 & 24.89 & 11.77 & 37.63 & 28.85 \\
\hline
\end{tabular}

F-Critical at $1 \%=1.49,5 \%=1.33,10 \%=1.25$

Likelihood Ratio Under-Predicted Consumption

\begin{tabular}{|c|c|cccccc|}
\hline \multirow{3}{*}{ Chi-Squared } & & AEP & APS & ATSI & COMED & DAY & DUQ \\
& pre-retirement & 21.64 & 6.90 & 6.92 & 16.54 & 23.81 & 21.69 \\
& post-retirement & 11.53 & 7.12 & 13.99 & 19.25 & 16.40 & 13.74 \\
& two years & 14.02 & 20.55 & 8.04 & 23.55 & 37.38 & 20.63 \\
\hline F-Test & pre-retirement & 4.28 & 1.36 & 1.36 & 3.26 & 4.69 & 4.29 \\
& post-retirement & 2.27 & 1.39 & 1.60 & 3.80 & 3.23 & 2.68 \\
& two years & 2.79 & 4.07 & 2.77 & 4.68 & 7.43 & 4.09 \\
\hline
\end{tabular}

F-Critical at $1 \%=1.49,5 \%=1.33,10 \%=1.25$ 
Table 17: Hourly T-Test of Diff Against Zero

\begin{tabular}{|c|c|cccccc|}
\hline & & AEP & APS & ATSI & COMED & DAY & DUQ \\
t-value & Top 5\% & 27.349 & 23.833 & 23.357 & 22.335 & 24.684 & 26.662 \\
Early Retirement with Over- & Bottom 5\% & 10.751 & 10.016 & 13.205 & 23.417 & 11.683 & 16.599 \\
Predicted Consumption & Average & 25.064 & 28.011 & 25.945 & 25.013 & 23.318 & 24.042 \\
\hline t-test significance & Top 5\% & 0.000 & 0.000 & 0.000 & 0.000 & 0.000 & 0.000 \\
Early Retirement with Over- & Bottom 5\% & 0.000 & 0.000 & 0.000 & 0.000 & 0.000 & 0.000 \\
Predicted Consumption & Average & 0.000 & 0.000 & 0.000 & 0.000 & 0.000 & 0.000 \\
\hline & & & & & & & \\
\hline t-value & Top 5\% & 22.357 & 23.607 & 18.784 & 18.092 & 22.120 & 23.580 \\
No Retirement with Over- & Bottom 5\% & 39.951 & 45.789 & 49.419 & 65.132 & 37.722 & 45.943 \\
Predicted Consumption & Average & 33.245 & 37.729 & 24.295 & 23.760 & 22.116 & 37.947 \\
\hline t-test significance & Top 5\% & 0.000 & 0.000 & 0.000 & 0.000 & 0.000 & 0.000 \\
No Retirement with Over- & Bottom 5\% & 0.000 & 0.000 & 0.000 & 0.000 & 0.000 & 0.000 \\
Predicted Consumption & Average & 0.000 & 0.000 & 0.000 & 0.000 & 0.000 & 0.000 \\
\hline & & & & & & & \\
\hline t-value & Top 5\% & 23.168 & 26.608 & 27.820 & 29.193 & 22.653 & 23.569 \\
Early Retirement with Under- & Bottom 5\% & 11.918 & 27.536 & 18.440 & 10.025 & 27.608 & 13.175 \\
Predicted Consumption & Average & 25.435 & 21.924 & 22.501 & 17.582 & 20.468 & 22.316 \\
\hline t-test significance & Top 5\% & 0.000 & 0.000 & 0.000 & 0.000 & 0.000 & 0.000 \\
Early Retirement with Under- & Bottom 5\% & 0.000 & 0.000 & 0.000 & 0.000 & 0.000 & 0.000 \\
Predicted Consumption & Average & 0.000 & 0.000 & 0.000 & 0.000 & 0.000 & 0.000 \\
\hline t-value & & & & & & & \\
\hline No Retirement with Under- & Top 5\% & 0.000 & 0.000 & 0.000 & 0.000 & 0.000 & 0.000 \\
Predicted Consumption & Aottom 5\% & 0.000 & 0.000 & 0.000 & 0.000 & 0.000 & 0.000 \\
No Retirement with Under- & Top 5\% & 14.907 & 9.020 & 10.322 & 12.946 & 9.699 & 11.575 \\
& Bottom 5\% & 28.966 & 50.407 & 22.527 & 21.847 & 49.958 & 26.142 \\
& Average & 0.000 & 0.000 & 0.000 & 0.000 & 0.000 & 0.000 \\
\hline
\end{tabular}


Table 18: Daily T-Test of Zones' Observed LMP Against Market Prices

\begin{tabular}{|c|c|c|c|c|c|c|c|}
\hline & & AEP & APS & ATSI & COMED & DAY & DUQ \\
\hline \multirow{3}{*}{ t-value ICE } & pre-retirement & 4.028 & 4.944 & 4.317 & 0.720 & 4.667 & 3.284 \\
\hline & post-retirement & 0.039 & 2.037 & 0.705 & 4.264 & 0.023 & 1.586 \\
\hline & two years & 1.948 & 3.790 & 2.686 & 2.808 & 2.377 & 0.643 \\
\hline \multirow{3}{*}{ t-test significance ICE } & post-retirement & 0.000 & 0.000 & 0.000 & 0.473 & 0.000 & 0.000 \\
\hline & pre-retirement & 0.923 & 0.014 & 0.388 & 0.000 & 0.982 & 0.052 \\
\hline & two years & 0.009 & 0.000 & 0.000 & 0.000 & 0.001 & 0.400 \\
\hline \multirow{3}{*}{ t-value ERCOT } & post-retirement & 1.761 & 2.486 & 1.966 & 0.532 & 2.149 & 1.297 \\
\hline & pre-retirement & 0.941 & 2.704 & 1.714 & 2.962 & 1.066 & 0.161 \\
\hline & two years & 1.738 & 3.439 & 2.416 & 2.420 & 2.079 & 0.725 \\
\hline \multirow{3}{*}{$\begin{array}{c}\text { t-test significance } \\
\text { ERCOT }\end{array}$} & post-retirement & 0.069 & 0.010 & 0.043 & 0.580 & 0.026 & 0.181 \\
\hline & pre-retirement & 0.331 & 0.007 & 0.070 & 0.001 & 0.265 & 0.861 \\
\hline & two years & 0.056 & 0.000 & 0.007 & 0.006 & 0.021 & 0.413 \\
\hline \multirow{3}{*}{ t-value INDIANA } & \begin{tabular}{|l} 
post-retirement \\
\end{tabular} & 2.230 & 0.650 & 1.942 & 6.834 & 1.829 & 3.074 \\
\hline & pre-retirement & 1.265 & 1.023 & 0.594 & 5.605 & 1.220 & 3.153 \\
\hline & two years & 1.851 & 0.713 & 1.194 & 7.150 & 1.667 & 3.777 \\
\hline \multirow{3}{*}{$\begin{array}{l}\text { t-test significance } \\
\text { INDIANA }\end{array}$} & post-retirement & 0.048 & 0.558 & 0.082 & 0.000 & 0.102 & 0.006 \\
\hline & pre-retirement & 0.076 & 0.181 & 0.409 & 0.000 & 0.082 & 0.000 \\
\hline & \begin{tabular}{|l} 
two years \\
\end{tabular} & 0.010 & 0.345 & 0.097 & 0.000 & 0.018 & 0.000 \\
\hline \multirow{3}{*}{$\begin{array}{l}\text { t-value MID } \\
\text { COLUMBIA }\end{array}$} & \begin{tabular}{|l|} 
post-retirement \\
\end{tabular} & 5.117 & 5.840 & 5.343 & 2.587 & 5.653 & 4.536 \\
\hline & pre-retirement & 6.011 & 6.742 & 7.055 & 2.696 & 6.582 & 5.648 \\
\hline & two years & 7.528 & 8.456 & 8.362 & 3.572 & 8.255 & 6.865 \\
\hline \multirow{3}{*}{$\begin{array}{c}\text { t-test significance MID } \\
\text { COLUMBIA }\end{array}$} & post-retirement & 0.000 & 0.000 & 0.000 & 0.007 & 0.000 & 0.000 \\
\hline & pre-retirement & 0.000 & 0.000 & 0.000 & 0.006 & 0.000 & 0.000 \\
\hline & two years & 0.000 & 0.000 & 0.000 & 0.000 & 0.000 & 0.000 \\
\hline \multirow{3}{*}{ t-value NEPOOL } & post-retirement & 5.391 & 4.489 & 5.235 & 7.954 & 5.129 & 5.919 \\
\hline & pre-retirement & 7.912 & 6.137 & 7.703 & 9.971 & 8.035 & 8.873 \\
\hline & two years & 8.778 & 6.929 & 8.523 & 11.502 & 8.764 & 9.792 \\
\hline \multirow{3}{*}{$\begin{array}{c}\text { t-test significance } \\
\text { NEPOOL }\end{array}$} & post-retirement & 0.000 & 0.000 & 0.000 & 0.000 & 0.000 & 0.000 \\
\hline & pre-retirement & 0.000 & 0.000 & 0.000 & 0.000 & 0.000 & 0.000 \\
\hline & two years & 0.000 & 0.000 & 0.000 & 0.000 & 0.000 & 0.000 \\
\hline \multirow{4}{*}{ t-value NP15 } & post-retirement & 4.428 & 3.268 & 4.086 & 6.942 & 3.822 & 4.827 \\
\hline & pre-retirement & 4.589 & 2.172 & 3.894 & 8.154 & 4.702 & 7.083 \\
\hline & two years & 5.738 & 3.170 & 4.989 & 9.737 & 5.532 & 7.746 \\
\hline & post-retirement & 0.000 & 0.000 & 0.000 & 0.000 & 0.000 & 0.000 \\
\hline
\end{tabular}




\begin{tabular}{|c|c|cccccc|} 
t-test significance NP 15 & pre-retirement & 0.000 & 0.039 & 0.000 & 0.000 & 0.000 & 0.000 \\
& two years & 0.000 & 0.001 & 0.000 & 0.000 & 0.000 & 0.000 \\
\hline & & & & & & & \\
\hline \multirow{3}{*}{ t-value PALO VERDE } & post-retirement & 4.975 & 5.852 & 5.268 & 1.643 & 5.708 & 4.214 \\
& pre-retirement & 2.837 & 4.259 & 3.775 & 1.081 & 3.156 & 1.945 \\
& two years & 4.713 & 6.092 & 5.576 & 0.050 & 5.375 & 3.765 \\
\hline \multirow{3}{*}{ t-test significance PALO } & post-retirement & 0.000 & 0.000 & 0.000 & 0.072 & 0.000 & 0.000 \\
VERDE & pre-retirement & 0.005 & 0.000 & 0.000 & 0.249 & 0.002 & 0.051 \\
& two years & 0.000 & 0.000 & 0.000 & 0.954 & 0.000 & 0.000 \\
\hline & & & & & & & \\
\hline & & & & & & & \\
t-value PJM & pre-retirement & 6.576 & 4.302 & 6.227 & 9.439 & 6.745 & 7.889 \\
& two years & 8.914 & 6.324 & 8.505 & 12.852 & 8.930 & 10.386 \\
\hline \multirow{3}{*}{ t-test significance PJM } & post-retirement & 0.000 & 0.000 & 0.000 & 0.000 & 0.000 & 0.000 \\
& pre-retirement & 0.000 & 0.000 & 0.000 & 0.000 & 0.000 & 0.000 \\
& two years & 0.000 & 0.000 & 0.000 & 0.000 & 0.000 & 0.000 \\
\hline & & & & & & & \\
\hline & post-retirement & 3.284 & 2.142 & 3.005 & 6.826 & 2.788 & 3.948 \\
& pre-retirement & 4.679 & 1.805 & 4.199 & 9.309 & 5.049 & 6.685 \\
& two years & 5.215 & 2.432 & 4.668 & 10.454 & 5.186 & 6.946 \\
\hline \multirow{3}{*}{ t-test significance SP 15 } & post-retirement & 0.000 & 0.017 & 0.001 & 0.000 & 0.003 & 0.000 \\
& pre-retirement & 0.000 & 0.086 & 0.000 & 0.000 & 0.000 & 0.000 \\
& two years & 0.000 & 0.010 & 0.000 & 0.000 & 0.000 & 0.000 \\
\hline
\end{tabular}

Table 19: Hourly T-Test of Zones' Electricity Consumption Between Time Periods

\begin{tabular}{|lrrrrrr|}
\hline & AEP & APS & ATSI & COMED & DAY & DUQ \\
T-Value & 17.017 & 17.851 & 16.413 & 7.991 & 8.902 & 13.107 \\
T-Test & 0.000 & 0.000 & 0.000 & 0.000 & 0.000 & 0.000 \\
\hline
\end{tabular}


Table 20: Early Retirement with Over-Predicted Consumption Model Measured in $\$ / \mathrm{MWh}$ Observed - projected price (early retirement)

\begin{tabular}{|c|cccccc|}
\hline & AEP & APS & ATSI & COMED & DAY & DUQ \\
Top 5\% & $\$ 59.59$ & $\$ 79.49$ & $\$ 72.17$ & $\$ 67.19$ & $\$ 69.77$ & $\$ 54.43$ \\
Bottom 5\% & $-\$ 12.56$ & $-\$ 12.85$ & $-\$ 17.65$ & $-\$ 20.48$ & $-\$ 15.10$ & $-\$ 17.41$ \\
Observations & $(234)$ & $(291)$ & $(269)$ & $(270)$ & $(295)$ & $(253)$ \\
\hline Average & $\$ 6.05$ & $\$ 8.35$ & $\$ 7.47$ & $\$ 6.83$ & $\$ 6.16$ & $\$ 5.33$ \\
Observations & $(4677)$ & $(5818)$ & $(5386)$ & $(5395)$ & $(5903)$ & $(5051)$ \\
\hline
\end{tabular}

Table 21: No Retirement with Over-Predicted Consumption Model Measured in \$/MWh

\begin{tabular}{|c|cccccc|}
\hline & AEP & APS & ATSI & COMED & DAY & DUQ \\
Top 5\% & $\$ 31.25$ & $\$ 35.03$ & $\$ 33.99$ & $\$ 31.81$ & $\$ 33.63$ & $\$ 31.98$ \\
Bottom 5\% & $-\$ 24.36$ & $-\$ 37.09$ & $-\$ 30.76$ & $-\$ 26.98$ & $-\$ 26.93$ & $-\$ 22.66$ \\
Observations & $(281)$ & $(330)$ & $(151)$ & $(253)$ & $(281)$ & $(342)$ \\
\hline Average & $-\$ 5.51$ & $-\$ 7.15$ & $-\$ 6.07$ & $-\$ 4.39$ & $-\$ 3.97$ & $-\$ 5.62$ \\
Observations & $(5623)$ & $(6599)$ & $(3015)$ & $(5060)$ & $(5627)$ & $(6843)$ \\
\hline
\end{tabular}

Table 22: Early Retirement with Under-Predicted Consumption Model Measured in $\$ / \mathrm{MWh}$

\begin{tabular}{|c|cccccc|}
\hline & AEP & APS & ATSI & COMED & DAY & DUQ \\
Top 5\% & 98.64 & 126.31 & 76.66 & 60.54 & 73.58 & 94.25 \\
Bottom 5\% & -13.89 & -14.51 & -11.90 & -18.13 & -13.19 & -22.78 \\
Observations & $(205)$ & $(148)$ & $(170)$ & $(169)$ & $(141)$ & $(187)$ \\
\hline Average & 10.68 & 12.99 & 7.81 & 5.41 & 7.65 & 9.86 \\
Observations & $(4106)$ & $(2966)$ & $(3398)$ & $(3389)$ & $(2829)$ & $(3732)$ \\
\hline
\end{tabular}

Table 23: No Retirement with Under-Predicted Consumption Model Measured in $\$ / \mathrm{MWh}$

Observed - projected price (no retirement)

\begin{tabular}{|c|cccccc|}
\hline & AEP & APS & ATSI & COMED & DAY & DUQ \\
Top 5\% & $\$ 53.60$ & $\$ 55.82$ & $\$ 30.09$ & $\$ 31.98$ & $\$ 43.53$ & $\$ 59.30$ \\
Bottom 5\% & $-\$ 31.31$ & $-\$ 37.12$ & $-\$ 29.30$ & $-\$ 30.54$ & $-\$ 28.51$ & $-\$ 35.99$ \\
Observations & $(136)$ & $(83)$ & $(146)$ & $(131)$ & $(98)$ & $(88)$ \\
\hline Average & $-\$ 5.16$ & $-\$ 6.56$ & $-\$ 6.04$ & $-\$ 5.58$ & $-\$ 5.26$ & $-\$ 6.52$ \\
Observations & $(2723)$ & $(1660)$ & $(2926)$ & $(2610)$ & $(1950)$ & $(1769)$ \\
\hline
\end{tabular}


Table 24: Early Retirement with Over-Predicted Consumption Model

Percent change
\begin{tabular}{|ccccccc|} 
& AEP & APS & ATSI & COMED & DAY & DUQ \\
Top 5\% & $64.1 \%$ & $69.2 \%$ & $65.3 \%$ & $69.5 \%$ & $65.9 \%$ & $62.5 \%$ \\
Bottom 5\% & $-106.2 \%$ & $-117.3 \%$ & $-166.5 \%$ & $20060.8 \%$ & $-135.9 \%$ & $-209.8 \%$ \\
Observations & $(234)$ & $(291)$ & $(269)$ & $(270)$ & $(295)$ & $(253)$ \\
\hline Average & $18.1 \%$ & $23.7 \%$ & $21.4 \%$ & $22.1 \%$ & $18.0 \%$ & $16.9 \%$ \\
Observations & $(4677)$ & $(5818)$ & $(5386)$ & $(5395)$ & $(5903)$ & $(5051)$ \\
\hline
\end{tabular}

Table 25: No Retirement with Over-Predicted Consumption Model

Percent change

\begin{tabular}{|c|cccccc|}
\hline & AEP & APS & ATSI & COMED & DAY & DUQ \\
Top 5\% & $43.7 \%$ & $43.7 \%$ & $40.6 \%$ & $45.3 \%$ & $44.4 \%$ & $43.8 \%$ \\
Bottom 5\% & $-131.4 \%$ & $-208.6 \%$ & $-141.8 \%$ & $-157.5 \%$ & $-143.5 \%$ & $-130.2 \%$ \\
Observations & $(281)$ & $(330)$ & $(151)$ & $(253)$ & $(281)$ & $(342)$ \\
\hline Average & $-21.4 \%$ & $-26.9 \%$ & $-22.6 \%$ & $-18.0 \%$ & $-15.0 \%$ & $-21.9 \%$ \\
Observations & $(5623)$ & $(6599)$ & $(3015)$ & $(5060)$ & $(5627)$ & $(6843)$ \\
\hline
\end{tabular}

Table 26: Early Retirement with Under-Predicted Consumption Model

Percent change

\begin{tabular}{|c|cccccc|}
\hline & AEP & APS & ATSI & COMED & DAY & DUQ \\
Top 5\% & $76.1 \%$ & $75.8 \%$ & $67.2 \%$ & $65.3 \%$ & $65.9 \%$ & $73.7 \%$ \\
Bottom 5\% & $-90.6 \%$ & $-77.9 \%$ & $-72.1 \%$ & $-3817.5 \%$ & $-71.1 \%$ & $-398.0 \%$ \\
Observations & $(205)$ & $(148)$ & $(170)$ & $(169)$ & $(141)$ & $(187)$ \\
\hline Average & $28.3 \%$ & $29.2 \%$ & $20.6 \%$ & $16.6 \%$ & $20.1 \%$ & $26.5 \%$ \\
Observations & $(4106)$ & $(2966)$ & $(3398)$ & $(3389)$ & $(2829)$ & $(3732)$ \\
\hline
\end{tabular}

Table 27: No Retirement with Under-Predicted Consumption Model

Percent change
\begin{tabular}{|c|cccccc|} 
& AEP & APS & ATSI & COMED & DAY & DUQ \\
Top 5\% & $53.1 \%$ & $50.3 \%$ & $35.7 \%$ & $41.0 \%$ & $43.5 \%$ & $54.9 \%$ \\
Bottom 5\% & $-308.8 \%$ & $-274.0 \%$ & $-297.5 \%$ & $-1639.6 \%$ & $-223.2 \%$ & $-312.9 \%$ \\
Observations & $(136)$ & $(83)$ & $(146)$ & $(131)$ & $(98)$ & $(88)$ \\
\hline Average & $-17.0 \%$ & $-20.0 \%$ & $-21.6 \%$ & $-21.4 \%$ & $-17.2 \%$ & $-20.9 \%$ \\
Observations & $(2723)$ & $(1660)$ & $(2926)$ & $(2610)$ & $(1950)$ & $(1769)$ \\
\hline
\end{tabular}




\section{Works Cited}

Alexopoulos, Thomas A. "The Growing Importance of Natural Gas as a Predictor for Retail Electricity Prices in Us." Energy 137 (2017): 219-33. [Figure 2]

Biggar, D. R., and Mohammad Reza Hesamzadeh. The Economics of Electricity Markets. Wiley Blackwell, 2014. Print.

Borenstein, Severin, and James Bushnell. "The U.S. Electricity Industry after 20 Years of Restructuring." Annual Review of Economics 7.1 (2015): 437-63. Print.

Cabral, Joilson de Assis, Luiz Fernando Loureiro Legey, and Maria Viviana de Freitas Cabral. "Electricity Consumption Forecasting in Brazil: A Spatial Econometrics Approach." Energy 126 (2017): 124-31. Print.

"Capacity Market." 2016 State of the Market Report for PJM. Monitoring Analytics, LLC. March $9^{\text {th }}, 2017$, August $5^{\text {th }}, 2018$, http://www.monitoringanalytics.com/reports/ PJM_State_of_the_Market/2016/2016-som-pjm-sec5.pdf [Table 1]

Catalão, J. P. S., Mariano, S.J.P.S., Mendes, V.M.F., Ferreira, L.A.F.M., "Short-Term Electricity Prices Forecasting in a Competitive Market: A Neural Network Approach." Electric Power Systems Research 77.10 (2007): 1297-304. Print.

Coglianese, John, Todd Gerarden, and James H. Stock. "The Effects of Fuel Prices, Regulations, and Other Factors on U.S. Coal Production, 2008-2016." (2017). Harvard: Kennedy

School of Public Policy. https://heep.hks.harvard.edu/files/heep/files/dp90 stock.pdf

“Current PJM Website to Zone Map.” August 5 ${ }^{\text {th }}$, 2018. http://www.pjm.com/library/ /media/ about-pjm/pjm-zones.ashx. [Figure 7]

PJMe "Energy Markets Locational Marginal Pricing: Interconnection Training Program Module EM2.” PJM, 2011, pjm.com/ /media/training/nerc-certifications/EM2-LMP.ashx. 
EPA, "Federal Water Pollution Control Act." EPA, Environmental Protection Agency.

November 27, 2002, August $5^{\text {th }}$, 2018. https://www.epa.gov/sites/production/files/201708/documents/federal-water-pollution-control-act-508full.pdf

Fell, Harrison, and Daniel T. Kaffine. "The fall of coal: Joint impacts of fuel prices and renewables on generation and emissions." American Economic Journal: Economic Policy 10.2 (2018): 90-116. https://www.aeaweb.org/articles?id=10.1257/pol.20150321

Griffin, James M., and Steven L. Puller, eds. Electricity Deregulation: Choices and Challenges. Vol. 4. University of Chicago Press, 2009. Print.

Hargis, Lynn. "Puhca for Dummies: An Electricity Blackout and Energy Bill Primer." Public Citizen's Critical Mass Energy and Environment Program (2003). Print.

EPA, "History of the MATS Regulation." EPA, Environmental Protection Agency, 20 July 2017, August $5^{\text {th }}, 2018$ www.epa.gov/mats/history-mats-regulation.

Jell, Scott. "Most Coal Plants in the United States Were Built before 1990." Today in Energy (2017). Print.

Kaufmann, Robert K., and Devina Vaid. "Lower Electricity Prices and Greenhouse Gas Emissions Due to Rooftop Solar: Empirical Results for Massachusetts." Energy policy 93 (2016): 345-52. Print.

Kishimoto, Jo, Mika Goto, and Kotaro Inoue. "Do Acquisitions by Electric Utility Companies Create Value? Evidence from Deregulated Markets." Energy Policy 105 (2017): 212-24. Print.

Monitoring Analytics. "Congestion and Marginal Losses." Quarterly State of the Market Report for PJM: January through March. (2012). https://www.monitoringanalytics.com/ reports/PJM_State_of_the_Market/2012/2012q1-som-pjm-sec10.pdf 
Newey, Whitney K., and Kenneth D. West. "Hypothesis testing with efficient method of moments estimation." International Economic Review (1987): 777-787.

Ohio Environmental Protection Agency. "Maximum Achievable Control Technology (MACT) Standards." Division of Air Pollution Control. (2019) March, 2019. https://www.epa.ohio.gov/dapc/mact/mactmain

PJMa. “PJM History.” (2019) March, 2019. http://www.pjm.com/about-pjm/who-we-are/pjmhistory.aspx

PJMb. "Generation Deactivations.” (2019). March, 2019. https://www.pjm.com/planning/services-requests/gen-deactivations.aspx [Table 2]

Rahmani, Mohsen, Paulina Jaramillo, and Gabriela Hug. "Implications of Environmental Regulation and Coal Plant Retirements in Systems with Large Scale Penetration of Wind Power." Energy Policy 95 (2016): 196-210. Print.

PJMc “TEAC hears projects for PJM Board approval.”, PJM Inside Lines, March 12 ${ }^{\text {th }} 2018$, August $5^{\text {th }}, 2018$, http://insidelines.pjm.com/teac-hears-projects-for-board-approval/ [Figure 8] Tuttle, David P., et al. "The History and Evolution of the U.S. Electricity Industry." White Paper UTEI/2016-05-2 (2016). Print.

United States Congress. Energy Policy Act of 1992: Public Law 102-486: Law and Explanation. Oct. $24^{\text {th }}, 1992$. https://www.govinfo.gov/content/pkg/STATUTE-106/pdf/STATUTE- $^{-}$ 106-Pg2776.pdf

EPA United States Environmental Protection Agency. "Basic Information about Mercury and Air Toxics Standards.” 8 June 2017, August 5, 2018, www.epa.gov/mats/basic-informationabout- mercury-and-air-toxics-standards. 
United States Environmental Protection Agency. "U.S. Electricity Grid \& Markets". Green Power Partnership. July 30, 2018. https://www.epa.gov/greenpower/us-electricity-gridmarkets [Figure 4]

United States Environmental Protection Agency. "What are Hazardous Air Pollutants?". (2017) March, 2019. https://www.epa.gov/haps/what-are-hazardous-air-pollutants

United States Census Bureau. "U.S. and world population clock." (2013). https://www.census.gov/popclock/

Uribe, Jorge M., Montserrat Guillen, and Stephania Mosquera-López. "Uncovering the Nonlinear Predictive Causality between Natural Gas and Electricity Prices." Energy Economics 74 (2018): 904-16. Print.

U.S. Department of Energy. “Grid Resiliency Pricing Rule”. Docket No. RM17-3-000 January, 2018. 12 September, 2018. https://www.energy.gov/sites/prod/files/2017/09/f37/ Notice\%20of\%20Proposed\%20Rulemaking\%20.pdf

U.S. Energy Information Administration. "Appalachia Region: Drilling Productivity Report". Drilling Productivity Report: For key tight oil and shale gas regions. March, 2019. April, 2019. https://www.eia.gov/petroleum/drilling/pdf/dpr-full.pdf

U.S. Energy Information Administration, based on DrillingInfo Inc., New York State Geological Survey, Ohio State Geological Survey, Pennsylvania Bureau of Topographic \& Geologic Survey, West Virginia Geological \& Economic Survey, and U.S. Geological Survey. https://www.eia.gov/maps/pdf/marcellus-upd.pdf [Figure 6]

U.S. Energy Information Administration. "Electric Power Sector Energy Consumption". Total Energy. July 13, 2018. 
https://www.eia.gov/totalenergy/data/browser/index.php?tbl=T02.06\#/?f=A\&start=1995 \&end=2018\&charted=2-3-4-6-13 [Figure 1]

U.S. Energy Information Administration. "Form EIA-860 detailed data". Electricity. June 1, 2018. July 30, 2018. https://www.eia.gov/electricity/data/eia860/

U.S. Energy Information Administration. "Natural Gas Prices: Electric Power Price". Natural Gas. March 29, 2019. April, 2019. https://www.eia.gov/dnav/ng/ng_pri_sum_dcu_SWV_m.htm

U.S. Energy Information Administration. "Short-Term Energy Outlook (STEO)". March 29, 2019. March, 2019. https://www.eia.gov/outlooks/steo/pdf/steo_full.pdf [Figure 2]

U.S. Energy Information Administration. "The United States uses a mix of energy sources”. U.S. Energy Facts Explained. May 16, 2018. July 13, 2018. https://www.eia.gov/energyexplained/?page=us_energy_home [Figure 1]

Valor, Enric, Vicente Meneu, and Vicente Caselles. "Daily air temperature and electricity load in Spain." Journal of Applied Meteorology 40.8 (2001): 1413-1421.

Woo, C.K., Zarnikau, J., Olson, A., Jones, R., Chait, M., Horowitz, I., Wang, J., "Electricitymarket price and nuclear power plant shutdown: Evidence from California." Energy Policy 73 (2014): 234-244.

Weather Underground. "Morgantown Municipal-Hart, WV History: Weather Underground." August 5, 2018. March, 2019. www.wunderground.com/history/airport/KMGW/2014/1/7/DailyHistory.html?req_city $=\&$ req_state $=\&$ req_statename $=\&$ reqdb.zip $=\&$ reqdb.magic $=\&$ reqdb. $w m o=$. 
Monitoring Analytics 2012 